\title{
Painter Street Overcrossing Linear-Elastic Finite Element Dynamic Analysis
}

\author{
Matthew W. Salveson
}

August 1991

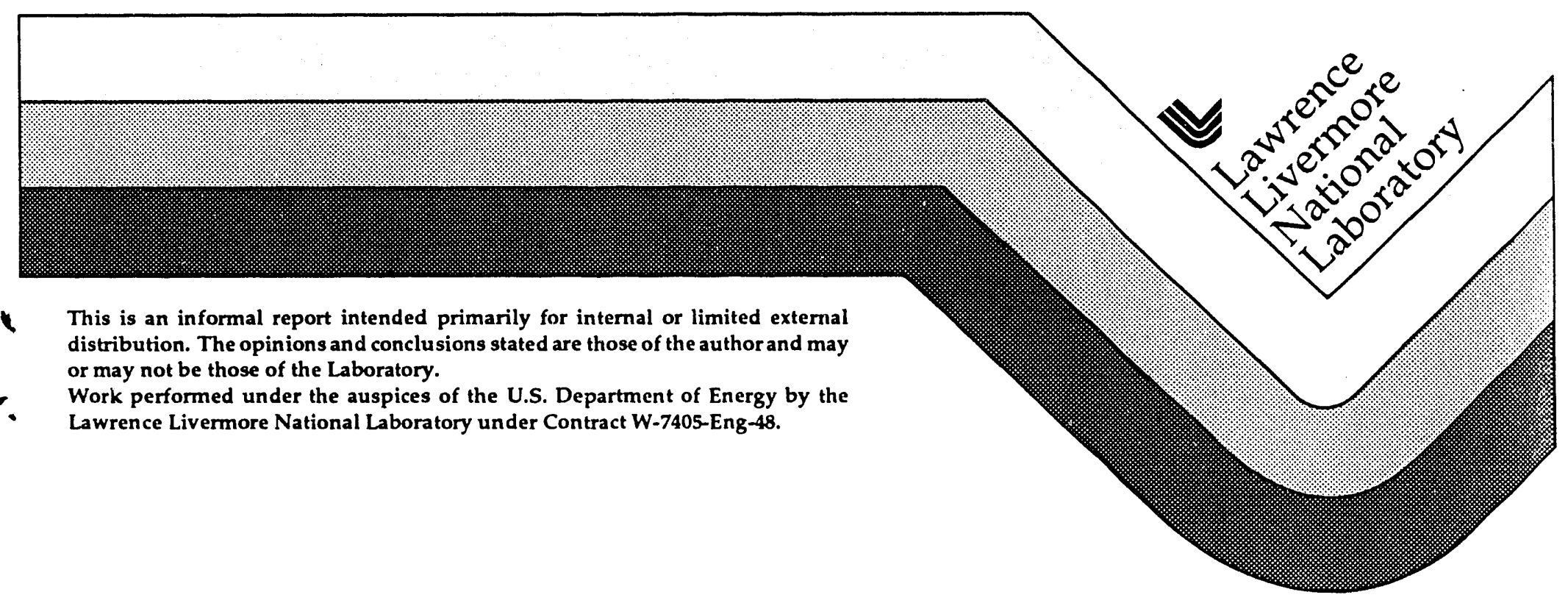




\section{DISCLAIMER}

This document was prepared as an acccount of work sponsored by an agency of the United States Government. Neither the United States Government nor the University of California nor any of their employees, makes any warranty, express or implied, or assumes any legal liability or responsibility for the accuracy, completeness, or usefulness of any information, apparatus, product, or process disclosed, or represents that its use would not infringe privately own rights. Reference herein to any specific commercial products, process, or service by trade name, trademark, manufacturer, or otherwise, does not necessarily constitute or imply its endorsement, recommendation, or favoring by the United States Government or the University of California. The views and opinions of authors expressed herein do not necessarily state or reflect those of the United States Government or the University of California, and shall not be used for advertising or product endorsement purposes.

This report has been reproduced directly from the best available copy.

Available to DOE and DOE contractors from the Office of Scientific and Technical Information P.O. Box 62, Oak Ridge, TN 37831

Prices available from (615) 576-8401, FTS 626-8401

Available to the public from the National Technical Information Service

U.S. Department of Commerce 5285 Port Royal Rd. Springfield, VA 22161 


\section{PAIYTER 8TREET OVBRCROBSING}

LINEAR-ELASTIC FINITE ELEMENT DYNAMIC ANALYSIS

UCRL-ID- -108573

DE92 002119

Matthew $\mathrm{W}$. Salveson

August 1991 
2 MODELS

2.1 Models Used

2.2 Structural Geometry

$2-1$

2.3 Section Properties

$2-1$

2.4 Loading

2.5 Viscous Damping

2.6 Torsional stiffness

2.7 Soil stiffness

2.8 Lumped Mass

2-1

$2-1$

$2-1$

2-1

$2-2$

$2-2$

3 RESULTS

3.1 Model 1

3.2 Model 2

3.3 Model 3

3.4 Model 4

3.5 Model 5

3.6 Model 6

3.7 Model 7

3-1

$3-1$

$3-1$

$3-1$

$3-1$

$3-1$

$3-1$

$3-2$

3.8 Model 8

$3-2$

3.9 Model 9

3-2

3.10 Model 10

$3-2$

3.11 Model 11

$3-3$

4 DISCUSSION

4-1

4.1 Geometry

4.2 Soil Stiffness

4-1

4-1

4.3 Rotational Inertia

4-1

5 CONCLUSION

5-1

6 REFERENCES

6-1

\section{APPENDIX}
A. 1 Model 1
A. 2 Model 2
A. 3 Model 3
A. 4 Model 4
A. 5 Model 5
A. 6 Model 6
A. 7 Model 7
A. 8 Model 8
A.9 Model 9
A. 10 Model 10
A.11 Model 11

A. 1-1

A. 2-1

A. 3-1

A. 4-1

A. 5-1

A. $6-1$

A. 7-1

A. 8-1

A. 9-1

A. 10-1

A. 11-1 


\section{IMTroouction}

Painter street Overcrossing is a two span continwous box girder bridge spanning Highway 101 near Rio Del, California. It has been heavily instrumented with strong motion accelerometers by the California Department of Mines and Geology Strong Motion Instrumentation Program. On 11/21/86, the response of the bridge to a magnitude 5.1 earthquake (epicentral distance $32 \mathrm{~km}$ ) was measured. This report considers the data generated at stations six, seven, and eight, during this ear'thquake. station six recorded the vertical accelerations at the midpoint of the long span. Station seven recorded the transverse accelerations at the top of the bent. Station eight recorded the vertical accelerations at the midpoint of the short span.

Typically, seismic analysis is done with the aid of a linear-elastic finite element code. Damping is assumed to be viscous. This report summarizes the results of such an analysis using the commercial P.C. based progran SAP9O. This analysis conforms as closely as possible to "typical" seismic analysis. It is intended to be used as basis for comparison against a non-linear analysis to be done using NIKE30.

Section two of this report contains detailed information about the models used to represent the bridge. Section three contains the results of each analysis. Section four contains a discussion of the results. Section five contains conclusions. Section six contains references. The Appendix contains SAP9O input and output files for each of the eleven models. 
2. MOOELS

2.1 Models Used

Eleven different models are used to represent the structure. The geometry, section properties, and load conditions are varied between the models. See figure 2.1-1 for a description of each of the models.

\subsection{Structural Geometry}

All of the models are stick models consisting of rigidly connected bean elements. The elements are assumed to be located along the centroidal axes of the structure. The dimensions of the bridge are taken from Caltrans asbuilt drawings. Skewed and non-skewed geometries are considered. See figure 2.2-1 for the skewed and non-skewed geometries. See Figure 2.2-2 for the nodal and element locations.

\subsection{Section Properties}

Section properties are calculated assuning homogeneous material. Figure 2.3-1 lists the section properties of the box girder. The rotational inertia of the box girder is given by:

$$
I_{x x}=\int r^{2} d A=\int y^{2}+z^{2} d A=I_{3 y}+I_{z z}
$$

SAP90 automatically calculates the properties for the abutments and the colums. Because of the nature of the stick model, it is necessary to artificially stiffen the bent cap. Therefore, the bending moments of inertia of the bent cap are increased by a factor of one thousand. A very rigid link is placed at the top and bottom of both of the colums at the center bent. This is to account for the finite depth of the bent beam which is otherwise not adequately represented in a line diagram model.

$2.4 \quad$ Loading

In several of the models, the structure is subjected to a time history of the ground acceleration. This acceleration is three dimensional. In two models, the structure is subjected to a static lateral load.

\section{$2.5 \quad$ Viscous Damping}

Each of the models that are subjected to the ground accelerations are also subject to viscous damping. The damping ratios are assigned somewhat arbitrarily and adjusted to produce the best results possible. The damping ratios vary between some of the models.

\subsection{Torsional stiffness}

Torsional stiffness was calculated automatically by SAP90 whenever possible. The stiffness

$$
2-1
$$


of the bridge deck was calculated by hand using shear flow / twisting moment equilibrium equations (See Reference 1). The torsional stiffness of the box girder is included in Figure 2.3-1.

\section{$2.7 \quad$ Soil stiffness}

\section{A. Abutments}

The effects of the soil at the abutments are modeled using linear-elastic longitudinal and transverse springs. The longitudinal spring is assumed to have a constant equal to $200 \mathrm{kips} / \mathrm{inch} / \mathrm{l}$ inear foot of wall. The longitudinal spring is applied at both ends, but only one wall contributes at any given time. Therefore, the longitudinal spring constant is divided by two. The transverse spring constant is taken to be $200 \mathrm{kips} / \mathrm{inch} / \mathrm{linear}$ foot of wall. Only one wingwall at each abutments is considered. It is assumed that only $2 / 3$ of the wingwall contributes to the soil spring (See Reference 2 ).

B. piles

The piles are modeled using longitudinal and transverse linear-elastic springs. The constants for these springs are assumed to be equal to $40 \mathrm{kips} / \mathrm{inch} / \mathrm{pile}$ (See Reference 2).

\section{Total Spring Constants}

The total spring constant for the longitudinal spring at each abutment is $2.74+e 6$ lbs/inch. The total spring constant for the transverse spring at each abutment is 4.11e+6 lbs/inch. The abutments are fixed in the vertical direction. The total spring constant for both the longitudinal and transverse spring at each colum is $8 e+5$ lbs/inch. The center bent is fixed in the vertical direction.

\subsection{Lumped Mass}

The structure is assumed to have a weight density of $150 \mathrm{lbs} / \mathrm{ft}^{3}$. In units of inch-poundseconds, the mass density is $2.25 \mathrm{e}-4 \mathrm{lbs}-\mathrm{sec} / \mathrm{in}^{4}$. The translational and rotational inertias are considered in all of the models with the exception of model 9 . Model 9 neglects rotational inertia. 
Abutments fixed at top. Skewed geometry. Eigenvalue analysis.

Abutments fixed at base. Skewed geometry. Eigenvalue analysis.

Abutments fixed at base. Non-skewed geometry. Eigenvalue analysis.

Abutments fixed at top. Non-skewed geometry. Eigenvalue analysis.

Abutments fixed at base. Skewed geometry. static lateral load.

Abutments fixed at base. Non-skewed geometry. Static lateral load.

Springs at base of abutments. skewed geometry. Eigenvalue analysis.

Springs at base of abutments. Skewed geometry. Time history analysis.

Springs at base of abutments. Skewed geometry. No rotational inertia. Time history analysis.

Springs distributed across abutments. Skewed geometry. Time history analysis.

springs at base of abutments. skewed geometry. Time history analysis. Damping = 28 , all modes.

Figure 2.1-1: Description of Models 


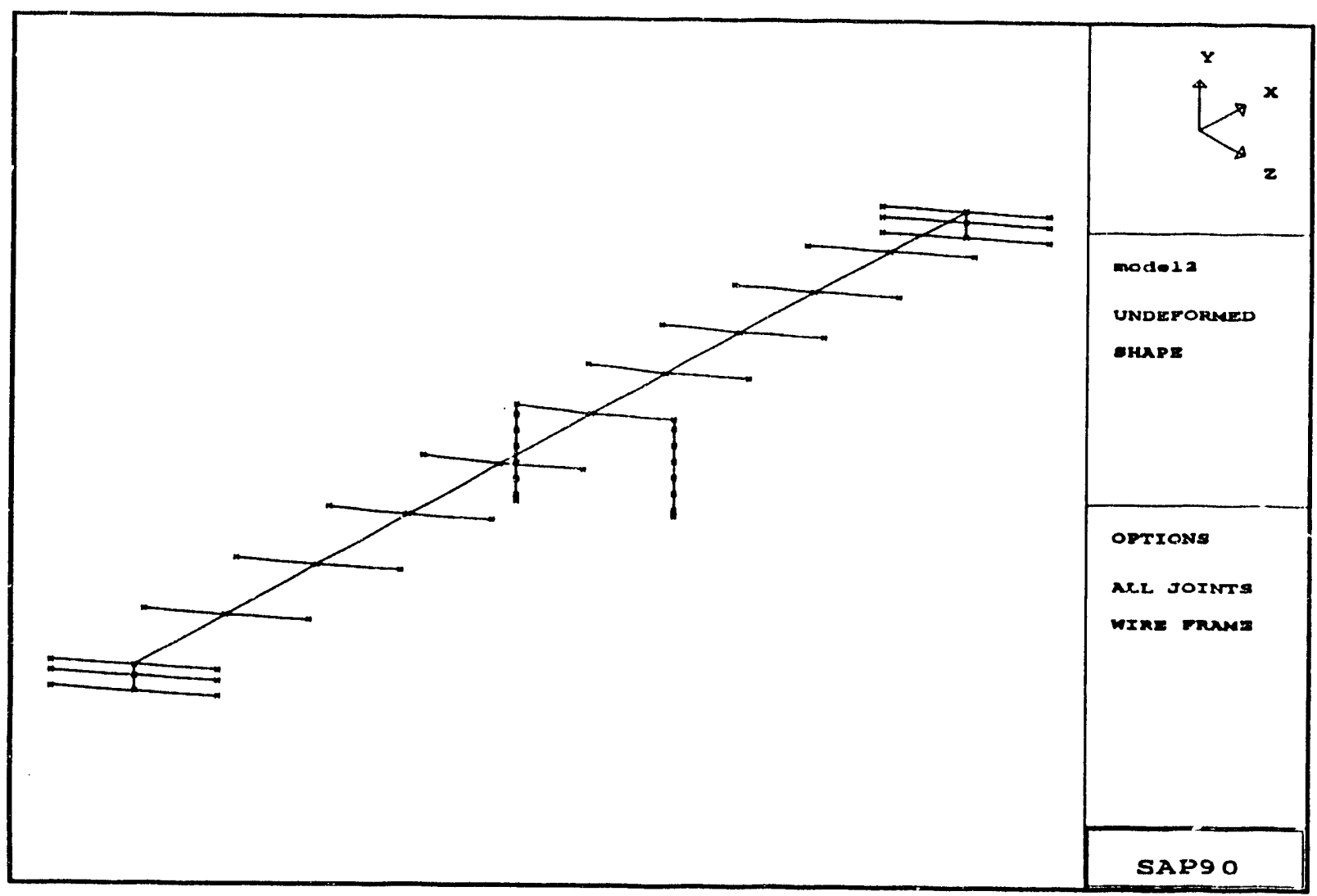

skewed Model

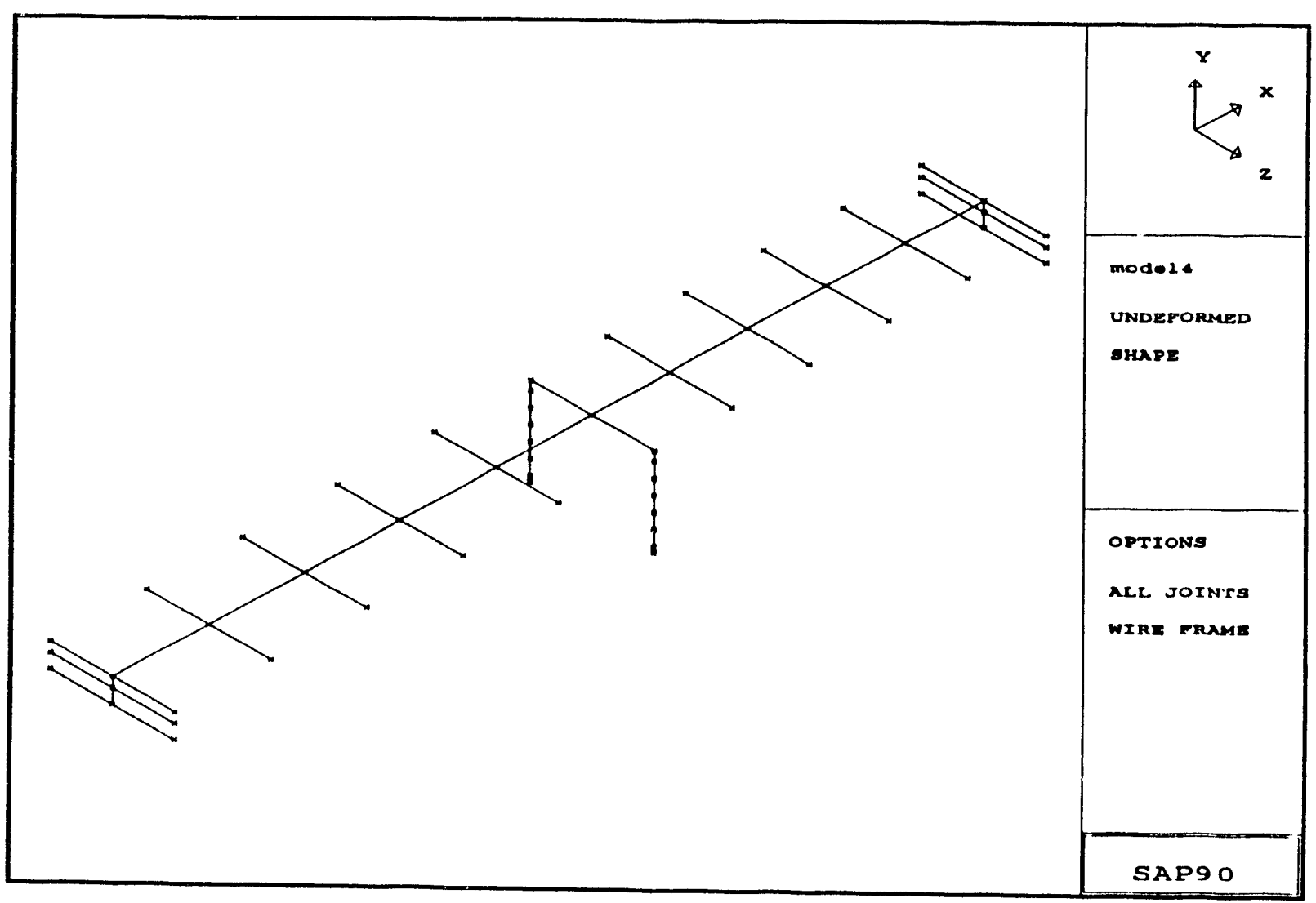

Non-skewed Nodel 


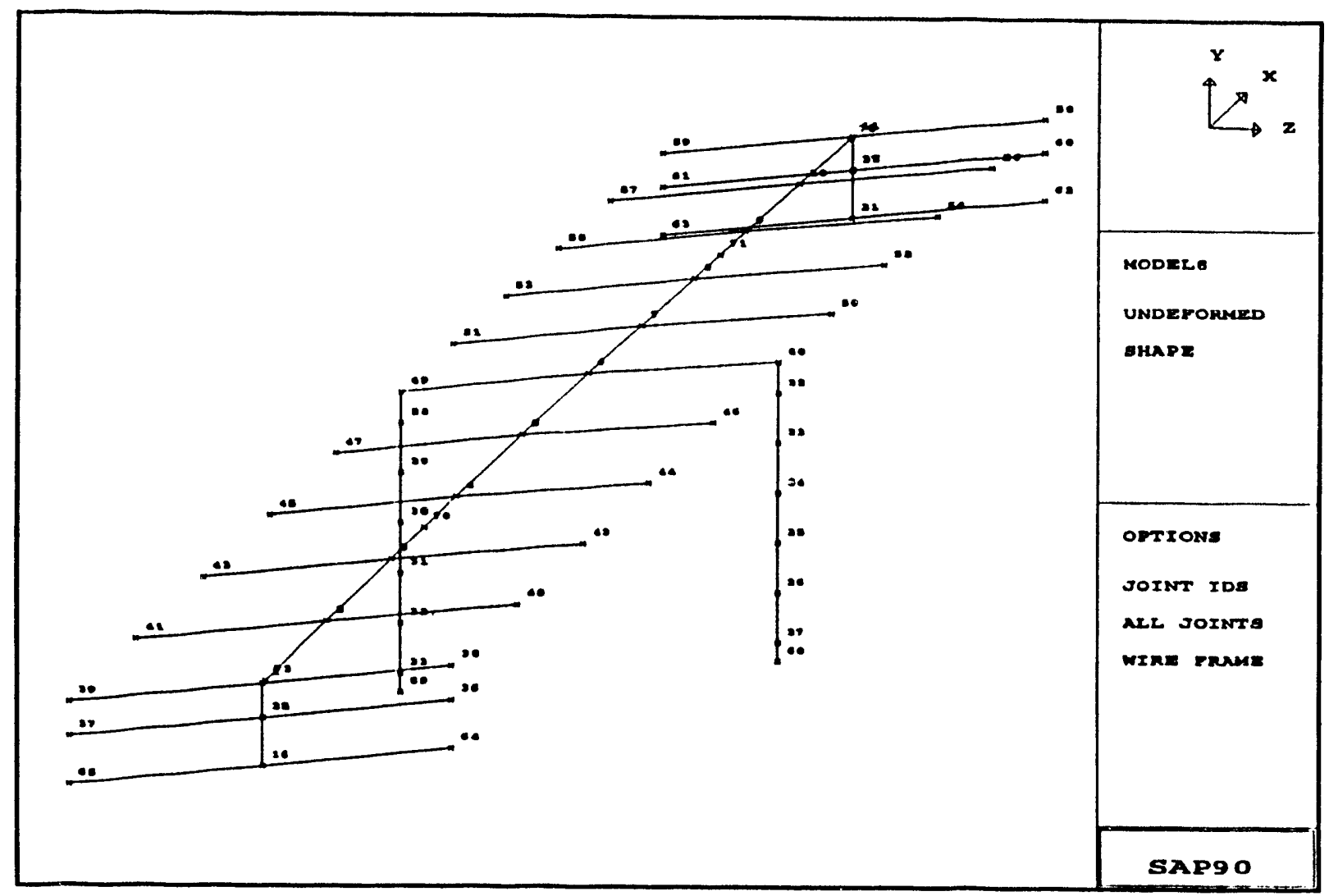

Nodal Geometry

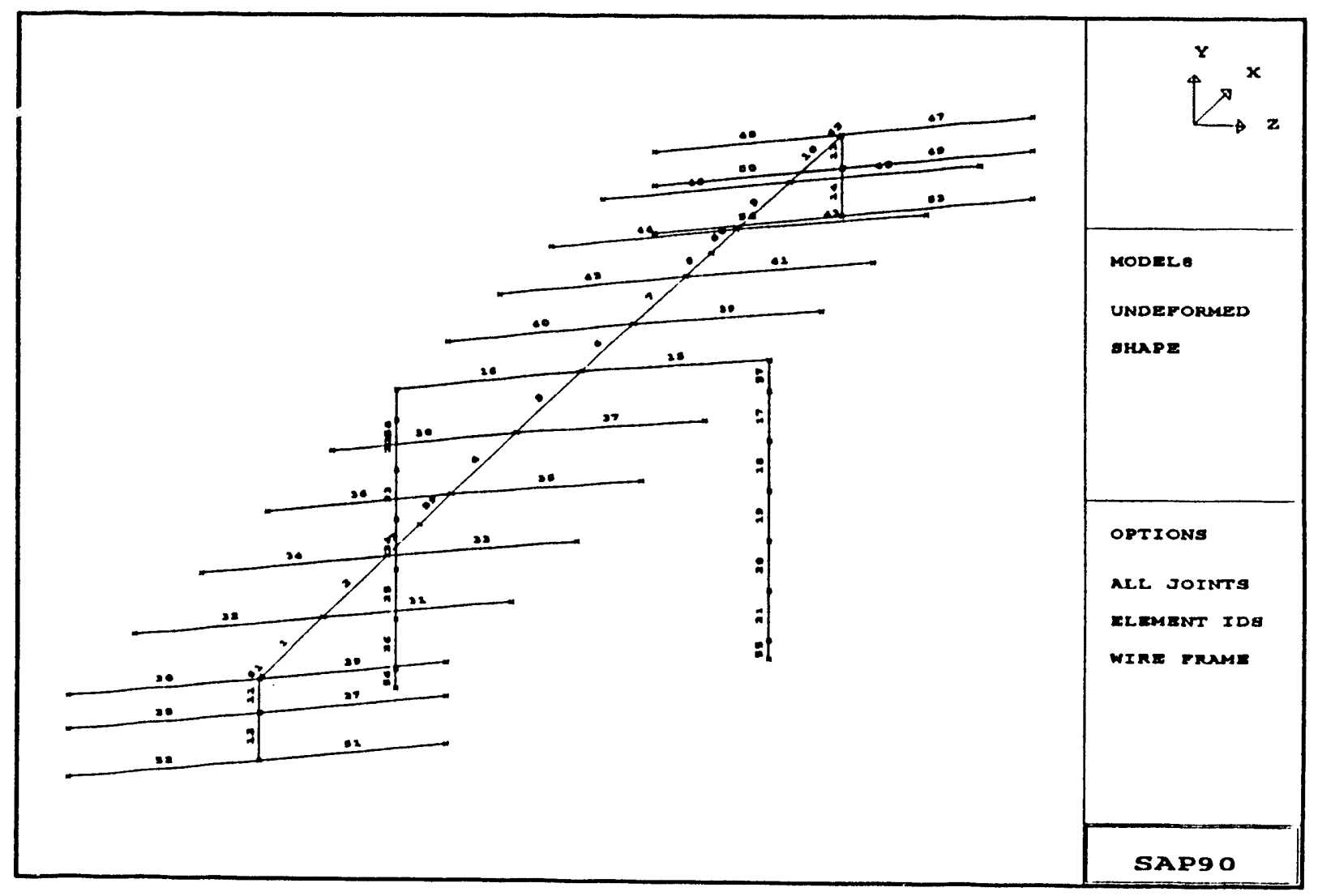

Element Geometry 
BECTION PROPERTIES

$$
\begin{aligned}
& \text { AREA }_{\text {gross }}=12,252 \mathrm{in}^{2} \\
& \text { AREA }_{\text {shear,y }}=4,617 \mathrm{in}^{2} \\
& \text { AREA }_{\text {shear,z }}=7,449 \mathrm{in}^{2} \\
& I_{22}=7,967,960 \mathrm{in}^{4} \\
& I_{y y}=374,710,000 \mathrm{in}^{4} \\
& I_{x x}=382,680,000 \mathrm{in}^{4} \\
& \text { Torsional stiffness }=24,293,000 \mathrm{in}^{4}
\end{aligned}
$$

Figure 2.3-1: Box Girder section Properties 


\section{RESULTS}

The first ten periods and frequencies for each of the eleven models ore summarized in figure 3-1. The recorded acceleration time histories at stations six, seven, and eight are shown in figure 3-2.

3.1 Model 1: Abutments fixed af top, Skewed geomerry.

Model 1 performs an eigenvalue analysis. There ore iive fundamental mode shapes: vertical symmetric, vertical asymetric, transverse, long span torsional, and short span torsional. see figure 3.1-1 for a plot of the mode shapes and frequencies.

3.2 Model 2: Abutments fixed at base, Skewed geometry.

Model 2 performs an eigenvalue analysis. There are six fundamental mode shapes: vertical symetric, vertical asymetric, transverse, long span torsional, short span torsional, and longitudinal. See figure 3.2-1 for a plot of the mode shapes and frequencies.

\subsection{Model 3: Abutments fixed at base. Non-skewed geometry.}

Model 3 performs an eigenvalue analysis. There are six fundamental mode shapes: vertical symmetric, vertical asymetric, transierse, long span torsional, longitudinal, and short span torsional. See figure 3.3-1 for a plot of the mode shapes and frequencies.

3.: Model 4: Abutments fixed at top, Mon-skewed geometry.

Model 4 performs on eigenvalue onalysis. There are five fundamental mode shapes: vertical symmetric, vertical asymetric, transverse, long span torsional, and short span torsional. See figure 3.4-1 for a plot of the mode shapes and frequencies.

3.5 Model 5: Abutments fixed at base, Skewed geometry.

Model 5 subjects the structure to a 0.5 g lateral load. See figure 3.5-1 for the bending moment diagrams. The moments are not symetric due to the asymetric geometry of the structure. Weak axis bending moments are produced on the bridge deck due to the skewed geometry.

3.6 Model 6: Abutments fixed at base. Mon-skewed geometry.

Model 6 subject'3 the structure to a 0.5g lateral load. See figure 3.6-1 for the bending moment diagrams. The moments are not symetric due to the asymetric geometry of the structure. There is no weak axis bending on the bridge deck.

3.7 Model 7: Springs at base of abutments, Skewed geometry.

Model 7 performs an eigenvalue analysis. Placing the springs at the base of the abutment wall is considered "typical." There are six fundamental mode shapes: vertical symetric, 
transverse, longitudinal, vertical asymetric, long span torsional, and short span

torsional. See Figure 3.7-1 for a plot of the mode shapes and frequencies.

3.8 Model 8: Springs at base of abutments, Skewed geometry.

Model 8 subjects the structure to a time history of the ground acceleration. The mode shapes and modal frequencies are identical to those of model 7 . The maximam longitudinal and transverse soil pressures at the abutments are about $1.3 \mathrm{ksf}$ and $0.8 \mathrm{ksf}$, respectively. These values are probably in the elastic range of the soil, and are certainly less then the ultimate strength of the soil. The modal damping coefficients and the theoretical acceleration time histories for stations six. seven, and eight are shown in Figure 3.8-1. At all three stations there is poor agreement between the theoretical and recorded accelerations after about three seconds.

3.9 Model 9: Springs at base of abutments, Skewed geometry, Mo Rotational Inertia.

Model 9 subjects the structure to time history of the ground acceleration. Unlike all of the other models, model 9 ignores the rotational inertias of all of the members. This is $a$ "tyrical" simplification. The modal damping coefficients are the same as those for model

8. Figure 3,9-1 shows the first four mode shapes and frequencies. The modal damping coefficients and the theoretical acceleration time histories for stations six, seven, and eight are shown in Figure 3.9-2. Ignoring the rotational inertias tends to somewhat decrease the theoretical accelerations at stations six and seven. However, there is a significant increase in the accelerations at station eight. As shown in model 11, the rotational mode shapes contribute a great deal to the accelerations at stations seven and eight.

3.10 Model 10: Springs distributed al ong abutments, Skewed model.

Model 10 subjects the structure to a time history of the ground acceleration. The longitudinal and transverse springs are distributed evenly along the height of the abutment wall. The modal damping coefficients are the same as those for model 8 . Figure 3.10-1 shows the first ten mode shapes and modal frequencies. The modal damping coefficients and the theoretical acceleration time histories for stations six, seven, and eight are shown in Figure 3.10-2. This arrangement of the soil springs seems to generate a better representation of the accelerations after the strong motion. However, the theoretical peak accelerations compare poorly to the actual peak accelerations.

3.11 Model 11: Springs at base of abutments, Skewed model.

Model 11 subjects the structure to a time history of the ground acceleration. All modal damping coefficients are equal to 0.02 . The mode shapes and :-equencies are identical to inose of model 7. The theoretical acceleration time histories for stations six, seven, and eight are shown figure 3.11-1. The first six mode shapes and their corresponding contribution to the theoretical acceleration time histories are shown in figures 3.11-2 through 3.11-19. These modal time histories offer some guidance in the assignment of modal 
damping coefficients.

$3-3$ 
Modal Frequencies (Hz)

\begin{tabular}{|c|c|c|c|c|c|c|c|c|c|c|}
\hline MODEL & 1 & 2 & 3 & 4 & $\begin{array}{l}\text { MODE } \\
5\end{array}$ & 6 & 7 & 8 & 9 & 10 \\
\hline 1 & 3.13 & 4.94 & 5.69 & 5.95 & 7.17 & 8.97 & 11.28 & 12.51 & 12.96 & 14.08 \\
\hline 2 & 2.74 & 4.27 & 4.48 & 5.34 & 6.64 & 8.14 & 10.45 & 10.75 & 11.39 & 12.89 \\
\hline 3 & 2.43 & 4.09 & 5.05 & 6.03 & 7.19 & 7.39 & 10.67 & 11.30 & 11.49 & 11.94 \\
\hline 4 & 3.08 & 4.94 & 5.97 & 6.05 & 7.40 & 8.80 & 11.50 & 12.53 & 12.59 & 14.09 \\
\hline 5 & $\mathrm{n} / \mathrm{a}$ & $\mathrm{n} / \mathrm{a}$ & $n / a$ & $\mathrm{n} / \mathrm{a}$ & $\mathrm{n} / \mathrm{a}$ & $n / a$ & $\mathrm{n} / \mathrm{a}$ & $\mathrm{n} / \mathrm{a}$ & $\mathrm{n} / \mathrm{a}$ & $\mathrm{n} / \mathrm{a}$ \\
\hline 6 & $n / a$ & $\mathrm{n} / \mathrm{a}$ & $n / a$ & $n / a$ & $n / a$ & $n / a$ & $\mathrm{n} / \mathrm{a}$ & $\mathrm{n} / \mathrm{a}$ & $n / a$ & $n / a$ \\
\hline 7 & 2.56 & 3.20 & 3.79 & 3.90 & 5.19 & 6.36 & 6.66 & 8.14 & 9.76 & 10.51 \\
\hline 8 & 2.56 & 3.20 & 3.79 & 3.90 & 5.19 & 6.36 & 6.66 & 8.14 & 9.76 & 10.51 \\
\hline 9 & 2.72 & 3.28 & 3.86 & 4.24 & 6.62 & 7.85 & 10.25 & 11.76 & 15.26 & 16.99 \\
\hline 10 & 2.68 & 3.31 & 3.90 & 4.08 & 5.30 & 6.55 & 6.72 & 8.24 & 10.01 & 10.60 \\
\hline 11 & 2.56 & 3.20 & 3.79 & 3.90 & 5.19 & 6.36 & 66 & 8.14 & 9.76 & 10.51 \\
\hline
\end{tabular}

Modal Periods (sec)

\begin{tabular}{cllllllllll} 
MODEL & 1 & 2 & 3 & 4 & 5 & 6 & 7 & 8 & 9 & 10 \\
\hline 1 & .320 & .202 & .176 & .168 & .139 & .111 & .089 & .080 & .077 & .071 \\
2 & .365 & .234 & .223 & .187 & .151 & .123 & .096 & .093 & .088 & .078 \\
3 & .411 & .245 & .198 & .166 & .139 & .135 & .094 & .089 & .087 & .084 \\
4 & .325 & .202 & .167 & .165 & .135 & .114 & .087 & .080 & .079 & .071 \\
5 & $\mathrm{n} / \mathrm{a}$ & $\mathrm{n} / \mathrm{a}$ & $\mathrm{n} / \mathrm{a}$ & $\mathrm{n} / \mathrm{a}$ & $\mathrm{n} / \mathrm{a}$ & $\mathrm{n} / \mathrm{a}$ & $\mathrm{n} / \mathrm{a}$ & $\mathrm{n} / \mathrm{a}$ & $\mathrm{n} / \mathrm{a}$ & $\mathrm{n} / \mathrm{a}$ \\
6 & $\mathrm{n} / \mathrm{a}$ & $\mathrm{n} / \mathrm{a}$ & $\mathrm{n} / \mathrm{a}$ & $\mathrm{n} / \mathrm{a}$ & $\mathrm{n} / \mathrm{a}$ & $\mathrm{n} / \mathrm{a}$ & $\mathrm{n} / \mathrm{a}$ & $\mathrm{n} / \mathrm{a}$ & $\mathrm{n} / \mathrm{a}$ & $\mathrm{n} / \mathrm{a}$ \\
7 & .391 & .312 & .264 & .256 & .193 & .157 & .150 & .123 & .102 & .095 \\
8 & .391 & .312 & .264 & .256 & .193 & .157 & .150 & .123 & .102 & .095 \\
9 & .368 & .304 & .259 & .236 & .151 & .127 & .098 & .085 & .066 & .059 \\
10 & .373 & .303 & .257 & .245 & .189 & .153 & .149 & .121 & .100 & .094 \\
11 & .391 & .312 & .264 & .256 & .193 & .157 & .150 & .123 & .102 & .095
\end{tabular}

Figure 3-1: Modal Frequencies and Periods 


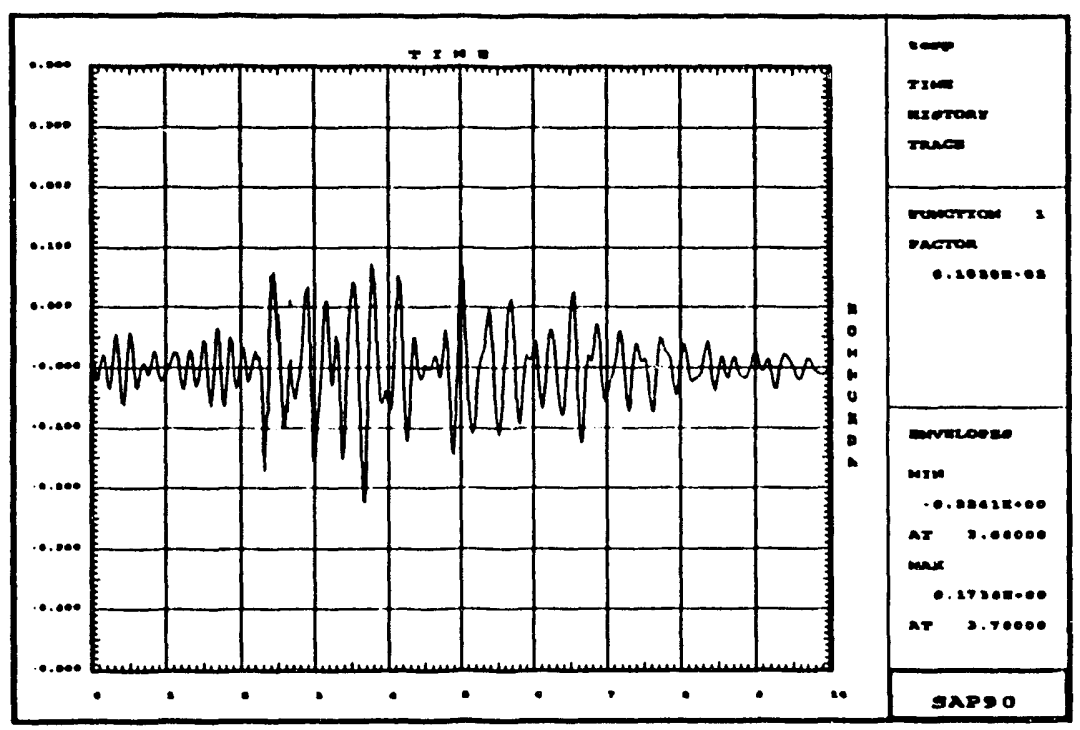

station 6 (Long 8pan, Vertical) Recorded Absolute Acceleration

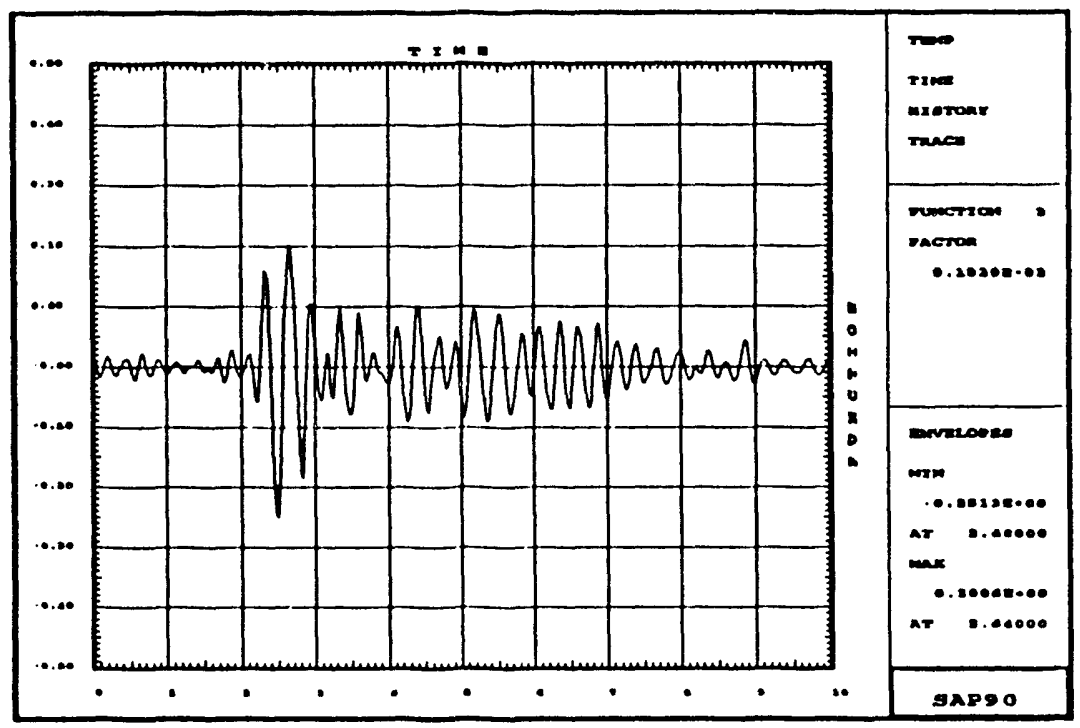

Station 7 (Bent, Transverse) Recorded Absolute Acceleration

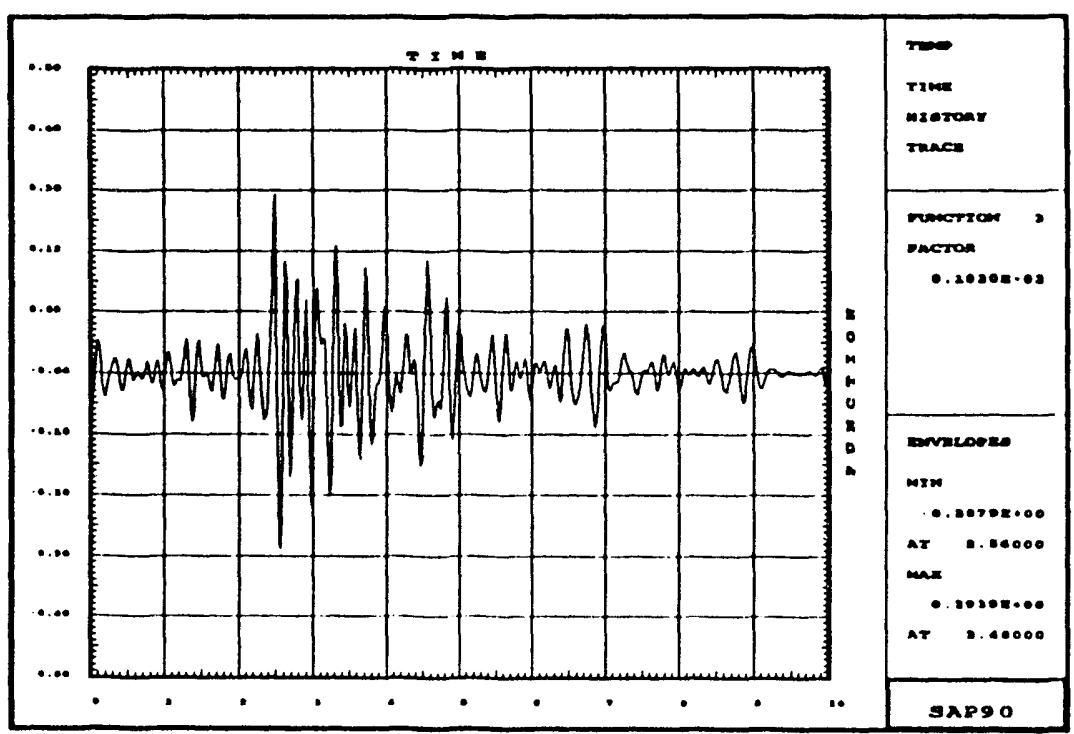

station 8 (short span, Vertical) Recorded Absolute Acceleration 


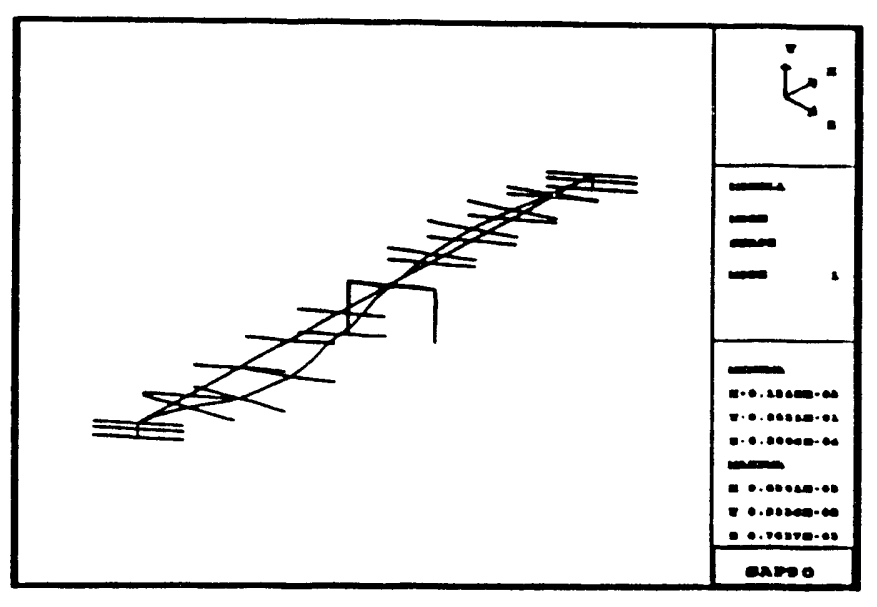

Model 1: Mode Shape 1 $F=3.13 \mathrm{~Hz}$

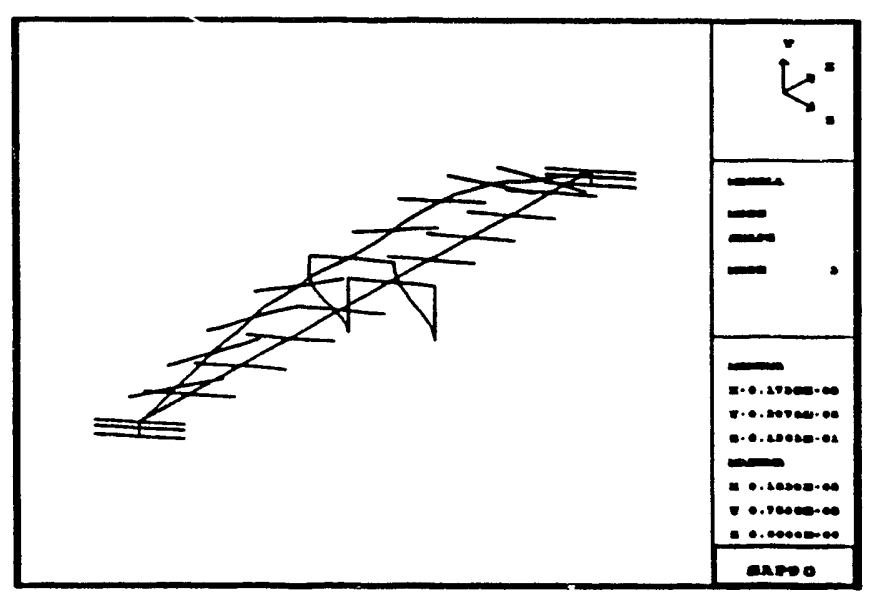

Model 1: Mode Shape 3 $F=5.69 \mathrm{~Hz}$

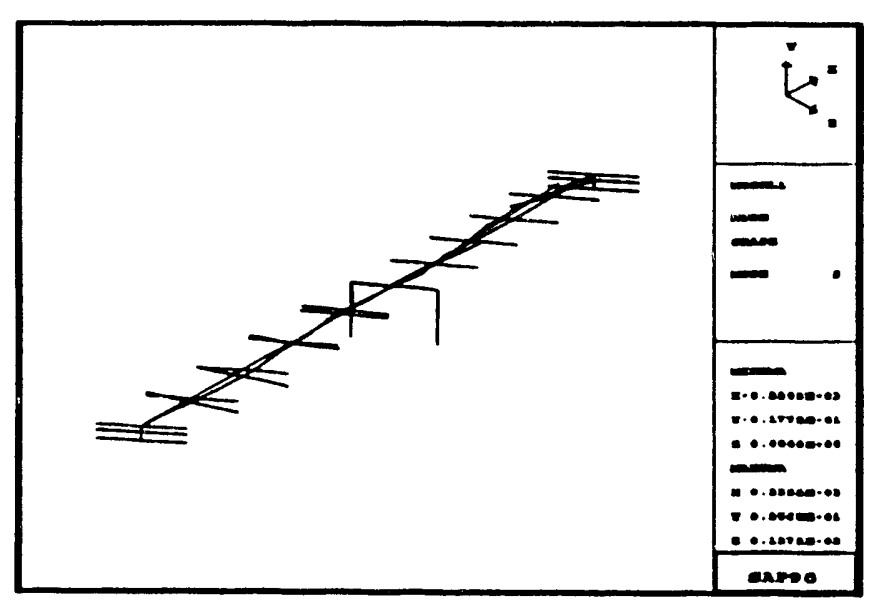

Model 1: Mode Shape 5 $F=7.17 \mathrm{~Hz}$
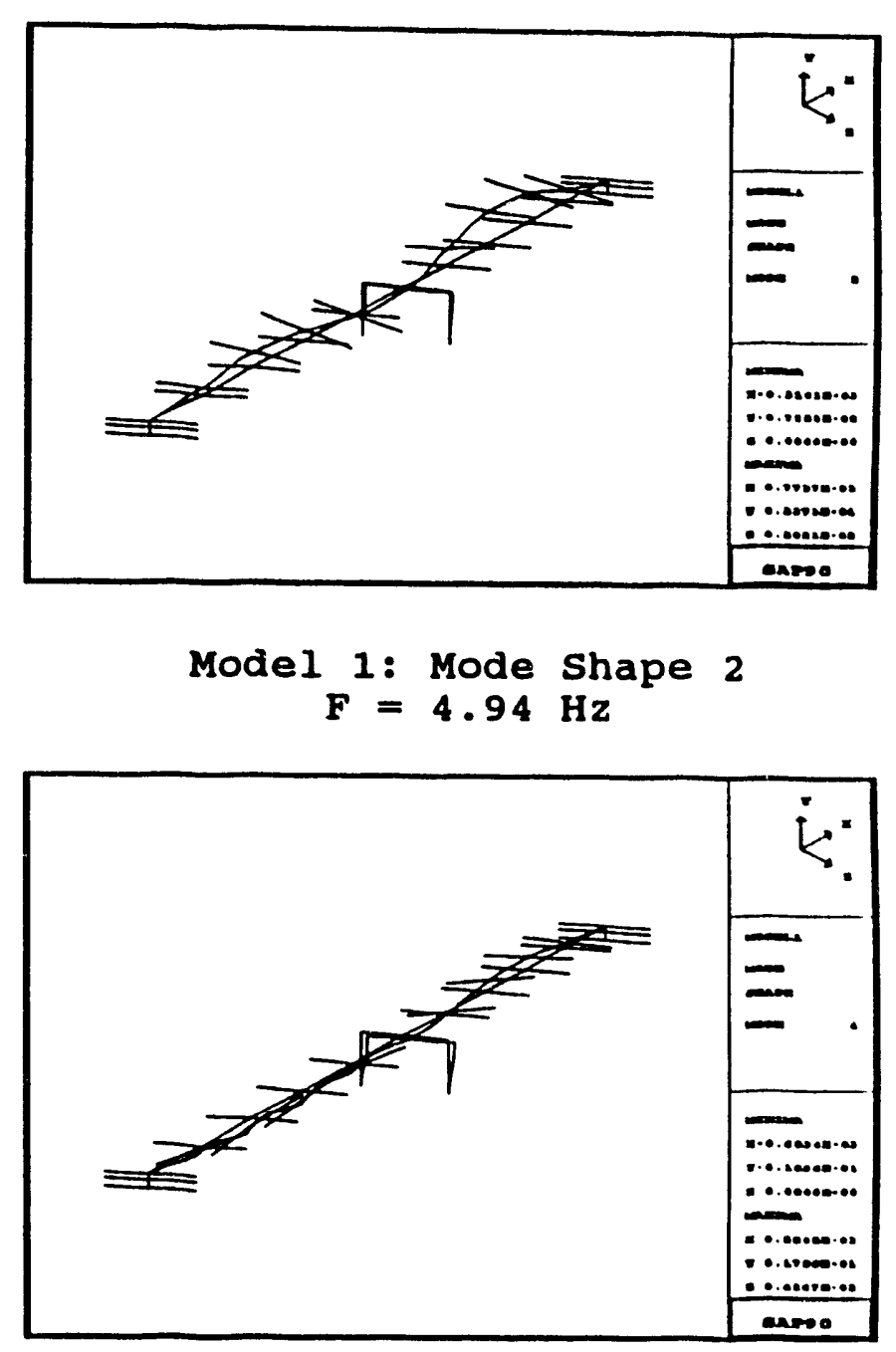

Model 1: Mode Shape 4 $F=5.95 \mathrm{~Hz}$ 


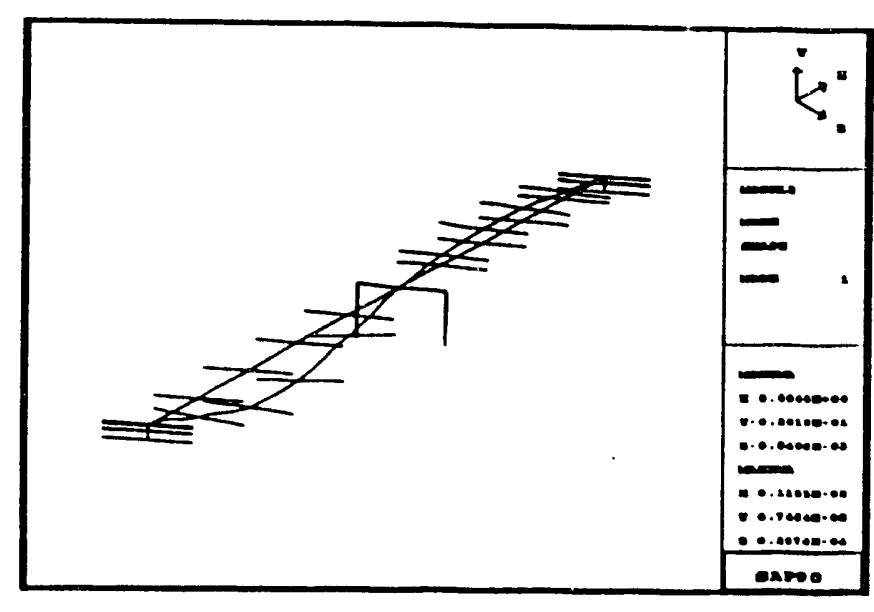

Model 2: Mode Shape 1 $F=2.74 \mathrm{~Hz}$

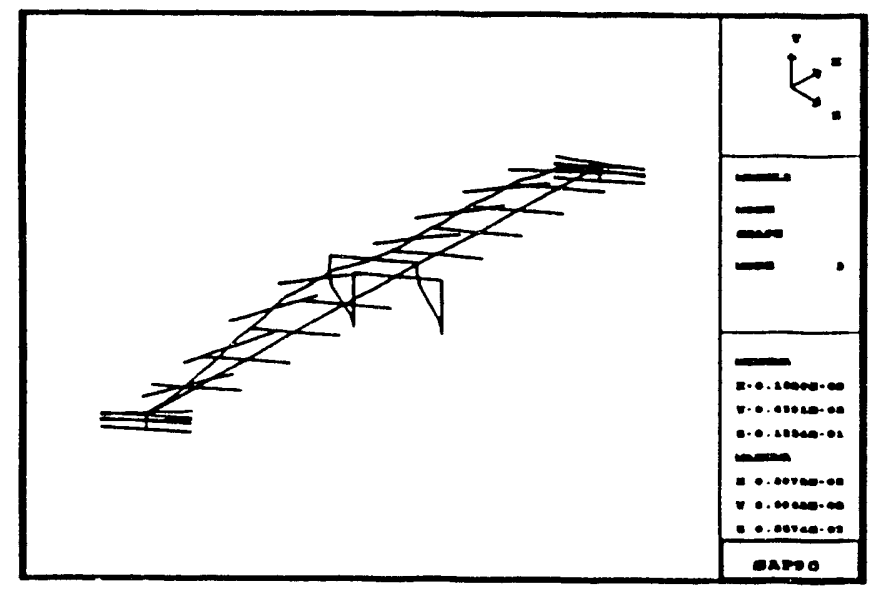

Model 2: Mode Shape 3

$F=4.48 \mathrm{~Hz}$

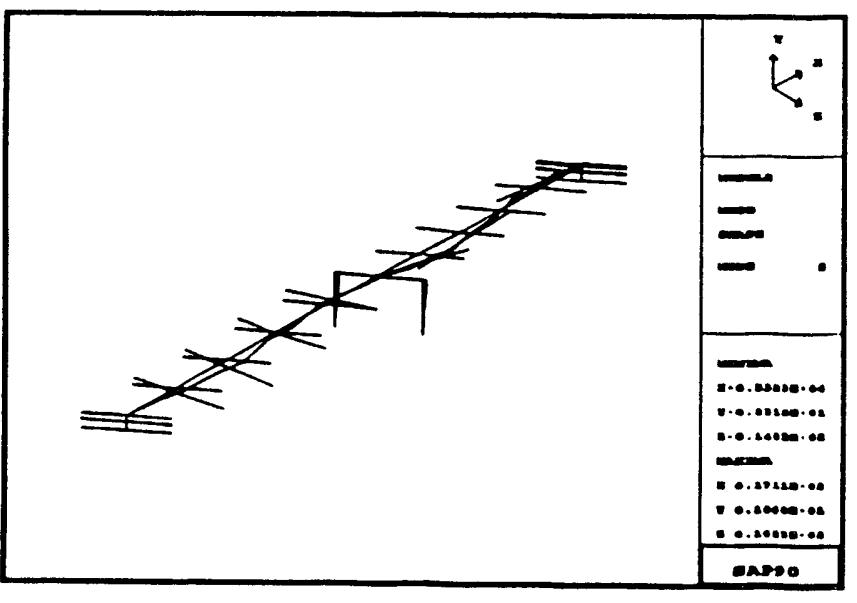

Model 2: Mode Shape 5

$F=6.64 \mathrm{~Hz}$

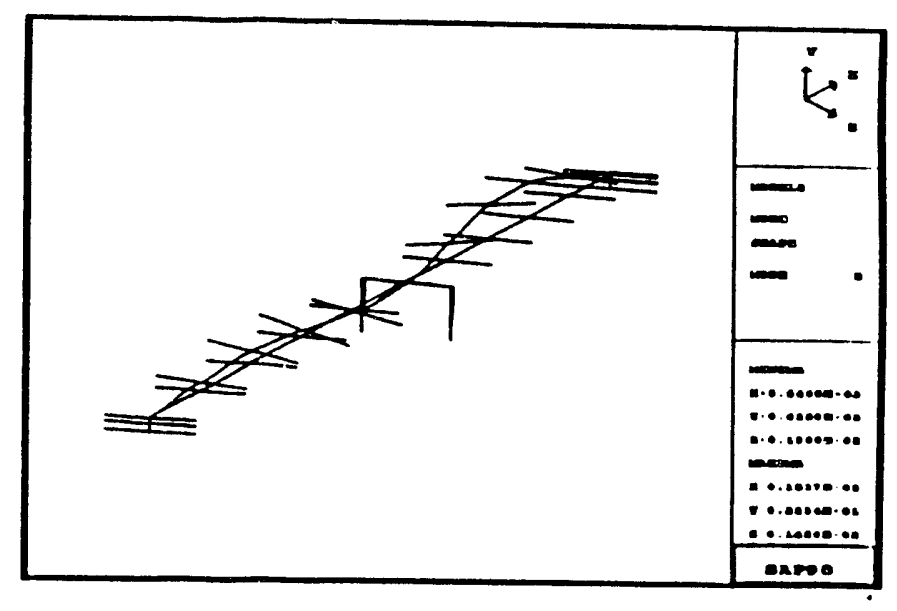

Model 2: Mode Shape 2

$F=4.27 \mathrm{~Hz}$

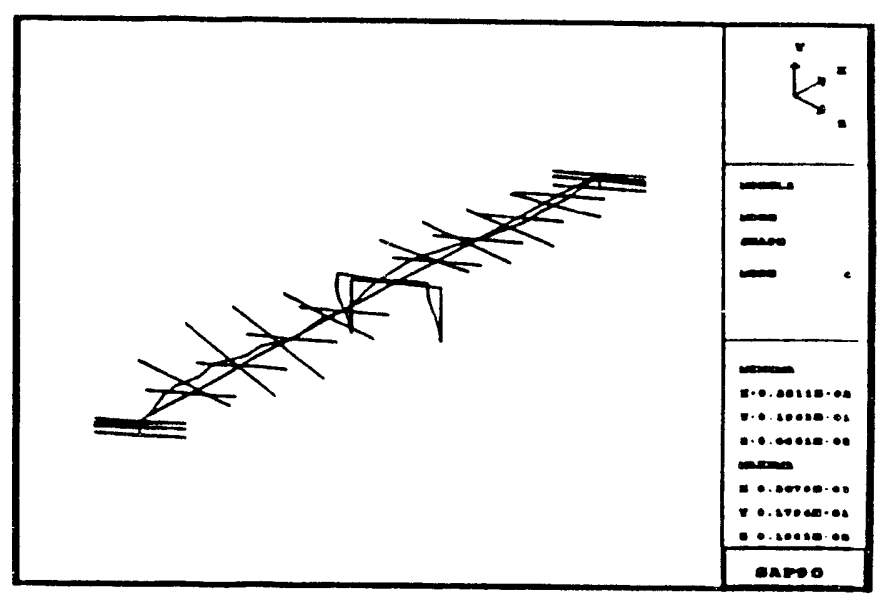

Model 2: Mode Shape 4 $F=5.34 \mathrm{~Hz}$

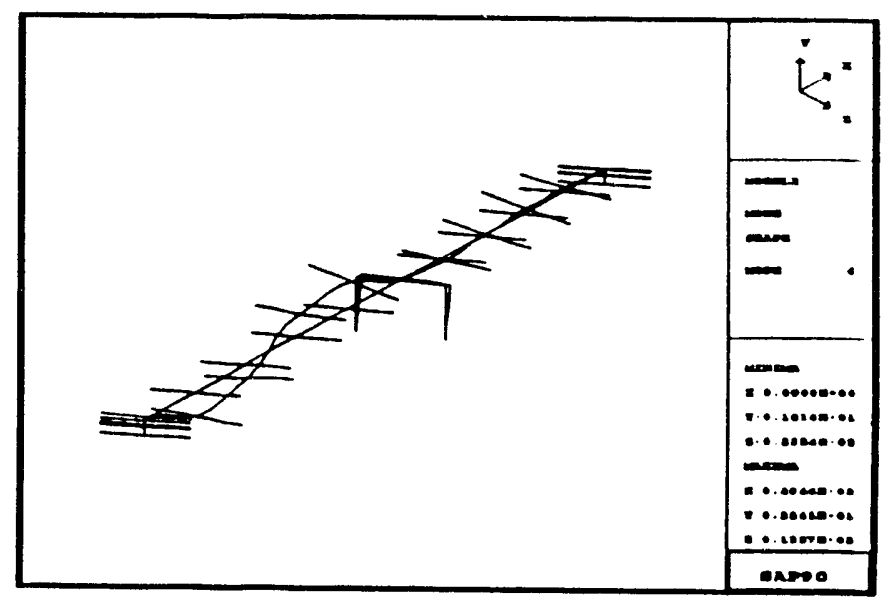

Model 2: Mode Shape 6 $F=8.14 \mathrm{~Hz}$ 


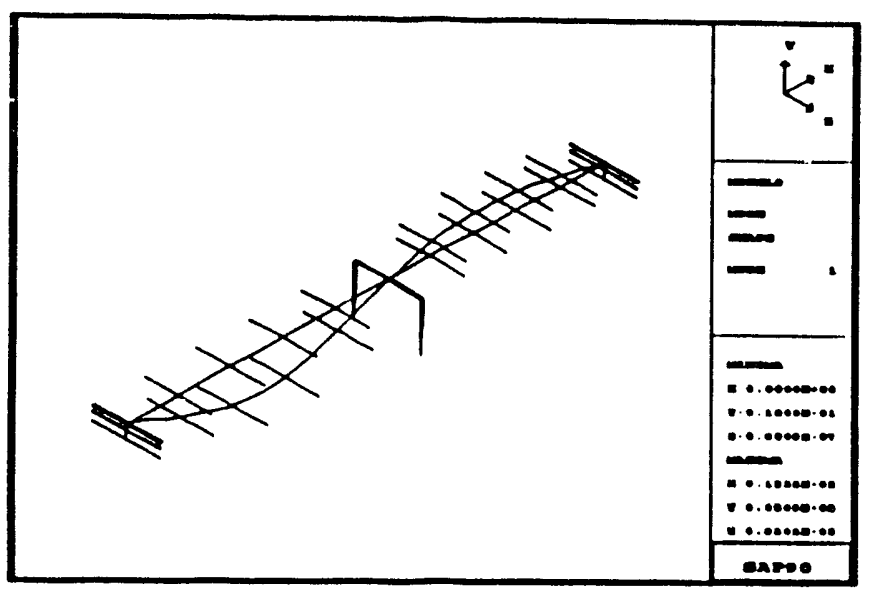

Model 3: Mode Shape 1 $F=2.43 \mathrm{~Hz}$

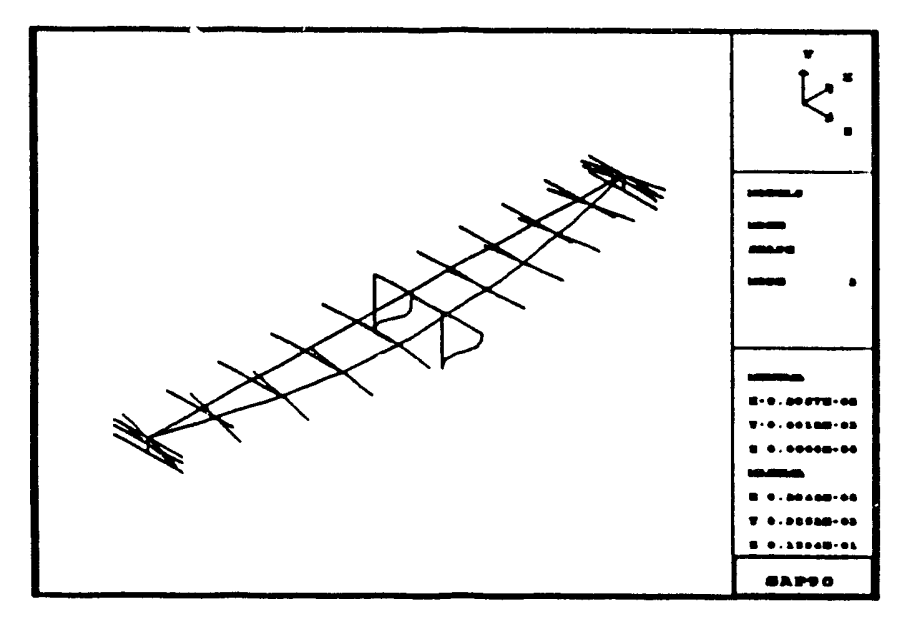

Model 3: Mode Shape 3 $F=5.05 \mathrm{~Hz}$

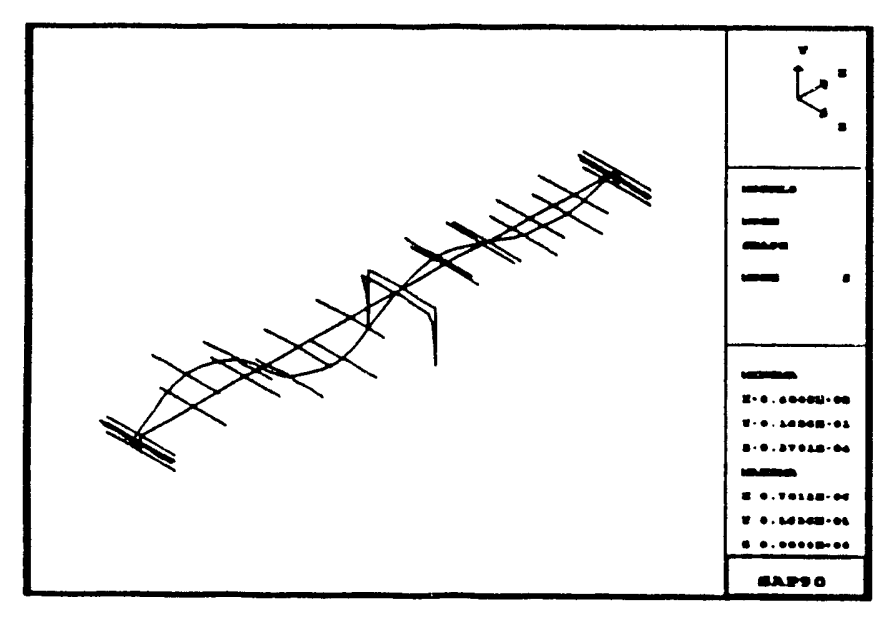

Model 3: Mode Shape 5 $F=7.19 \mathrm{~Hz}$

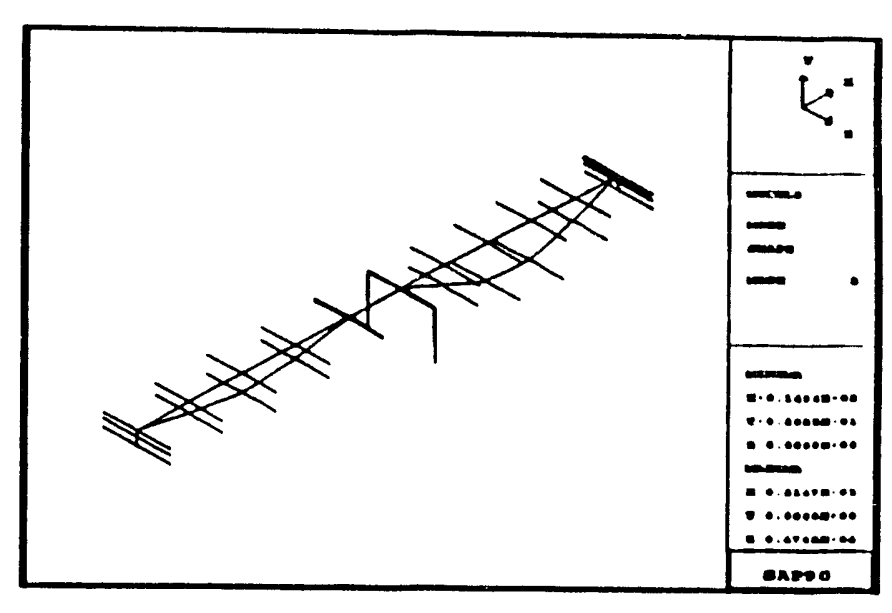

Model 3: Mode Shape 2
$F=4.09 \mathrm{~Hz}$

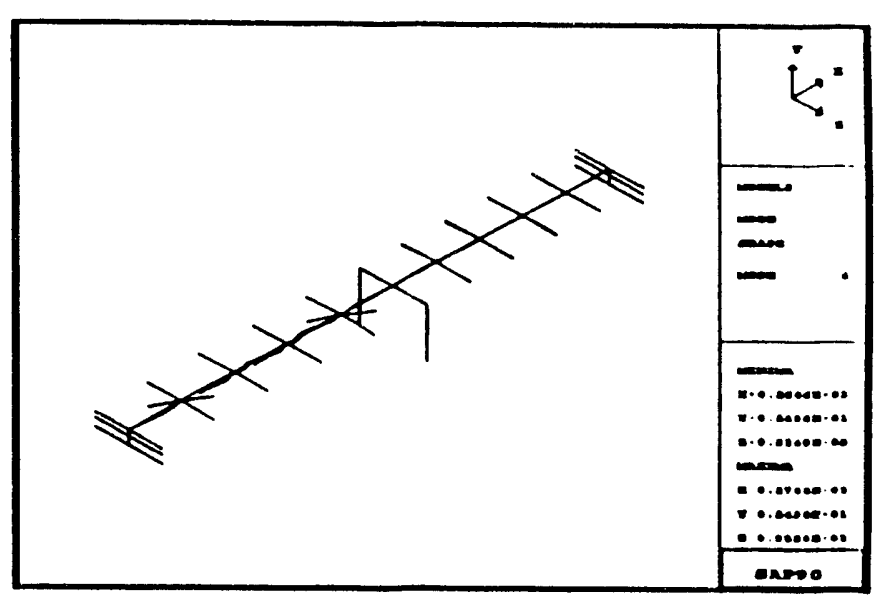

Model 3: Mode Shape 4 $F=6.03 \mathrm{~Hz}$

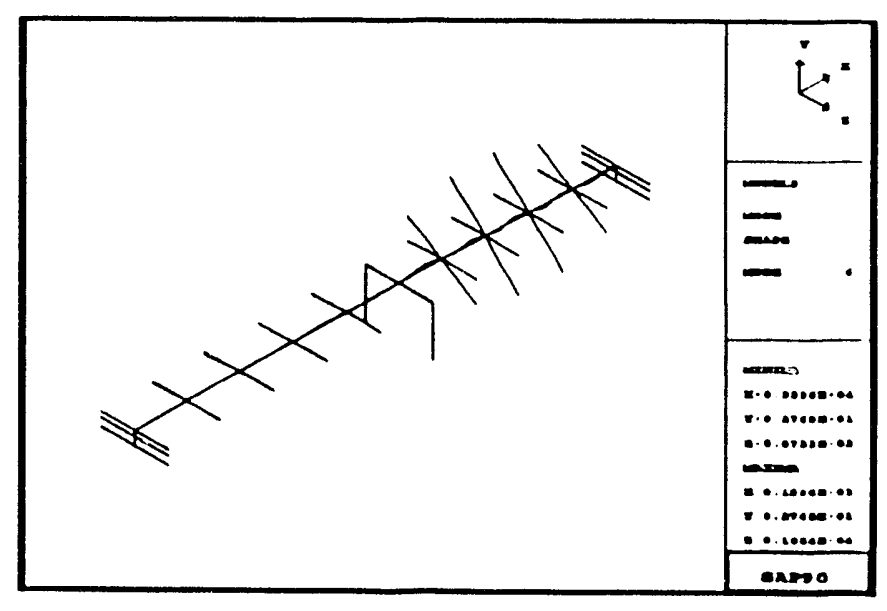

Model 3: Mode Shape 6 $F=7.39 \mathrm{~Hz}$ 


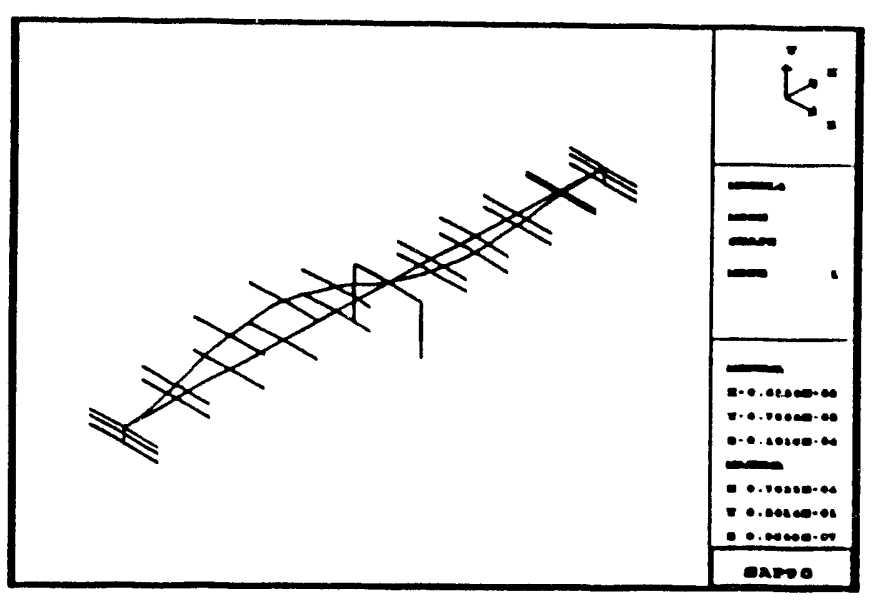

Model 4: Mode Shape 1 $F=3.08 \mathrm{~Hz}$

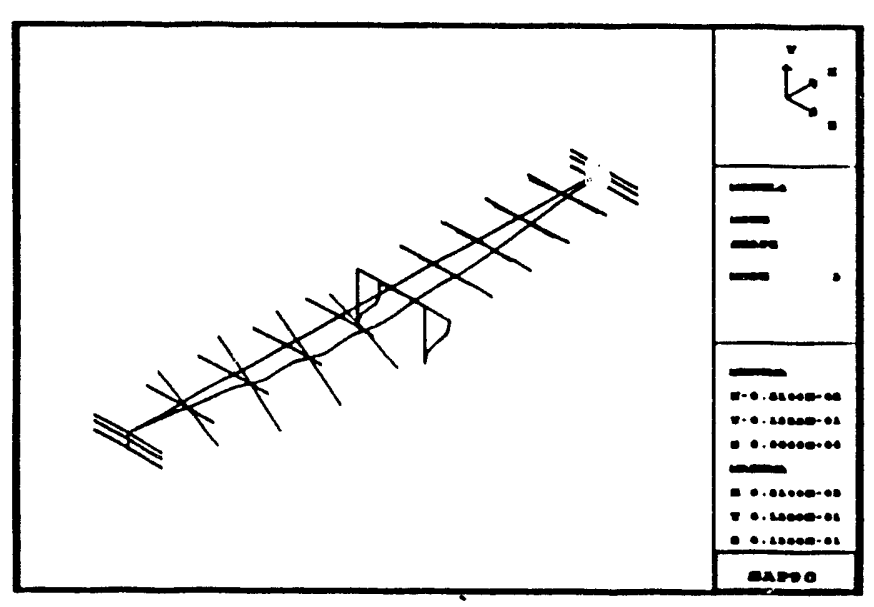

Model 4: Mode Shape 3

$F=5.97 \mathrm{~Hz}$

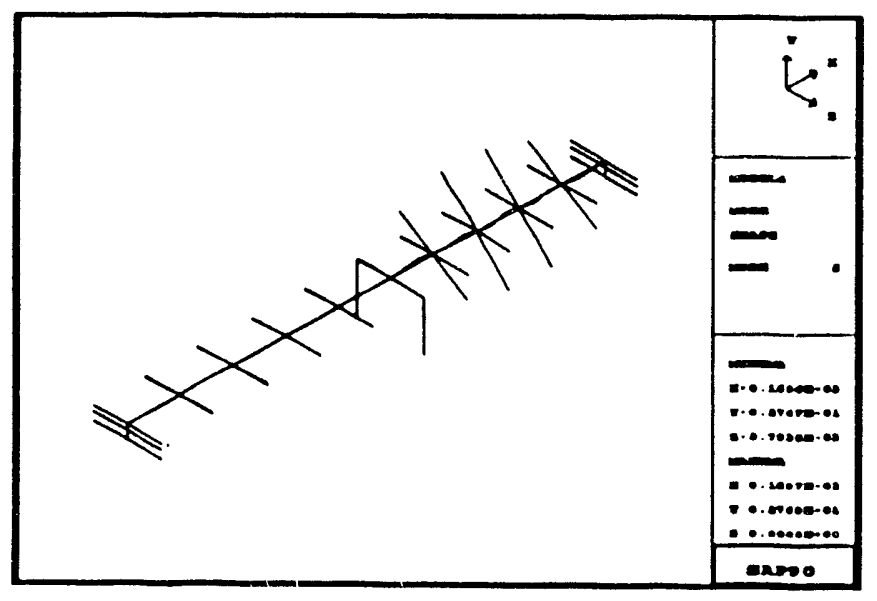

Model 4: Mode Shape 5

$F=7.40 \mathrm{~Hz}$

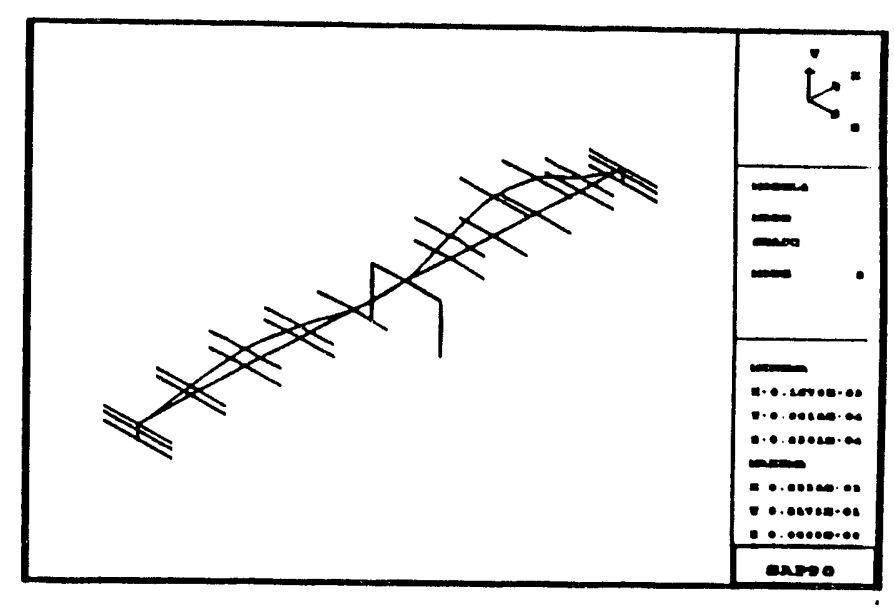

Model 4: Mode Shape 2 $F=4.94 \mathrm{~Hz}$

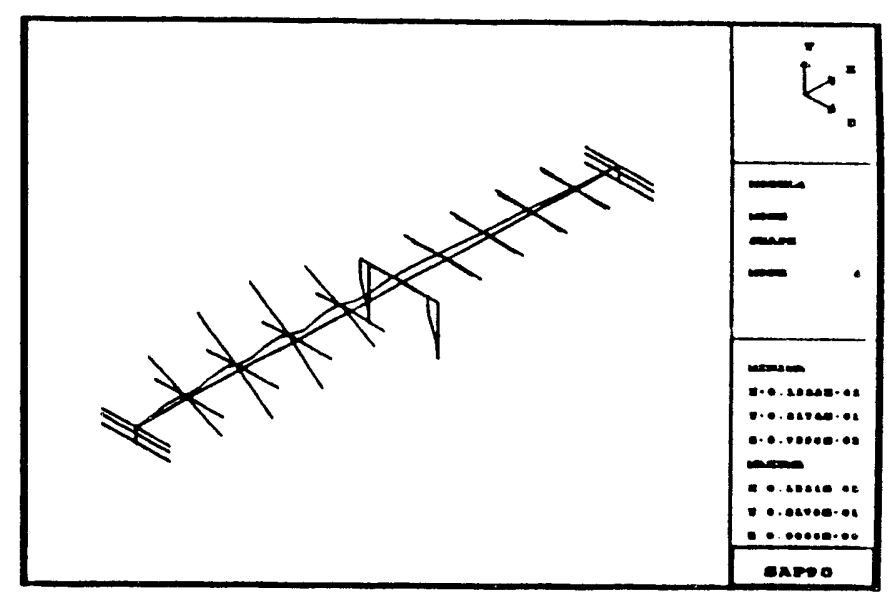

Model 4: Mode Shape 4 $F=6.05 \mathrm{~Hz}$ 


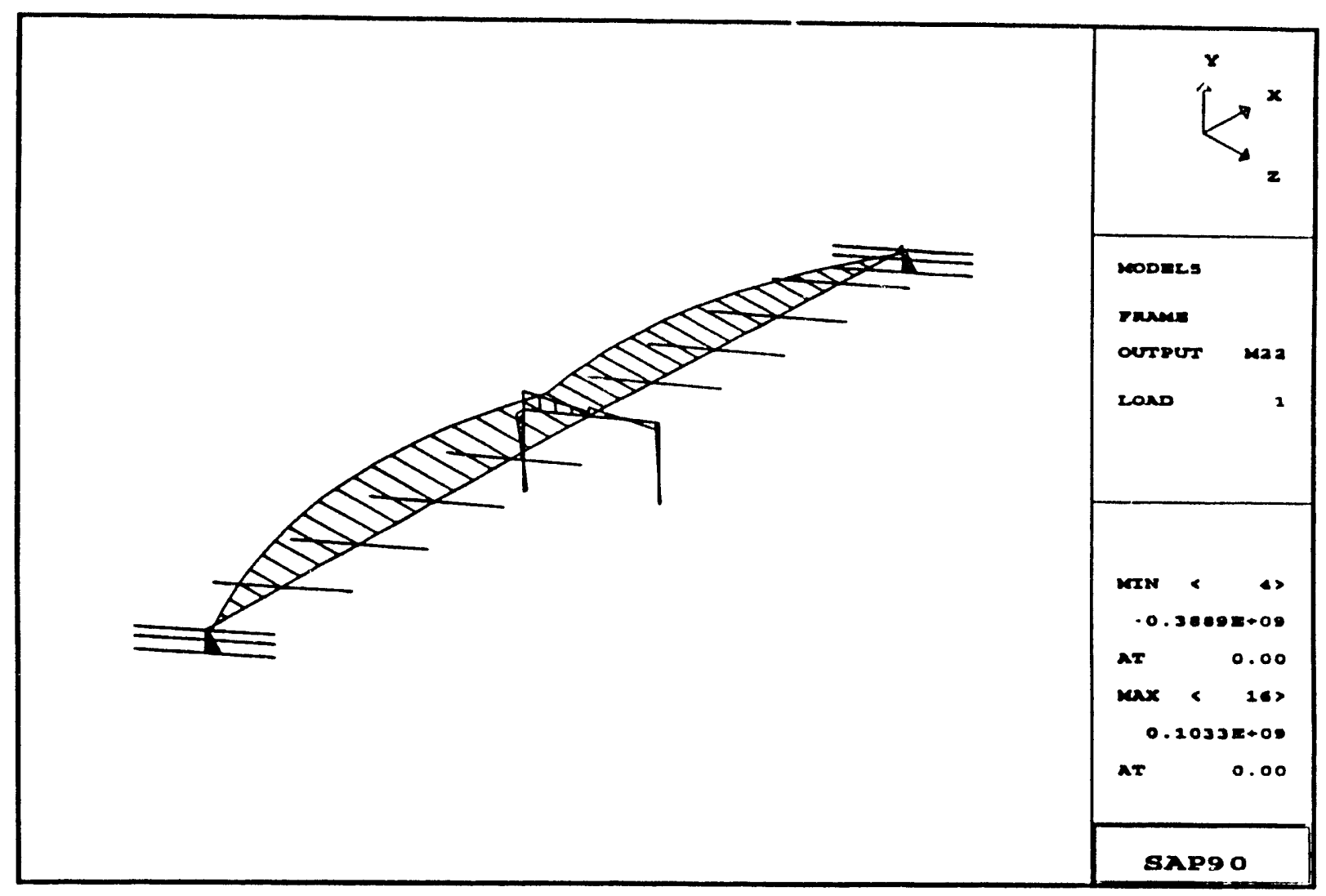

\section{8trong Axis Bending Moment (1nch-1bs)}

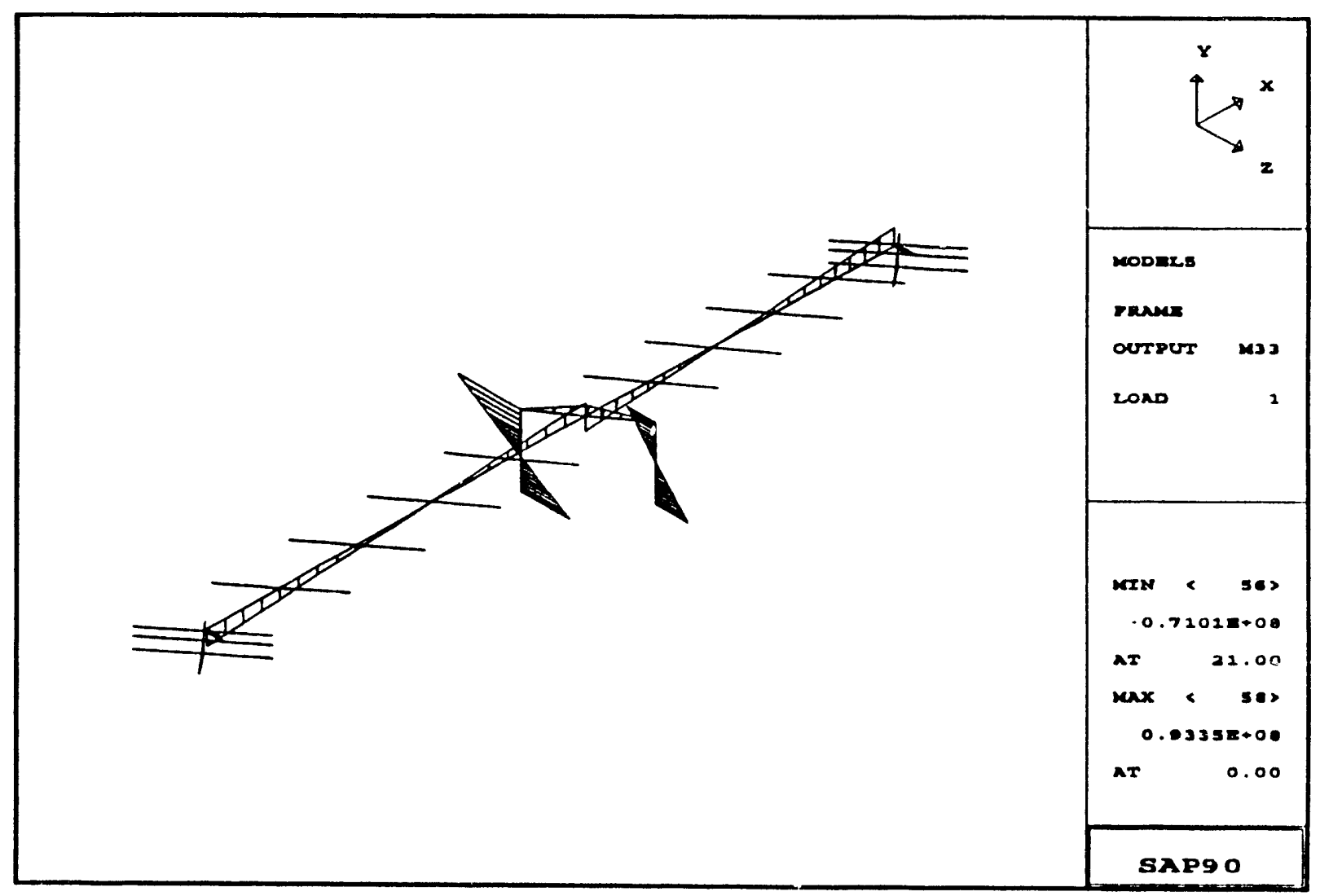

Weak Axis Bending Moment (inch-1bs) 


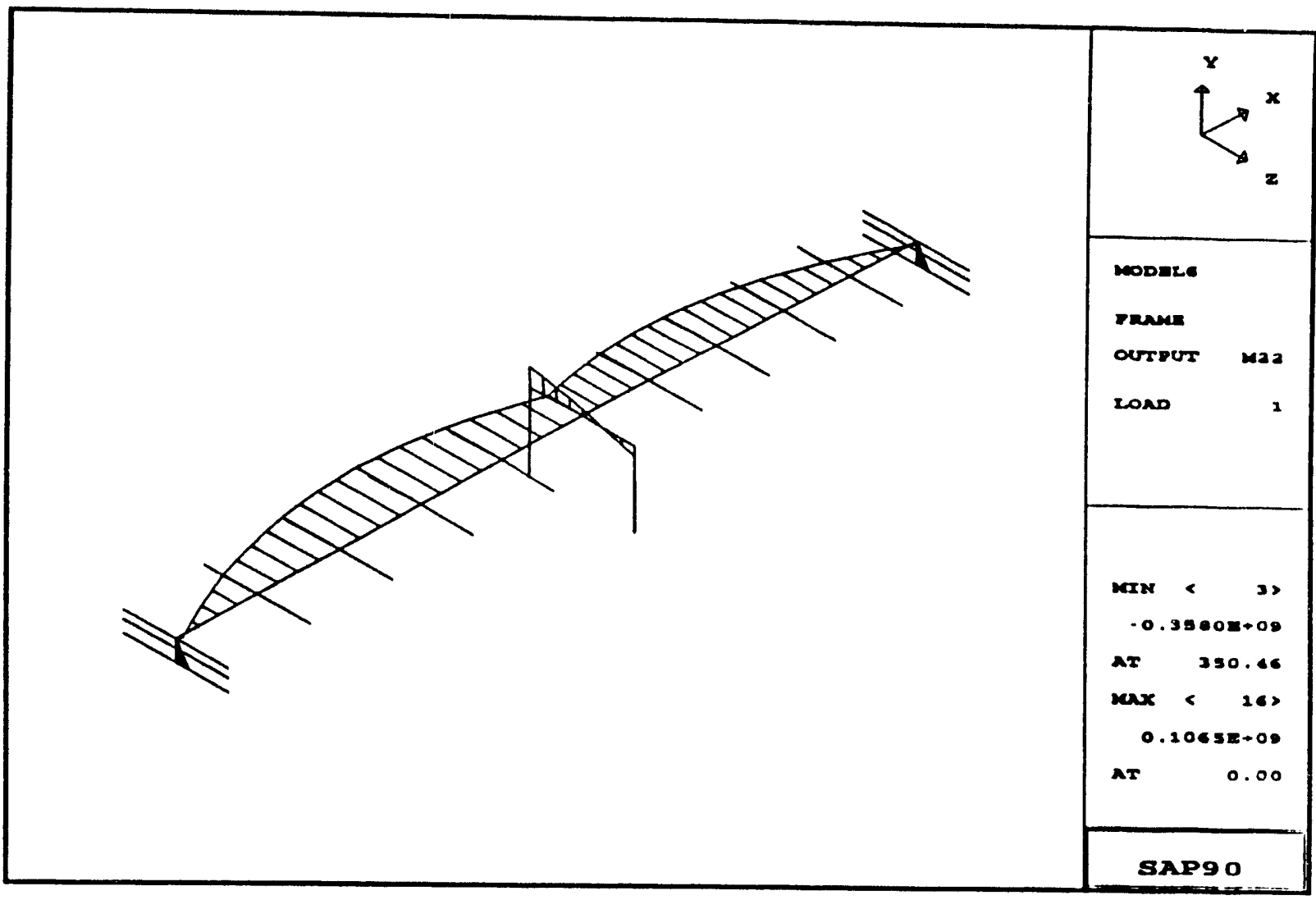

strong Axis Bending Koment (inch-1bs)

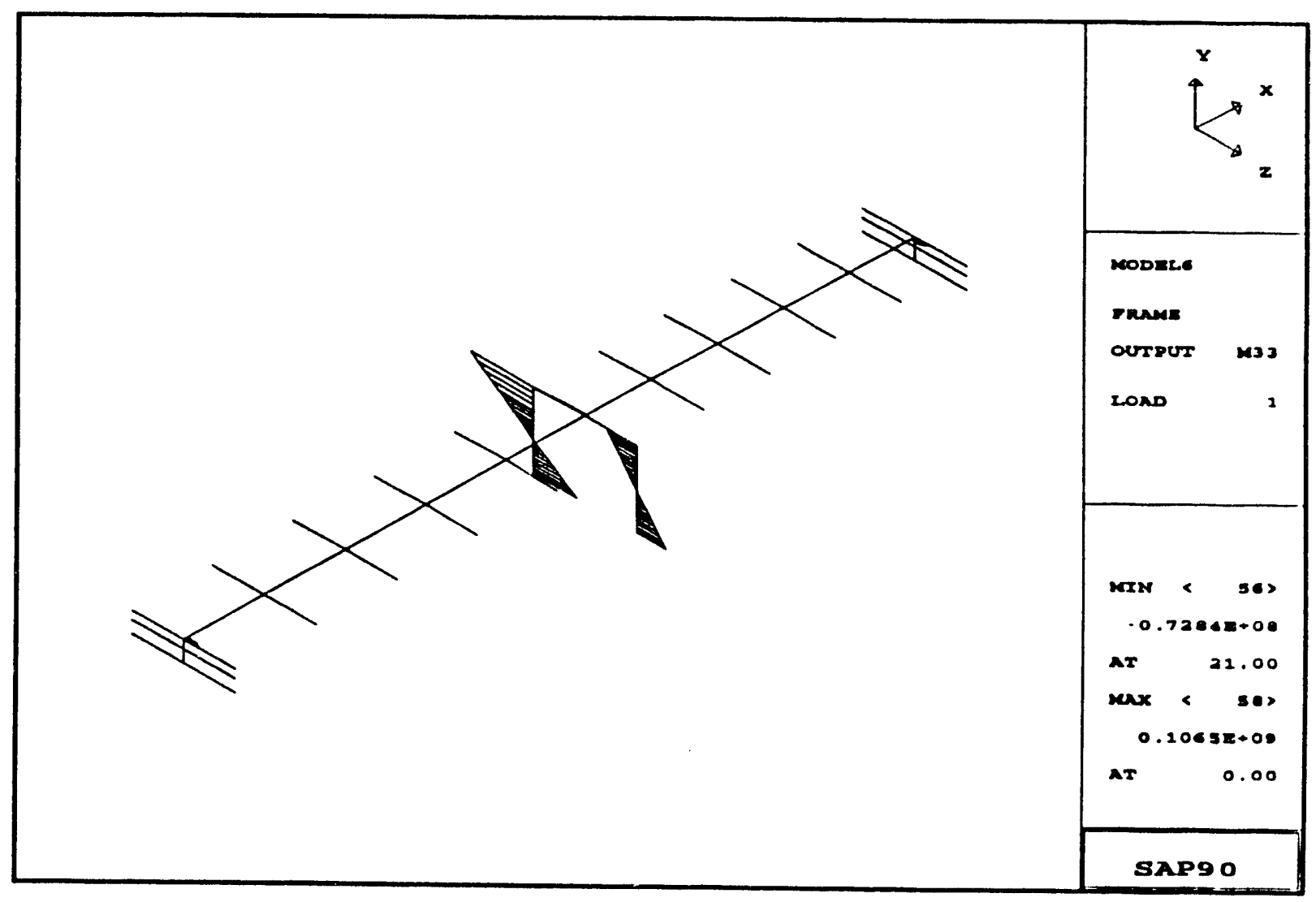

Weak Axis Bending Moment (inch-lbs) 


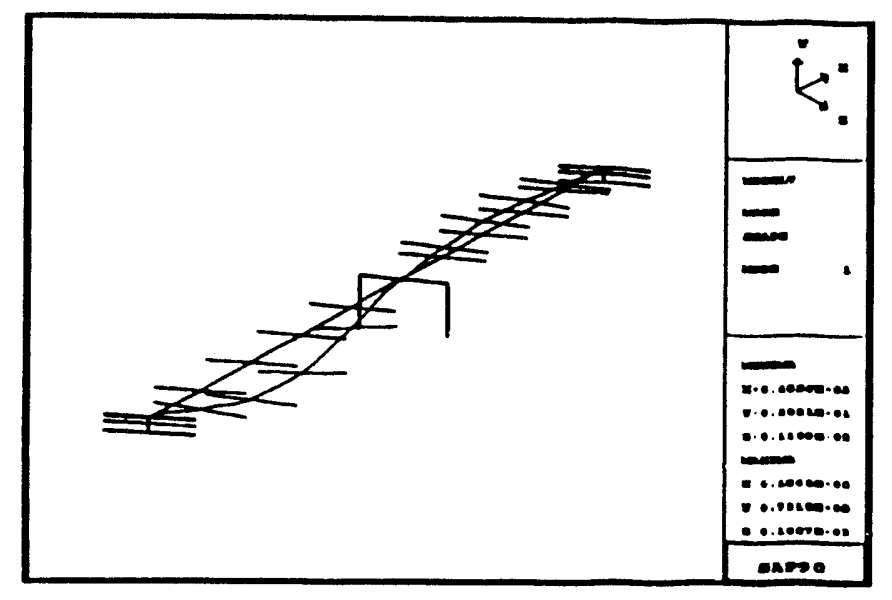

Model 7: Mode Shape 1 $F=.2 .56 \mathrm{~Hz}$

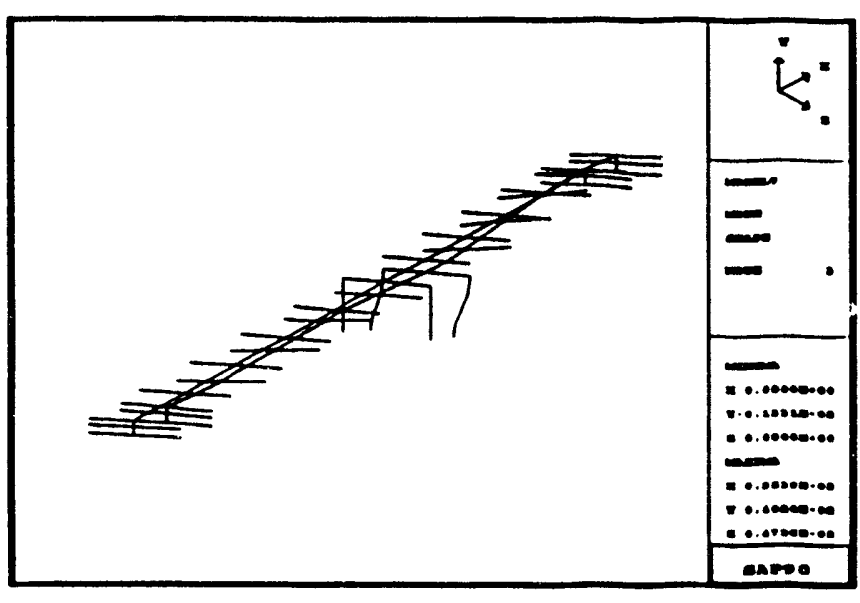

Model 7: Mode Shape 3 $F=3.79 \mathrm{~Hz}$

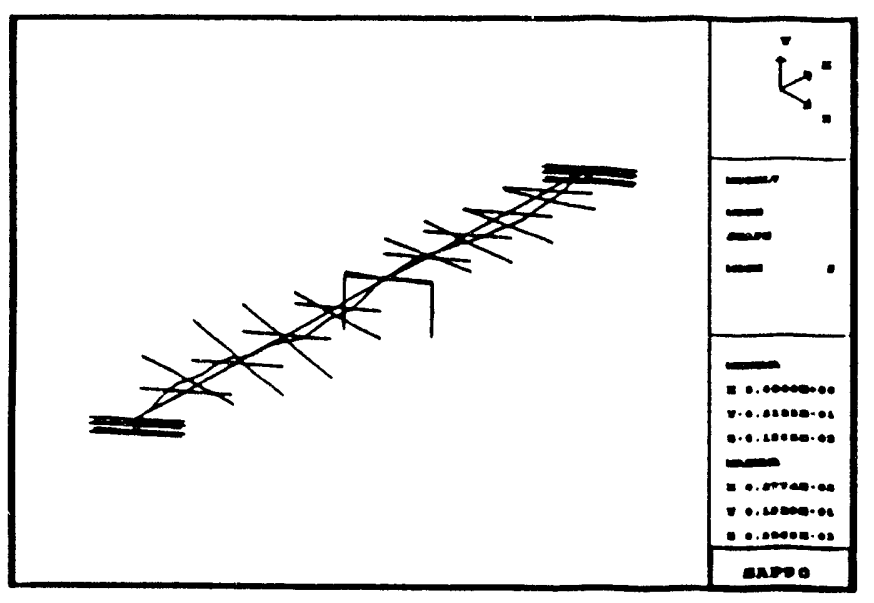

Model 7: Mode Shape 5 $F=5.19 \mathrm{~Hz}$

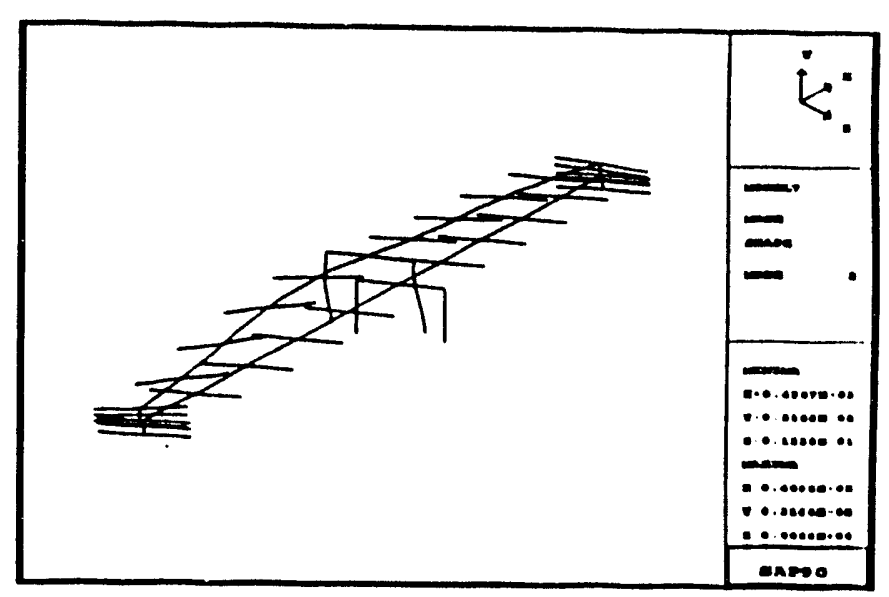

Model 7: Mode Shape 2 $F=3.20 \mathrm{~Hz}$

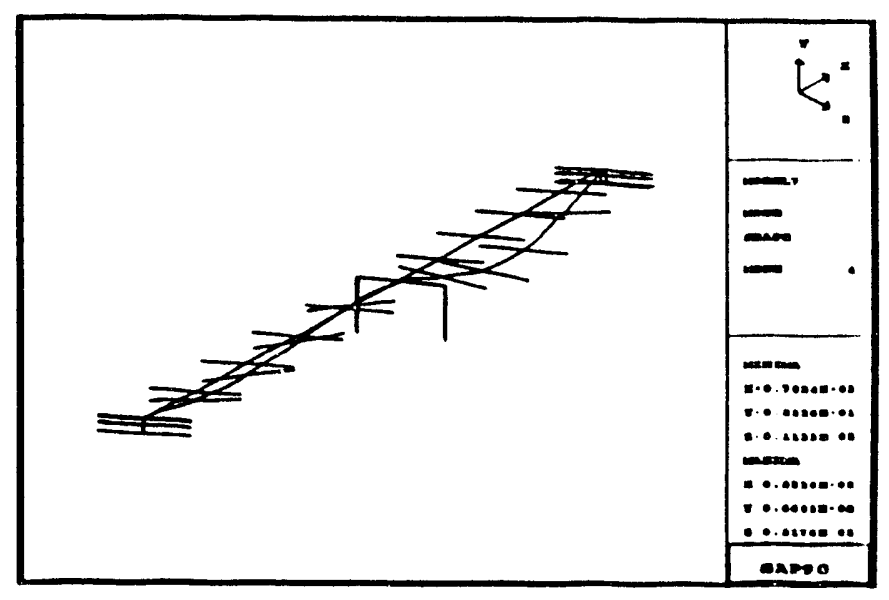

Model $7:$ Mode Shape 4
$F=3.90 \mathrm{~Hz}$

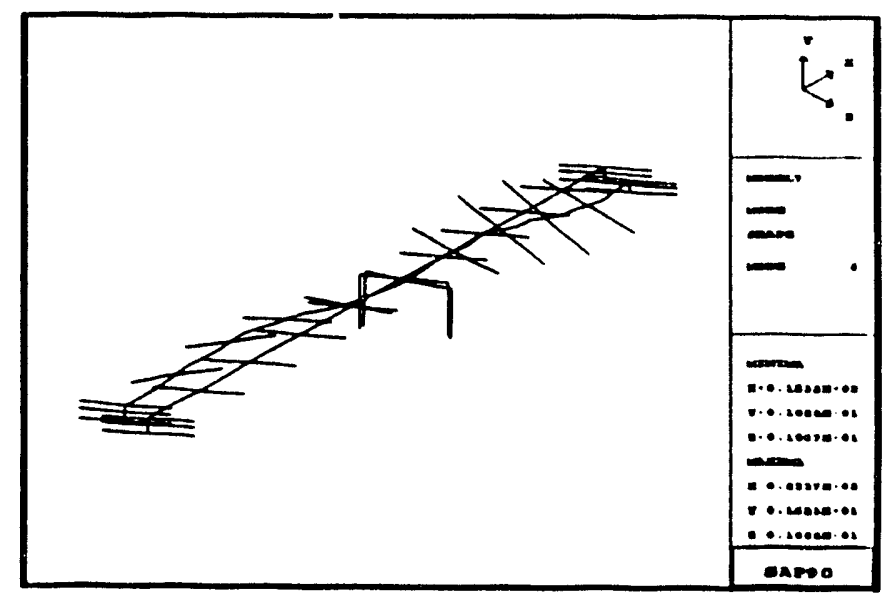

Model 7: Mode Shape 6 $F=6.36 \mathrm{~Hz}$ 


\begin{tabular}{cl} 
Model 8 \\
\hline Mode & $\frac{B}{\text { Beta }}$ \\
\hline 1 & 0.04 \\
2 & 0.40 \\
3 & 0.10 \\
4 & 0.04 \\
5 & 0.04 \\
6 & 0.04 \\
7 & 0.04 \\
8 & 0.04 \\
9 & 0.04 \\
10 & 0.04
\end{tabular}

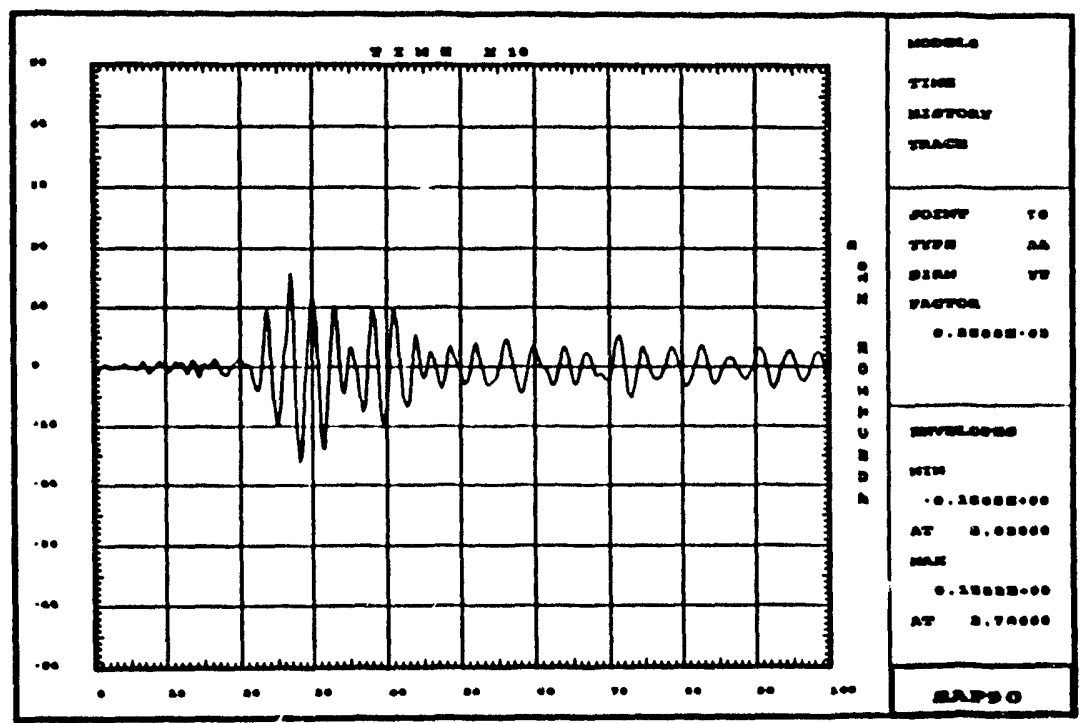

station 6 (Iong span, Vertical) Theoretical Absolute Acceleration

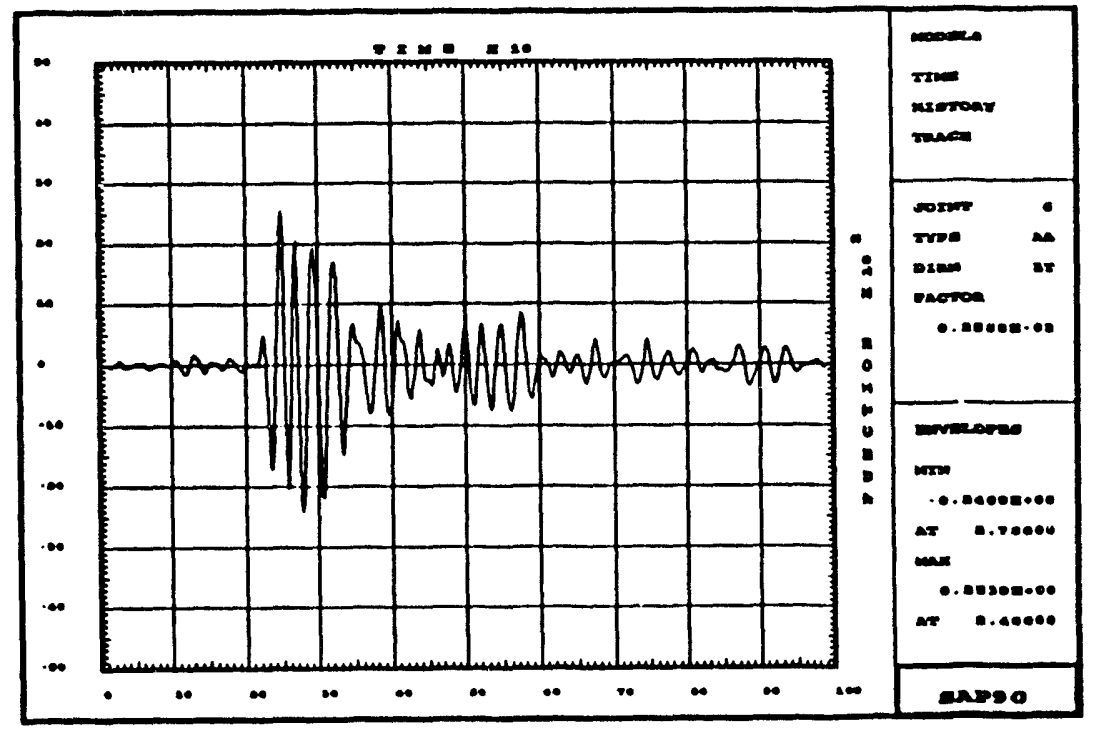

station 7 (Bent, Transverse) Theoretical Absolute Acceleration

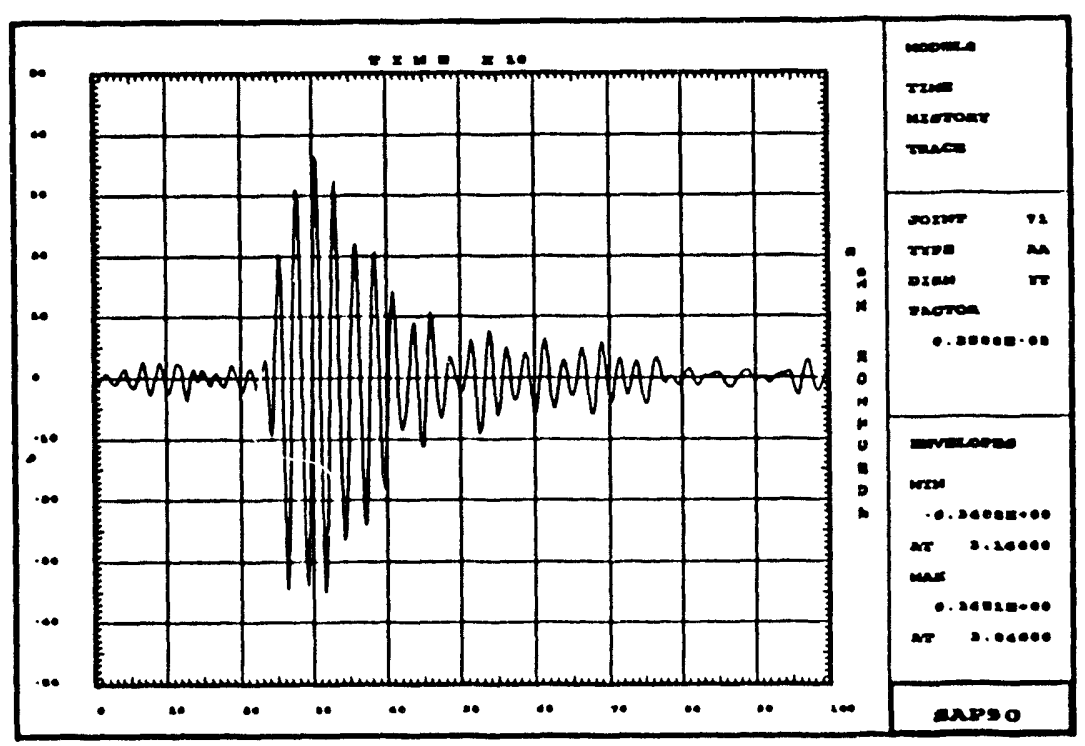

station 8 (short span, Vertical) Theoretical Absolute Acceleration 


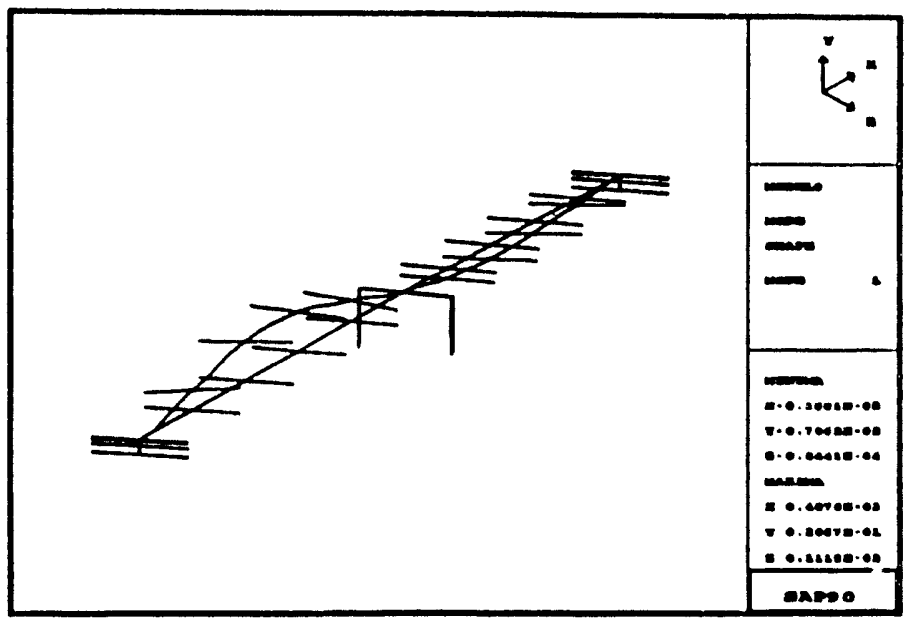

Model 9: Mode Shape 1

$F=2.72 \mathrm{~Hz}$

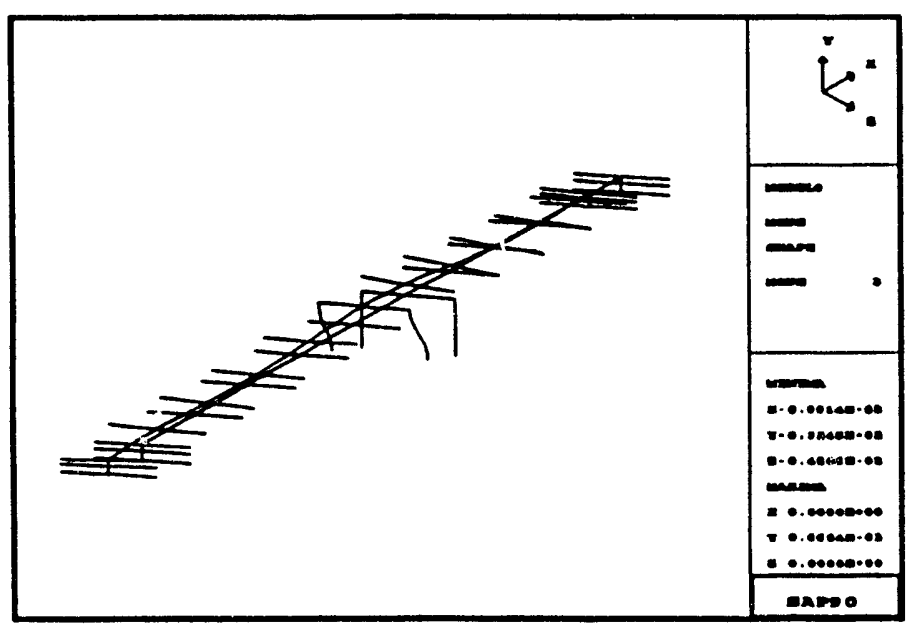

Model 9: Mode Shape 3

$F=3.86 \mathrm{~Hz}$

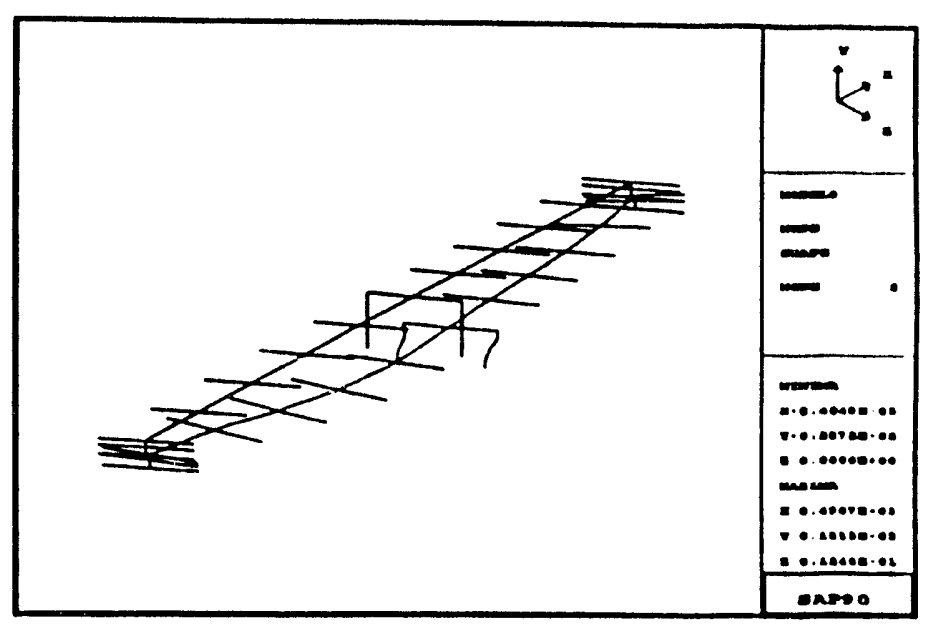

Model 9: Mode Shape 2
$F=3.28 \mathrm{~Hz}$

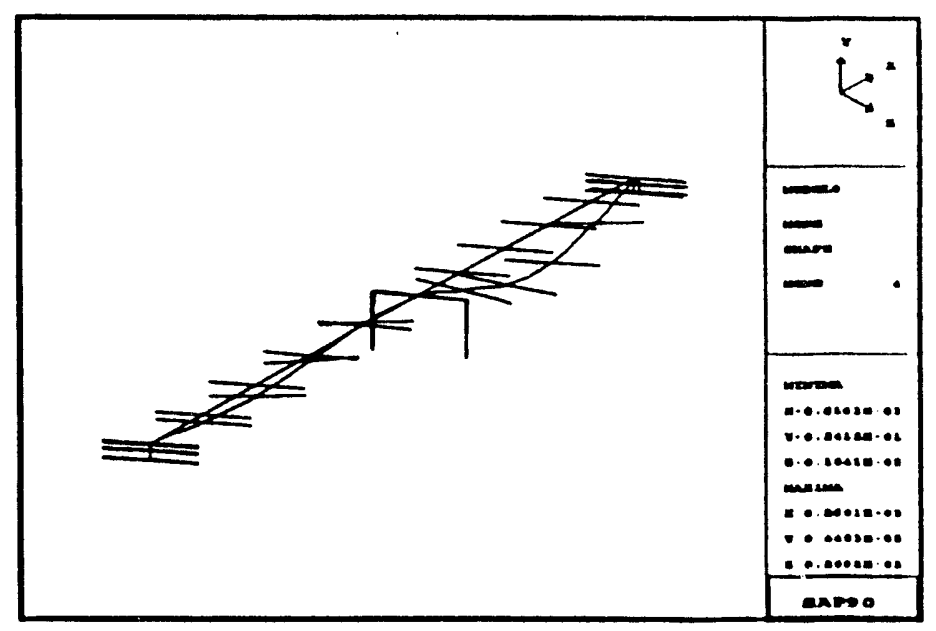

Model 9: Mode Shape 4 $F=4.24 \mathrm{~Hz}$ 
Model 9

\begin{tabular}{rr} 
Mode & Beta \\
\hline 1 & 0.04 \\
2 & 0.40 \\
3 & 0.10 \\
4 & 0.04 \\
5 & 0.04 \\
6 & 0.04 \\
7 & 0.04 \\
8 & 0.04 \\
9 & 0.04 \\
10 & 0.04
\end{tabular}

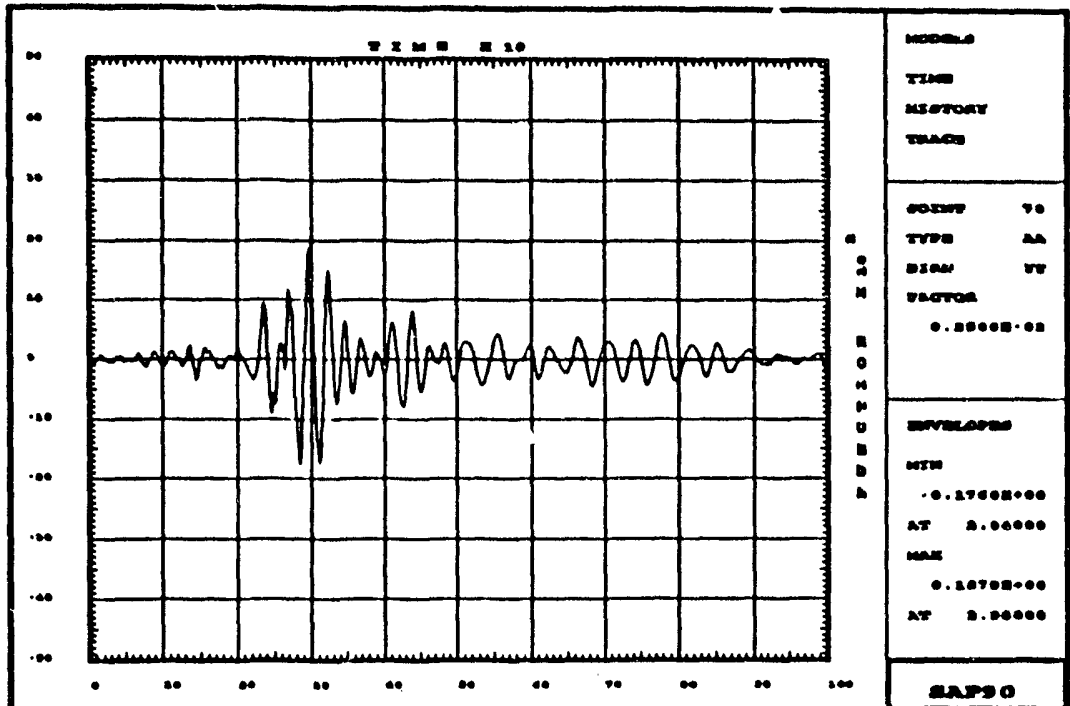

station 6 (Long 8pan, Vertical) Theoretical Absolute Acceleration

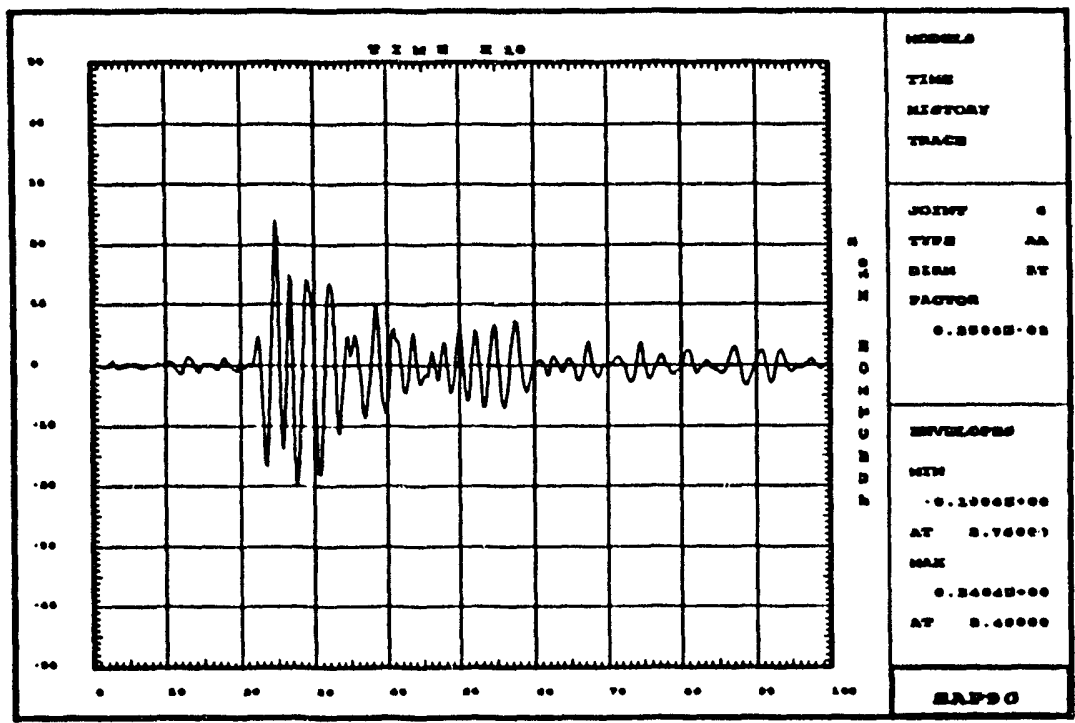

station 7 (Bent, Transverse) Theoretical Absolute Acceleration

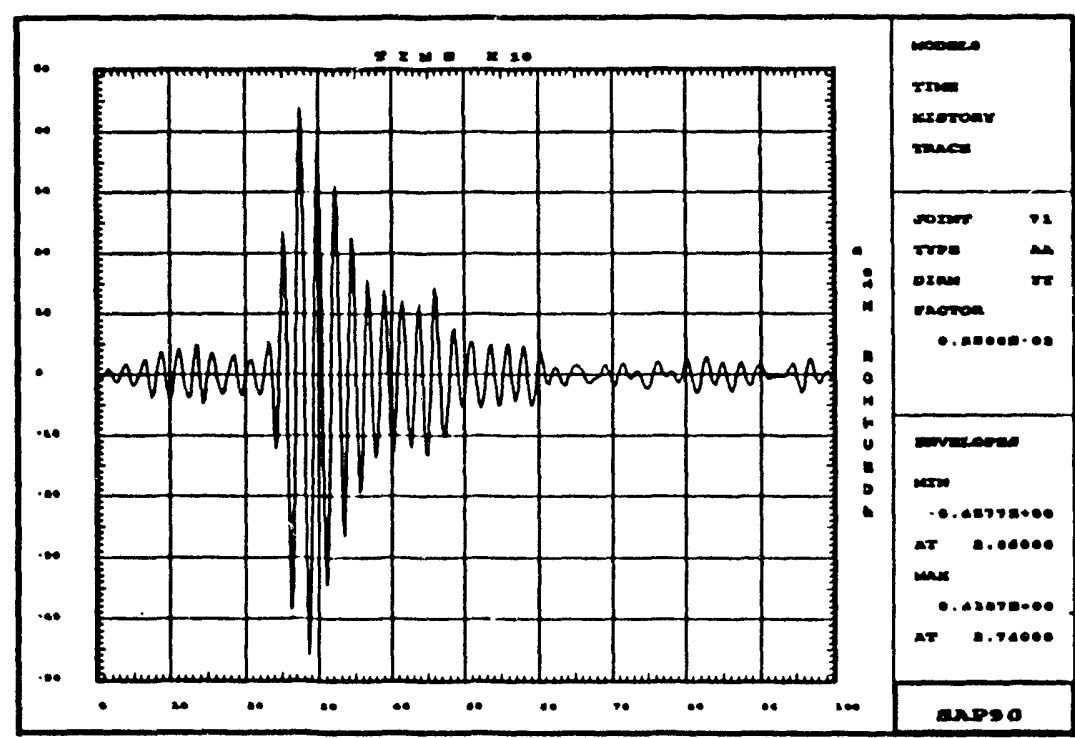

8tation 8 (short 8pan, Vertical) Theoretical Absolute Acceleration 


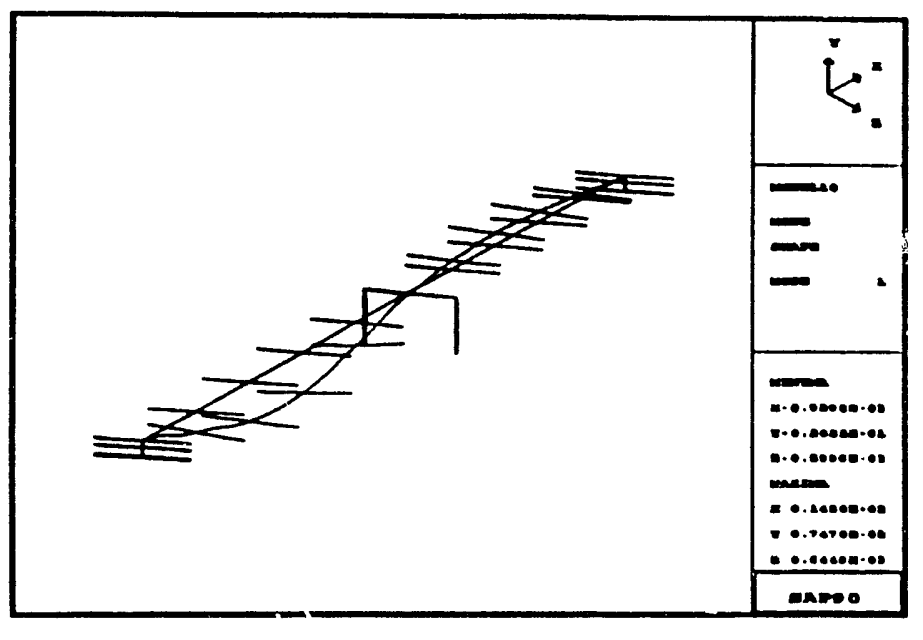

Model 10: Mode Shape 1 $F=2.68 \mathrm{~Hz}$

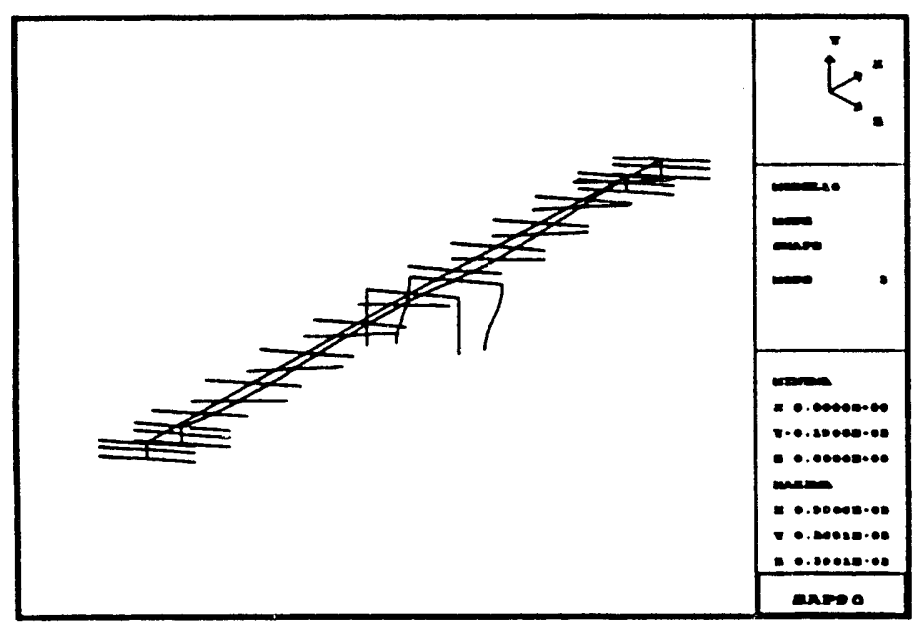

Model 10: Mode Shape 3 $F=3.90 \mathrm{~Hz}$

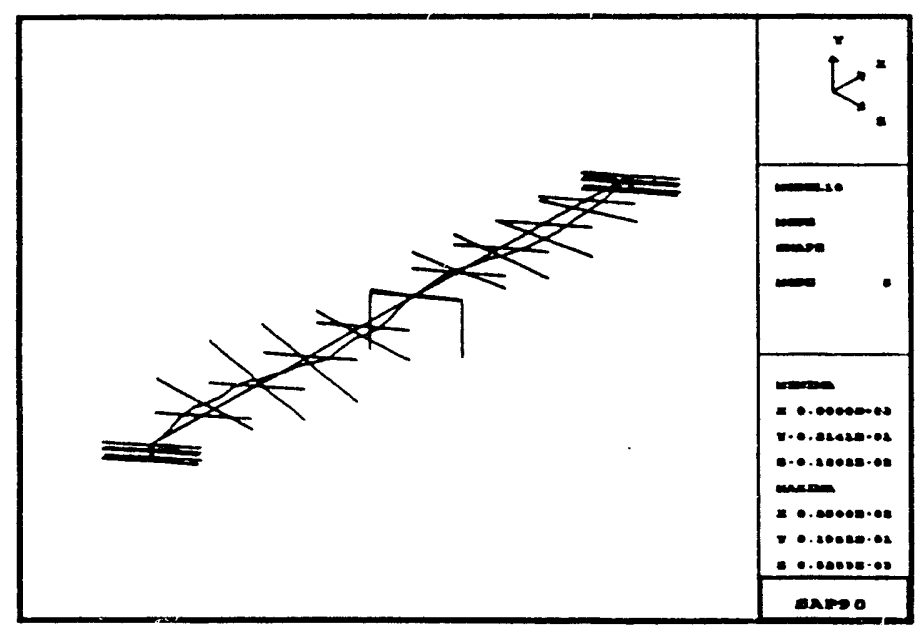

Model 10: Mode Shape 5 $F=5.30 \mathrm{~Hz}$

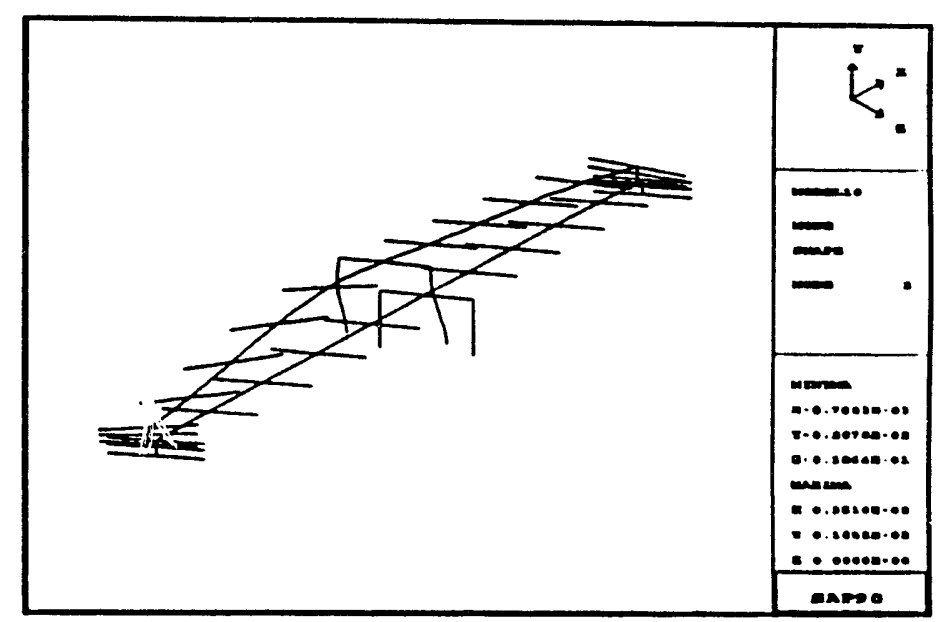

Model 10: Mode Shape 2 $F=3.31 \mathrm{~Hz}$

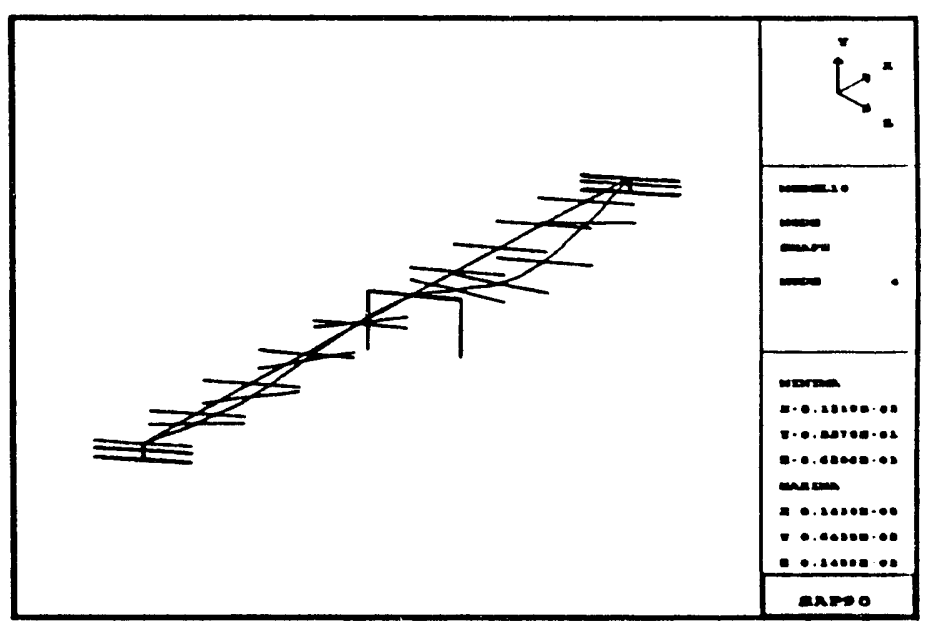
Model 10: Mode Shape 4
$F=4.08 \mathrm{~Hz}$

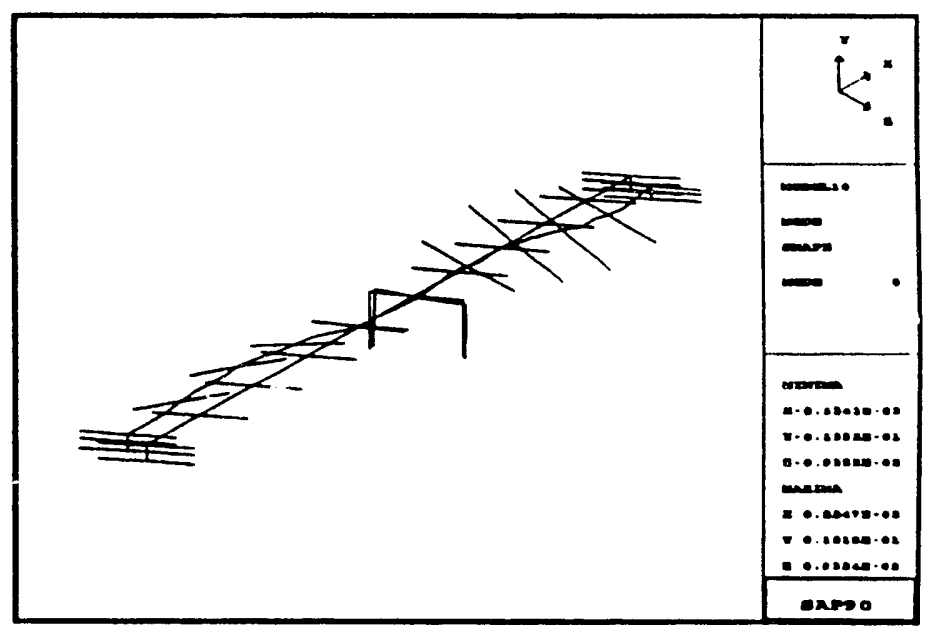

Model 10: Mode Shape 6 $F=6.55 \mathrm{~Hz}$ 
Model 10

\begin{tabular}{|c|c|}
\hline Mode & Bet: \\
\hline 1 & 0.0 \\
\hline 2 & 0.40 \\
\hline 3 & 0.10 \\
\hline 4 & 0 \\
\hline 5 & \\
\hline 6 & \\
\hline 7 & \\
\hline 8 & \\
\hline 9 & \\
\hline 10 & \\
\hline
\end{tabular}

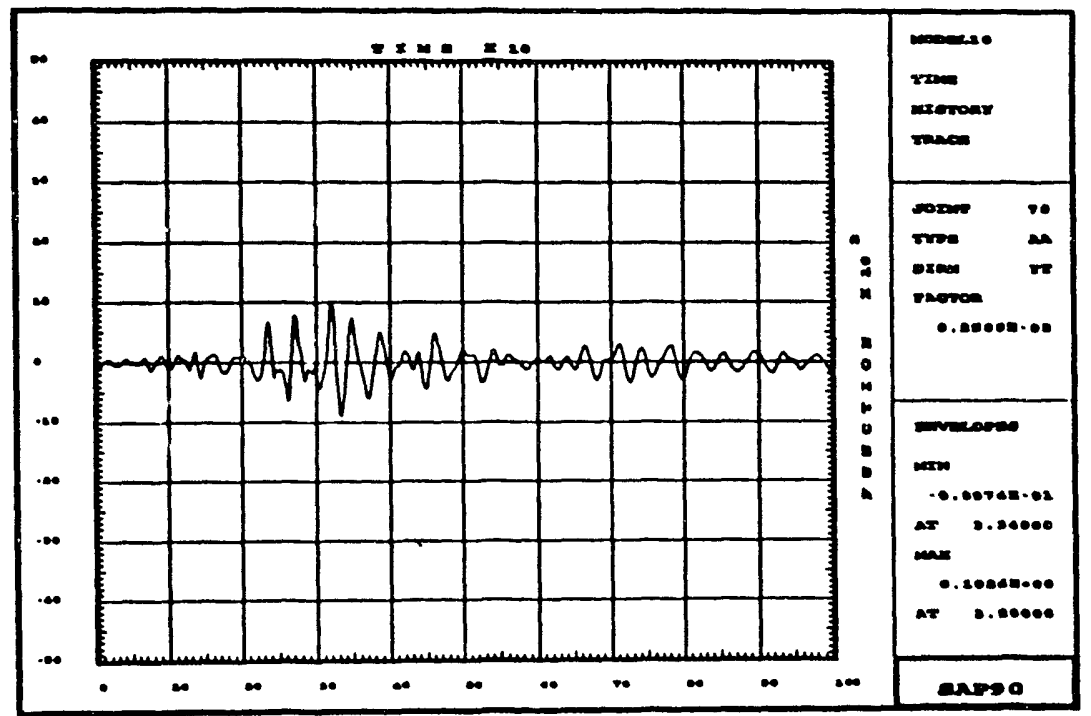

station 6 (Long 8pan, Vertical) Theoretical Absolute Acceleration

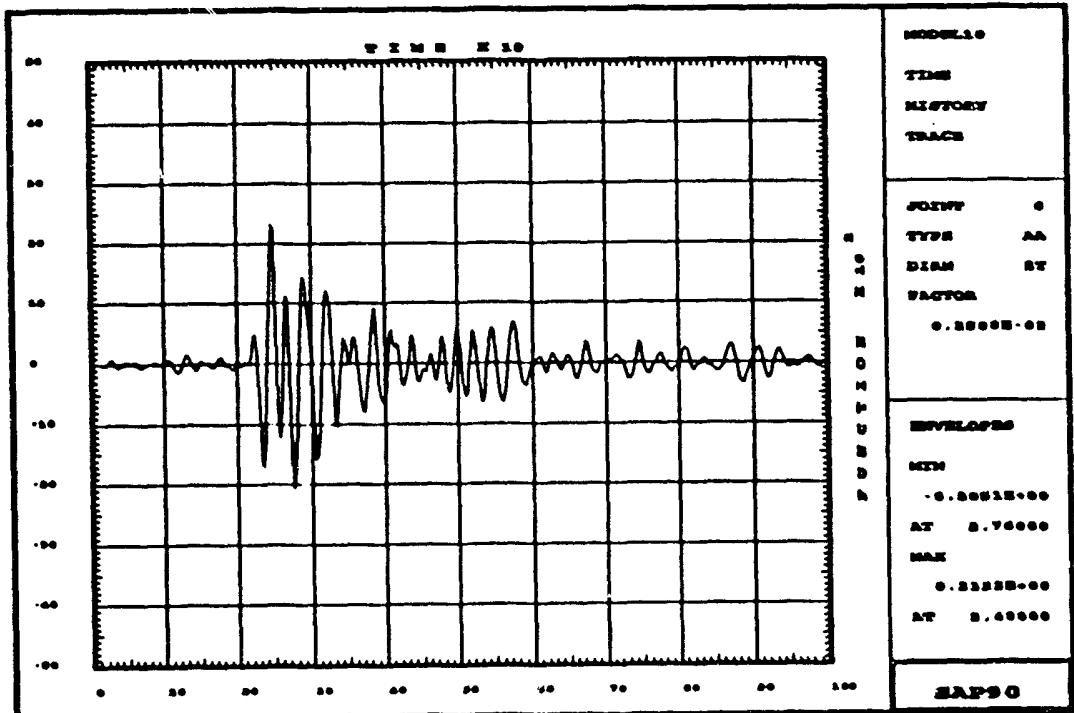

station 7 (Bent, Transverse) Theoretical Absolute Acceleration

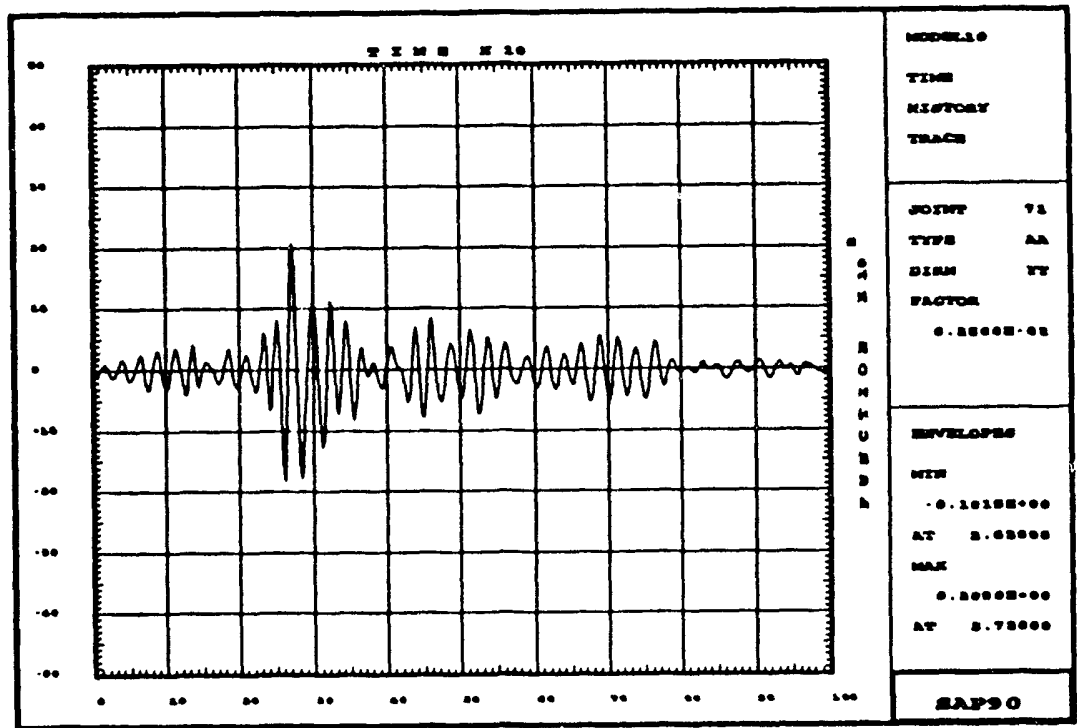

station s (bhort spañ, verticai) Theoretical Absolute Acceleration 


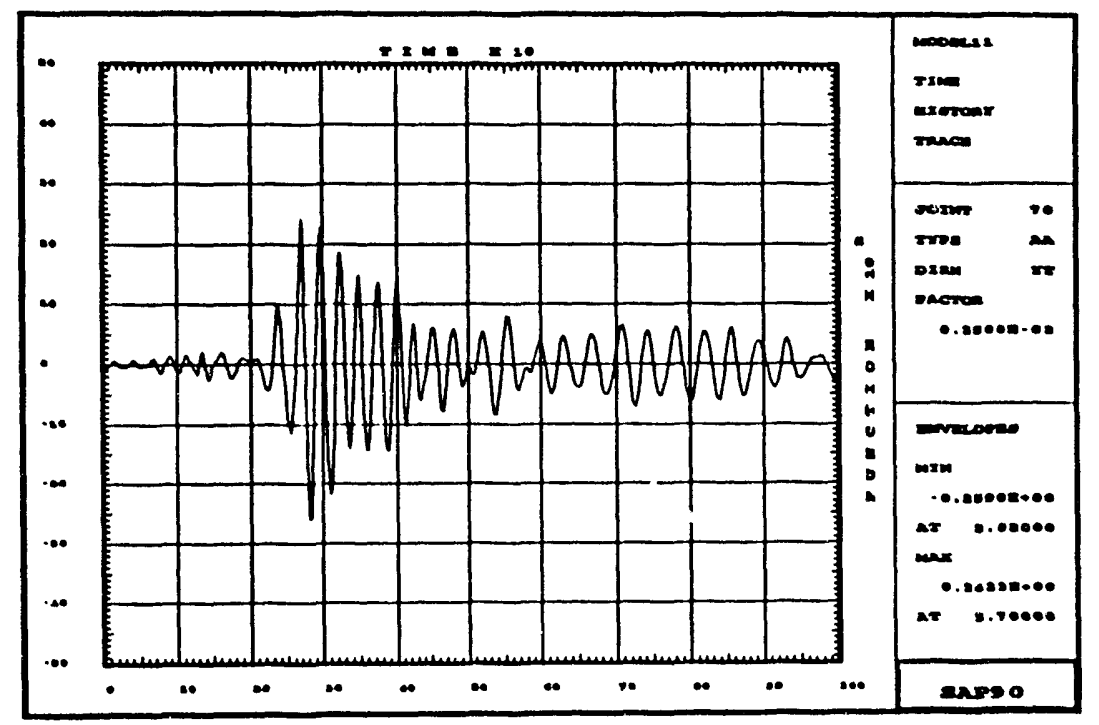

station 6 (Long 8pan, Vertical) Theoretical Absolute Acceleration

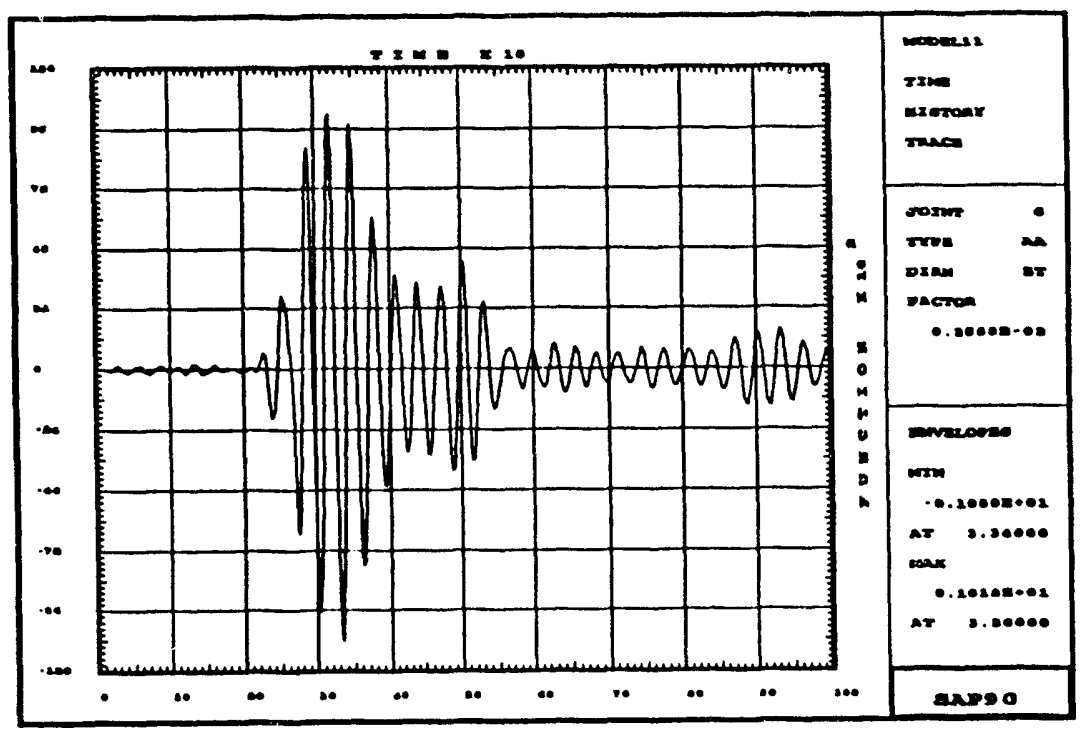

station 7 (Bent, Transverse) Theoretical Absolute Acceleration

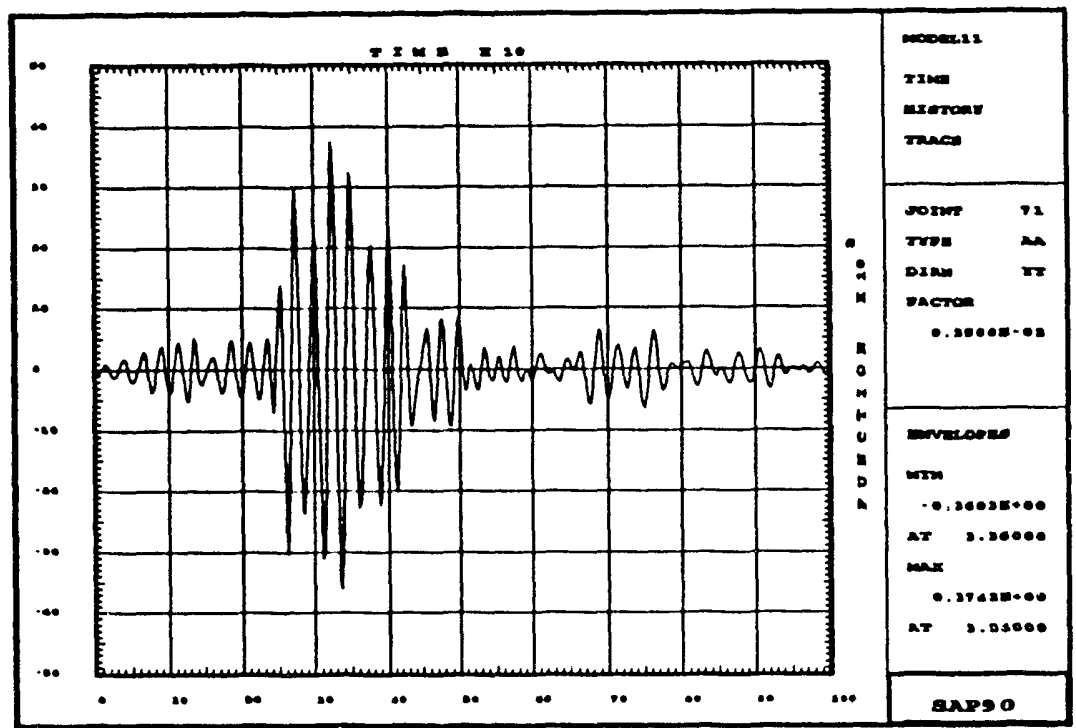

station 8 (short span, Vertical) Theoretical Absolute Acceleration 


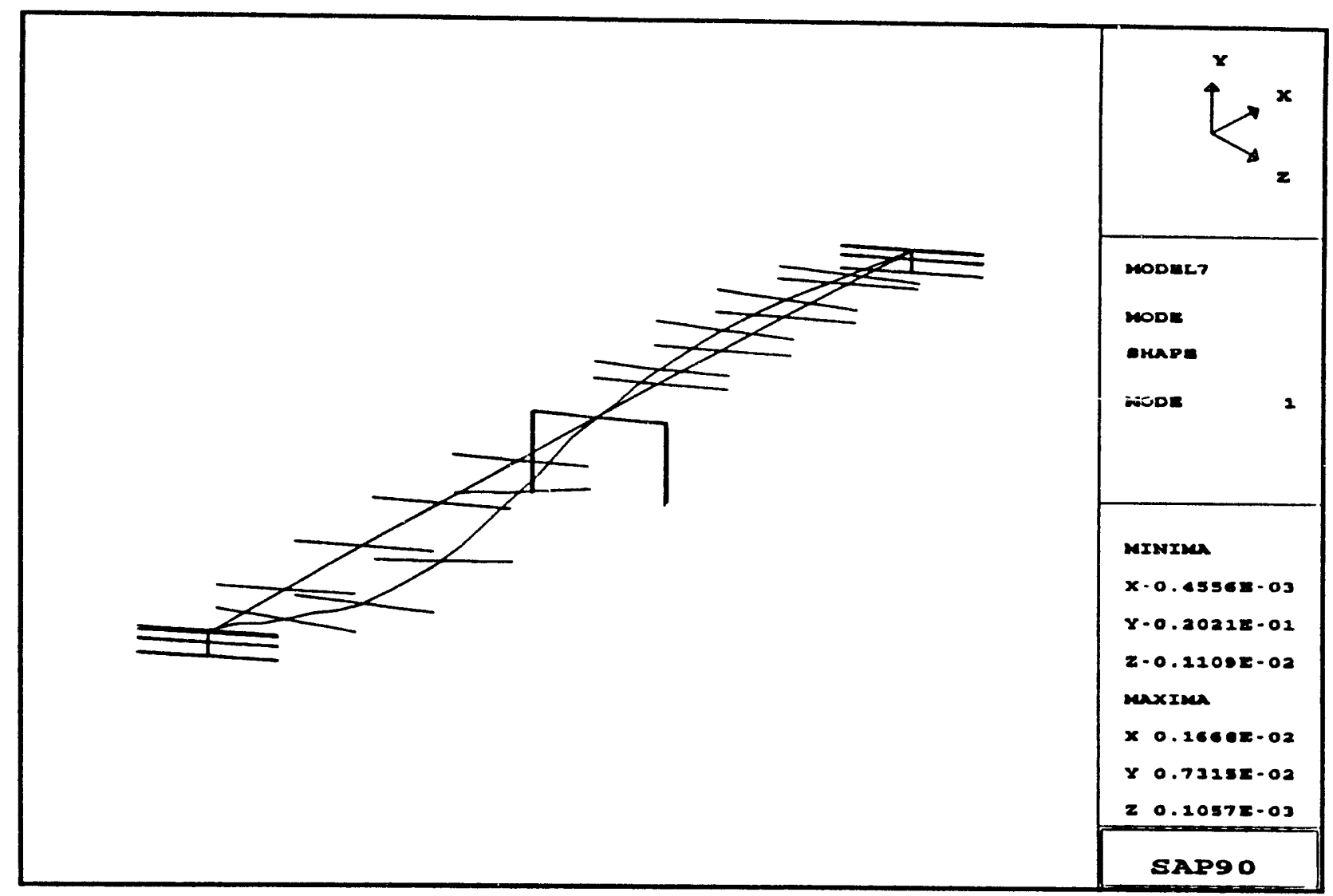

Model 11: Mode Shape 1

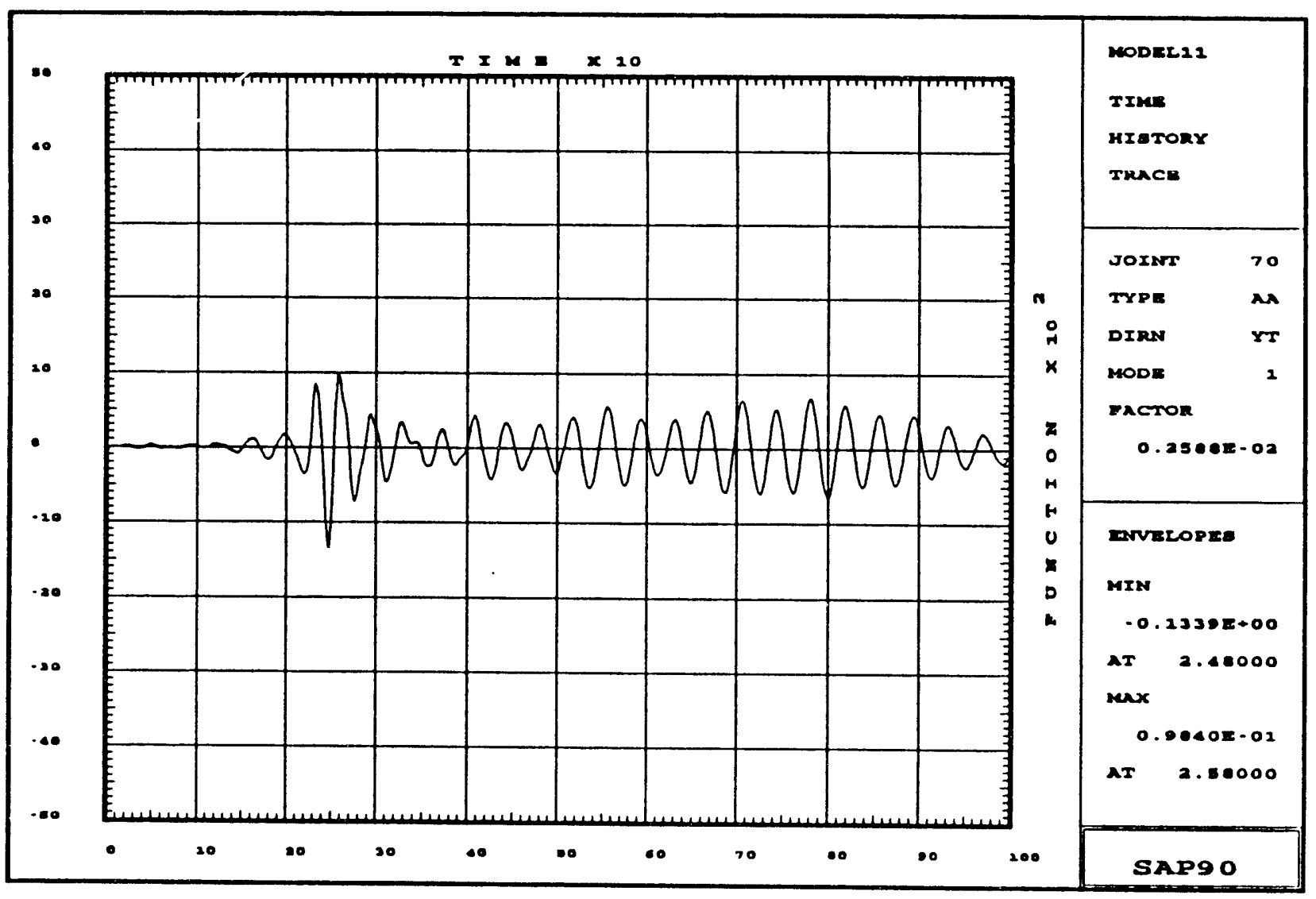

8tation 6 (Long 8pan, Vertical) Theoretical Absolute Acceleration

Figure $3.11-2$

Mode 1 Contribution to Acceleration at station 6 Mode1 11: Damping=02\%, all modes 


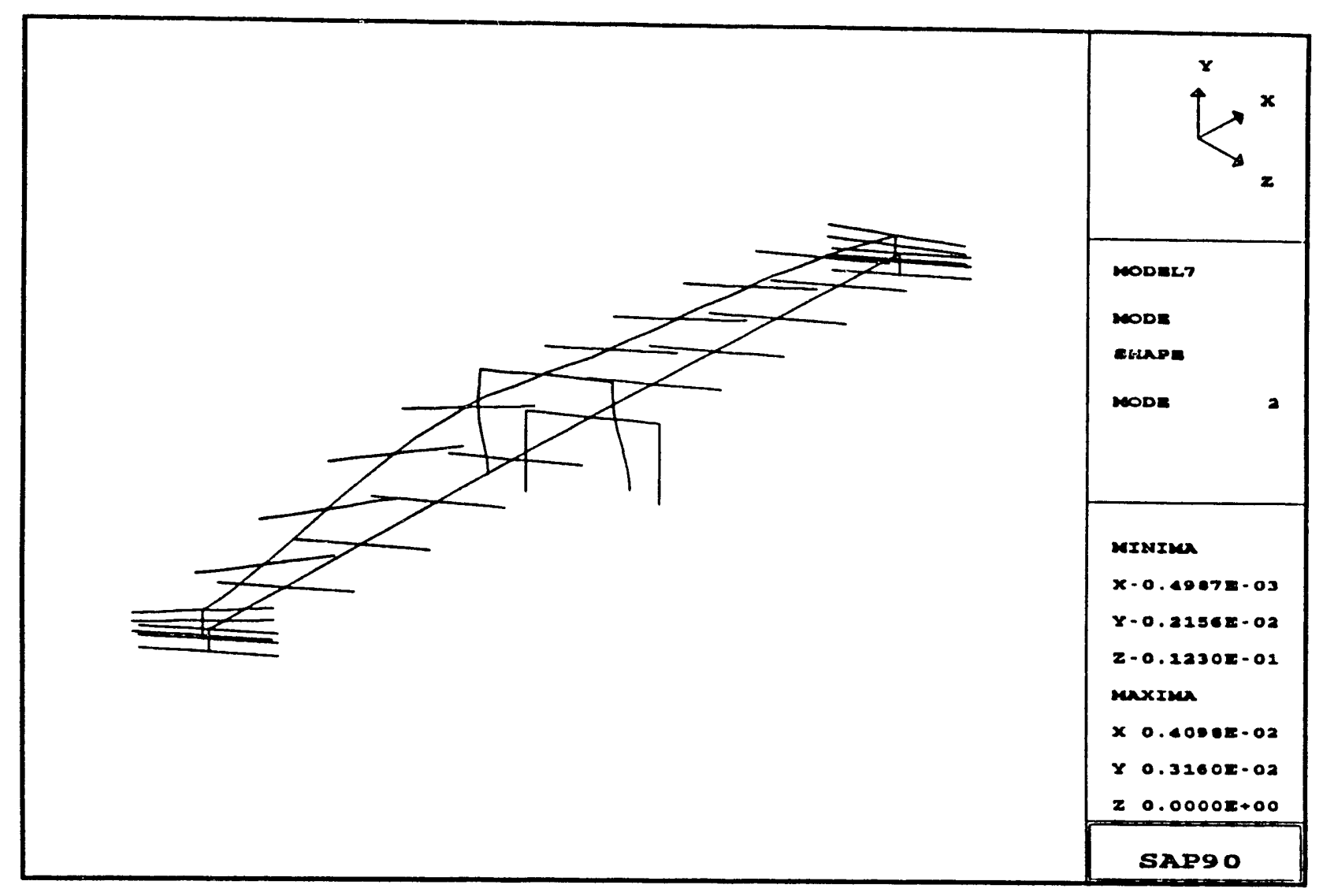

Model 11: Mode Shape 2

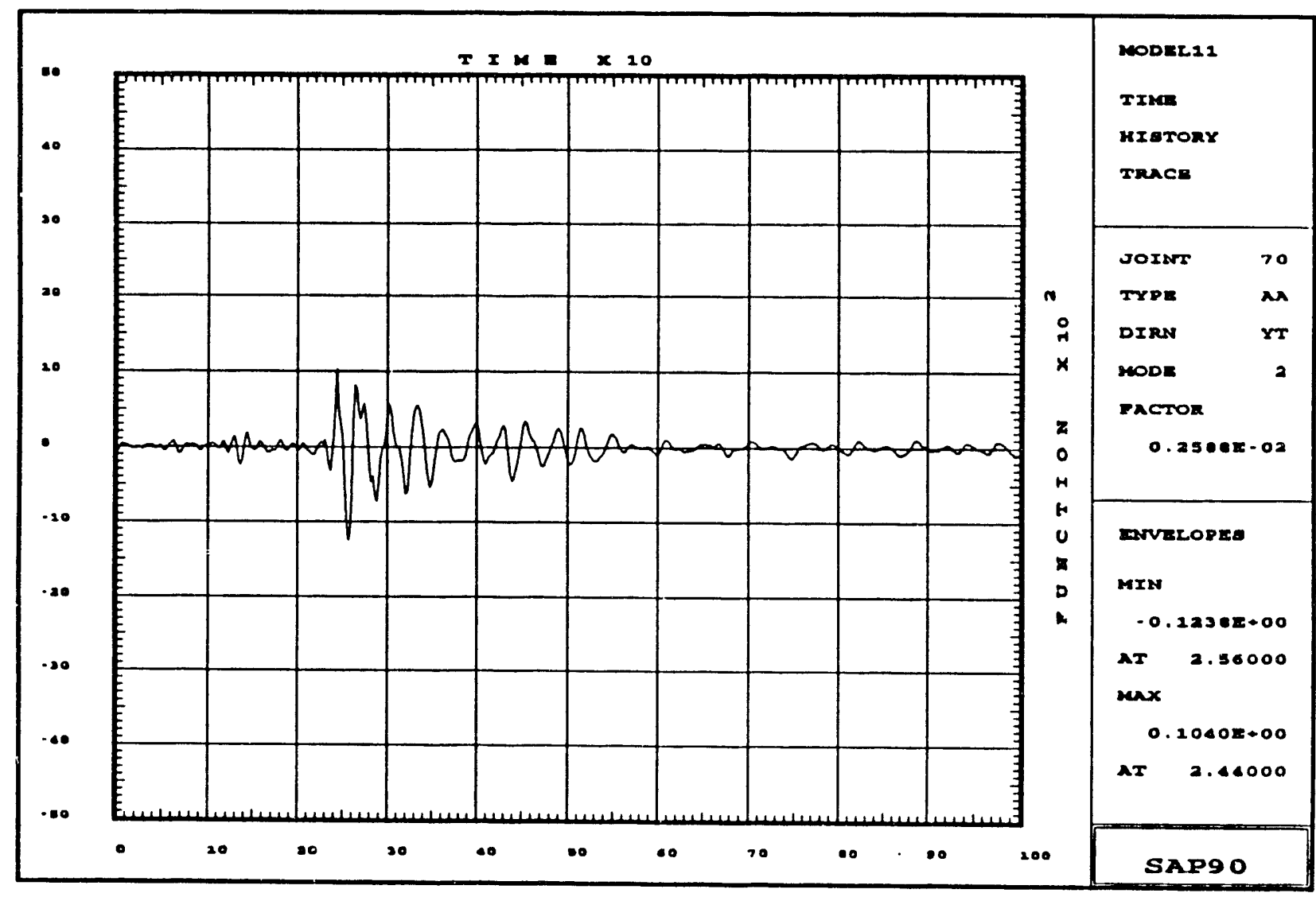

station 6 (Long span Vertical) Theoretical Absolute Acceleration 

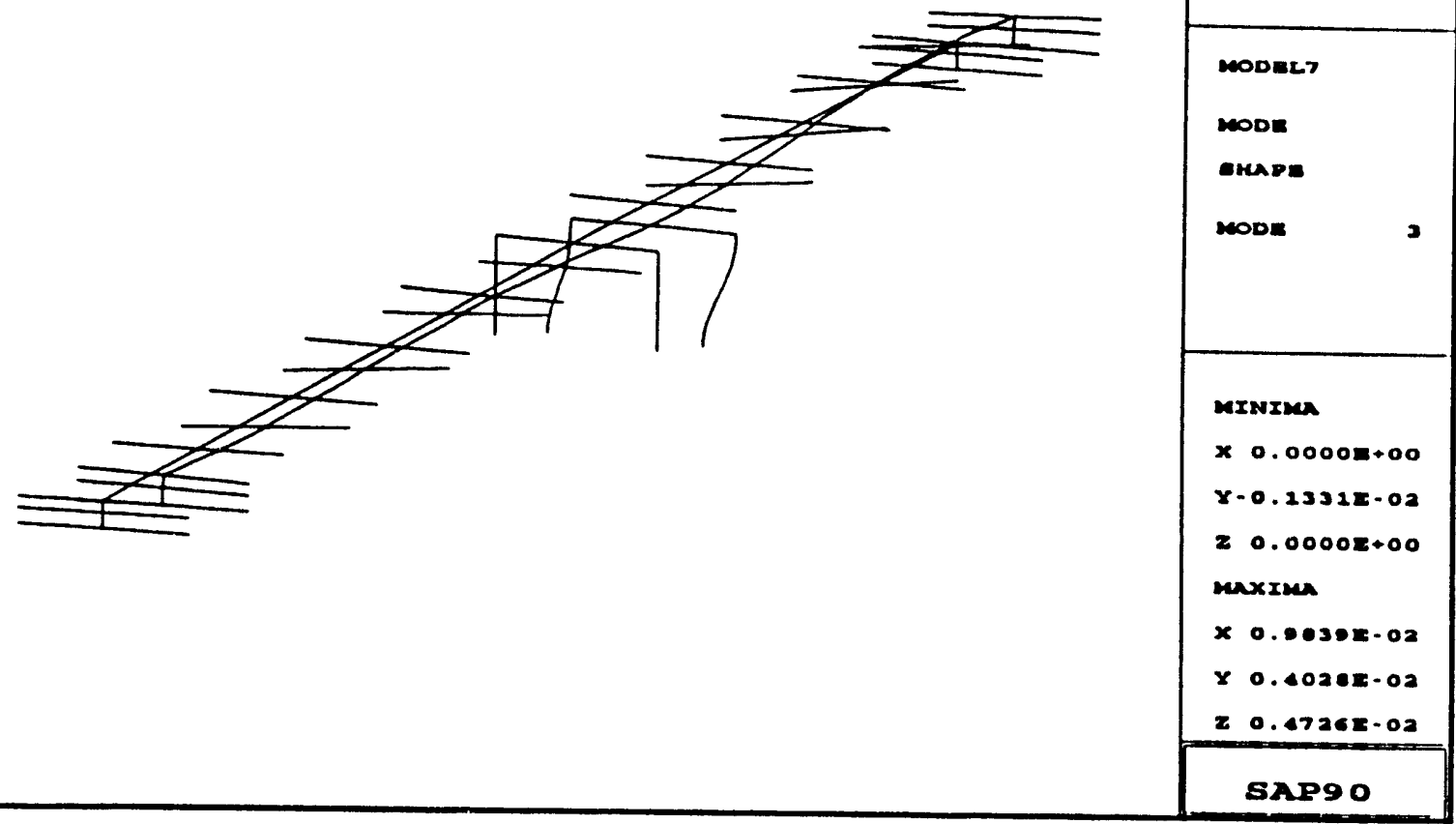

Model 11: Mode Shape 3

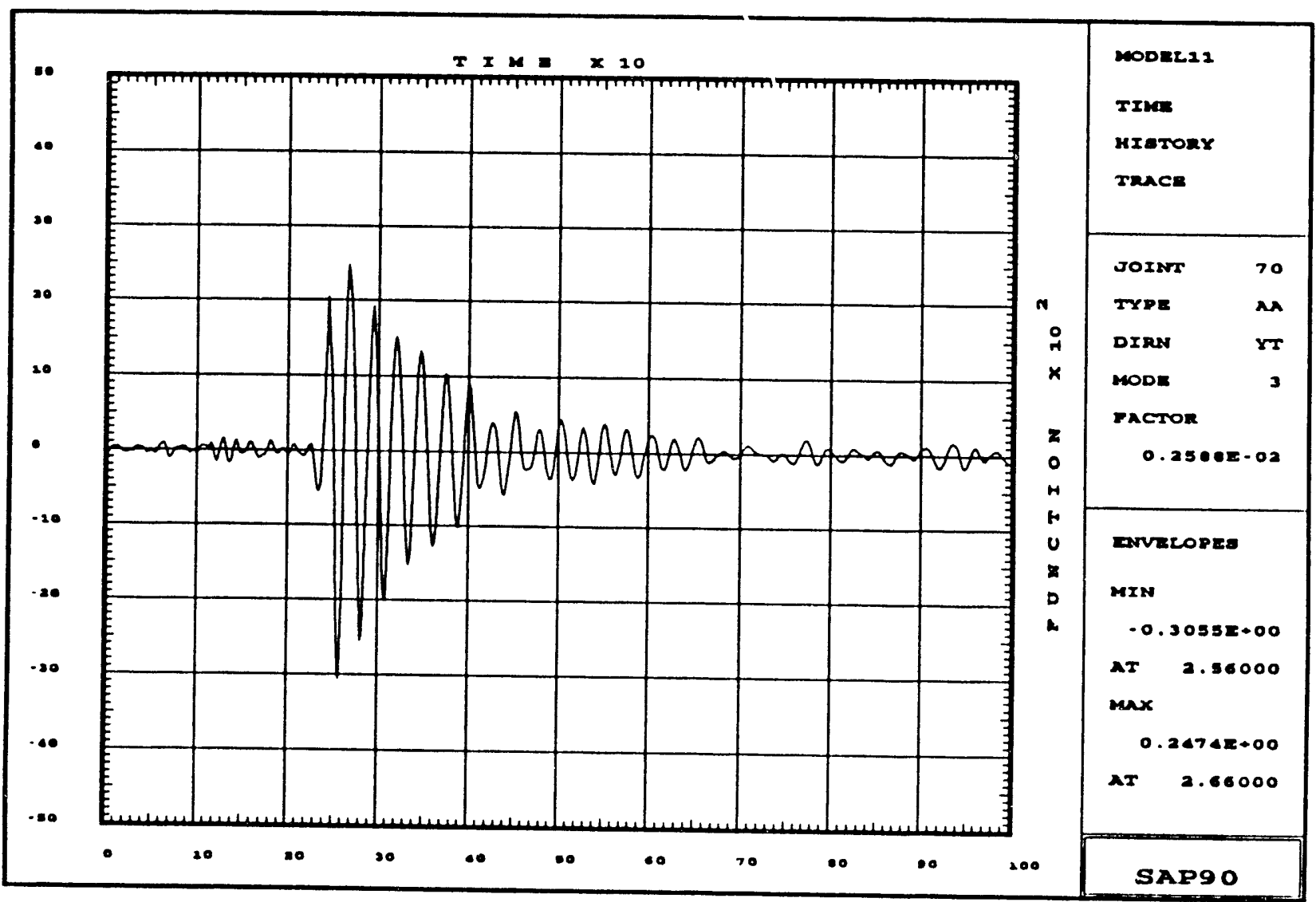

station 6 (Long span, Vertical) Theoretical Absolute Acceleration 


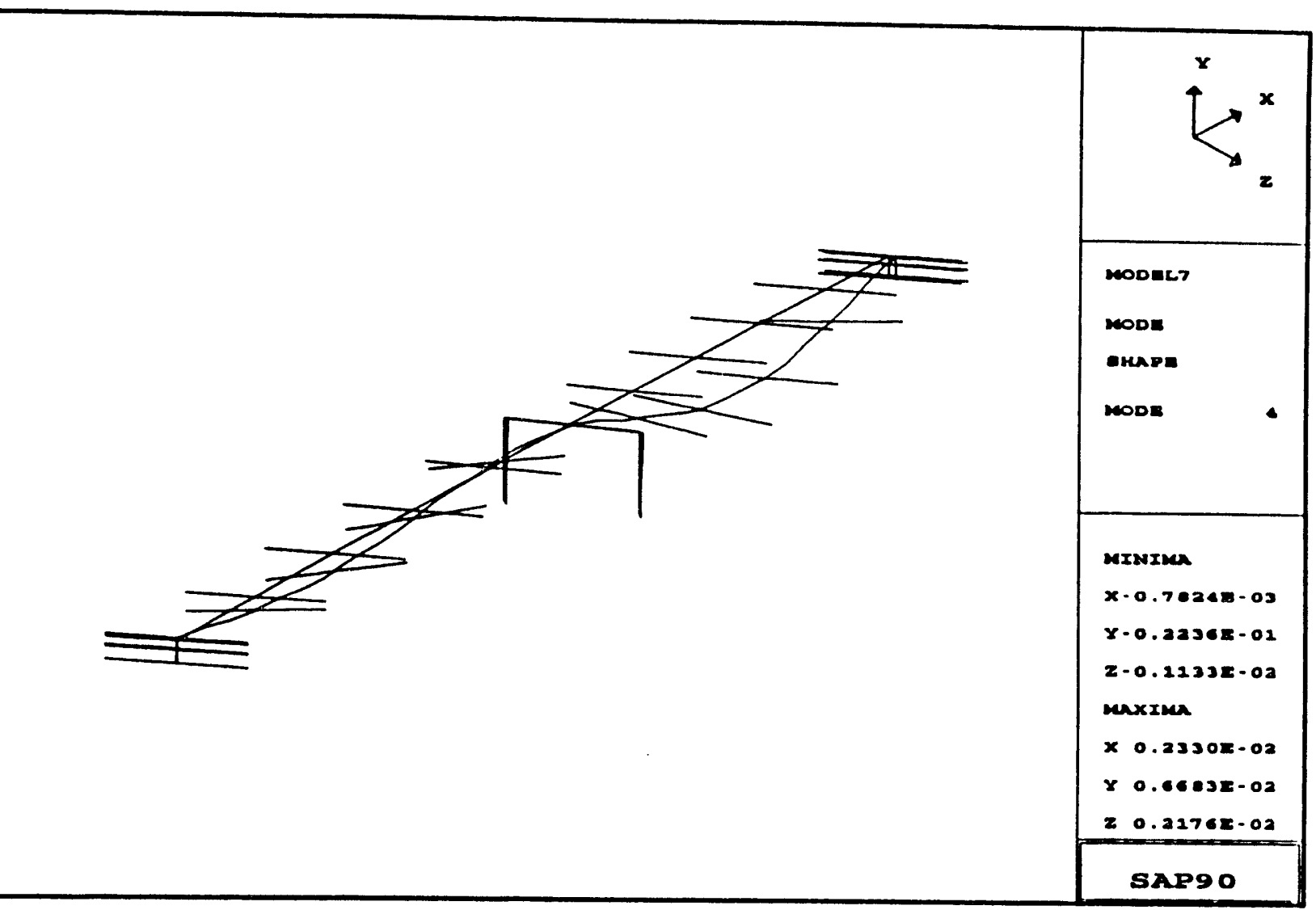

Model 11: Mode Shape 4

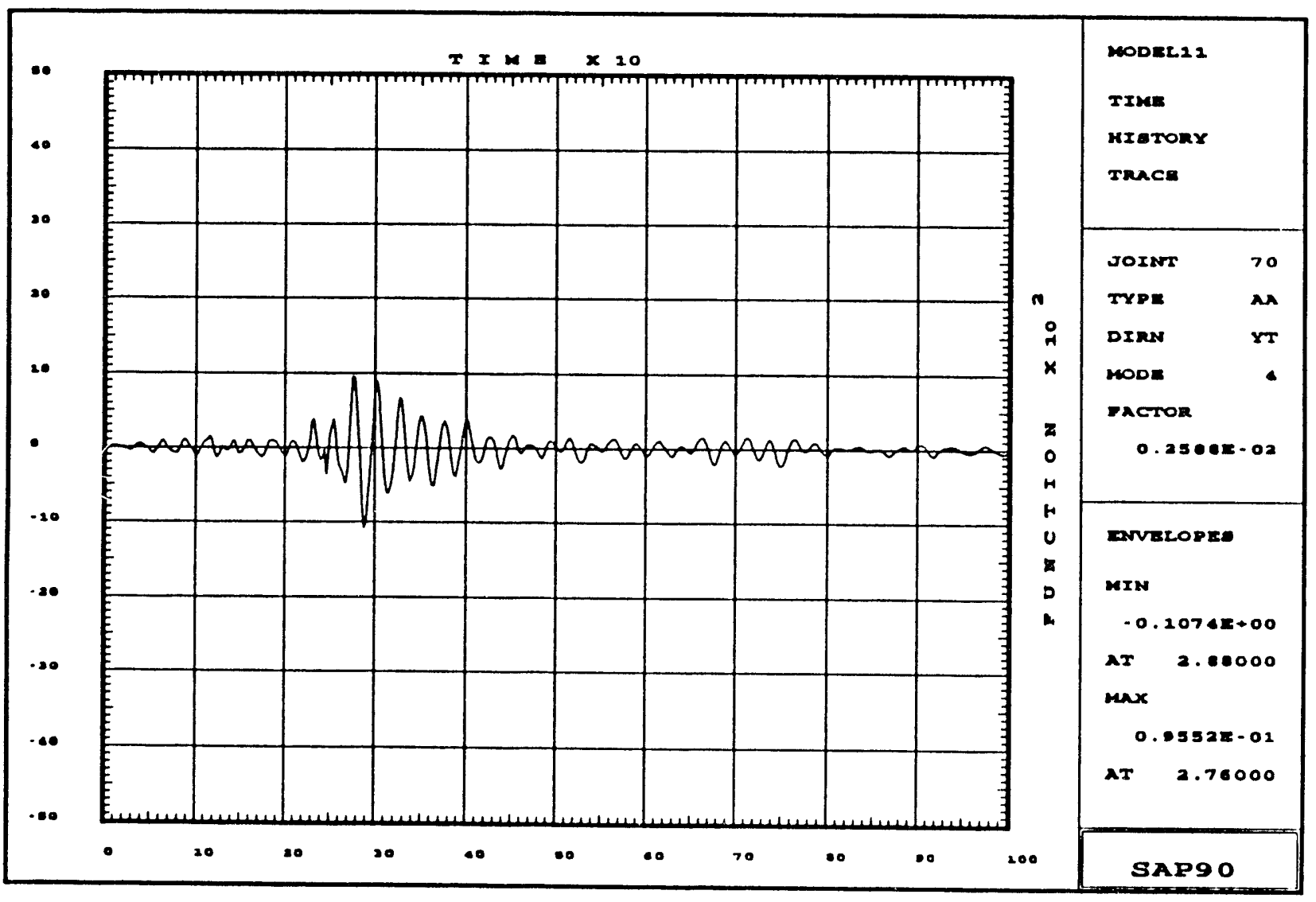

station 6 (Long span, Vertical) Theoretical Absolute Acceleration

Figure $3.11-5$

Mode 4 Contribution to Acceleration at station 6

Model 11: Damping $=02 \%$, all modes 


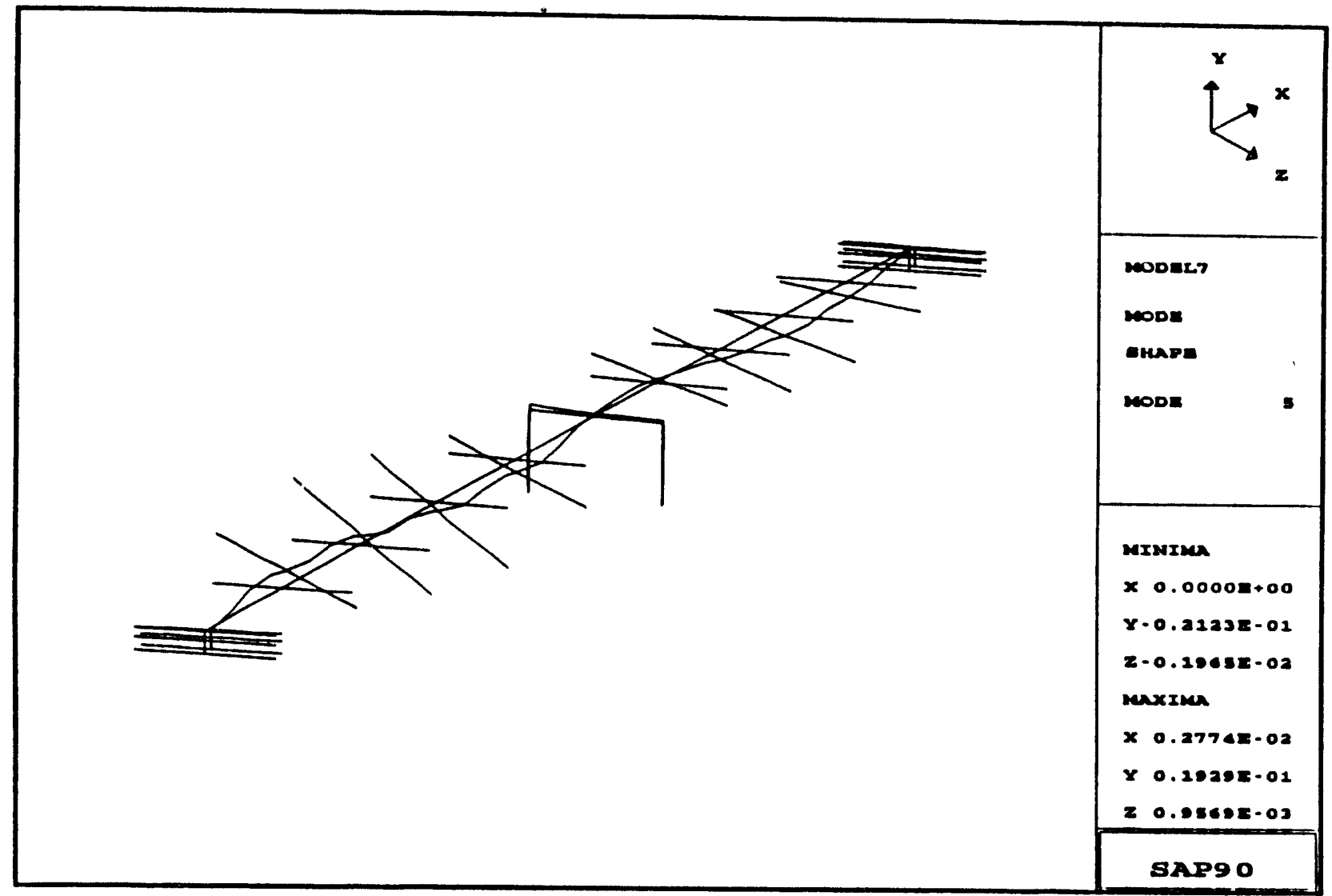

Model 11: Mode Bhape 5

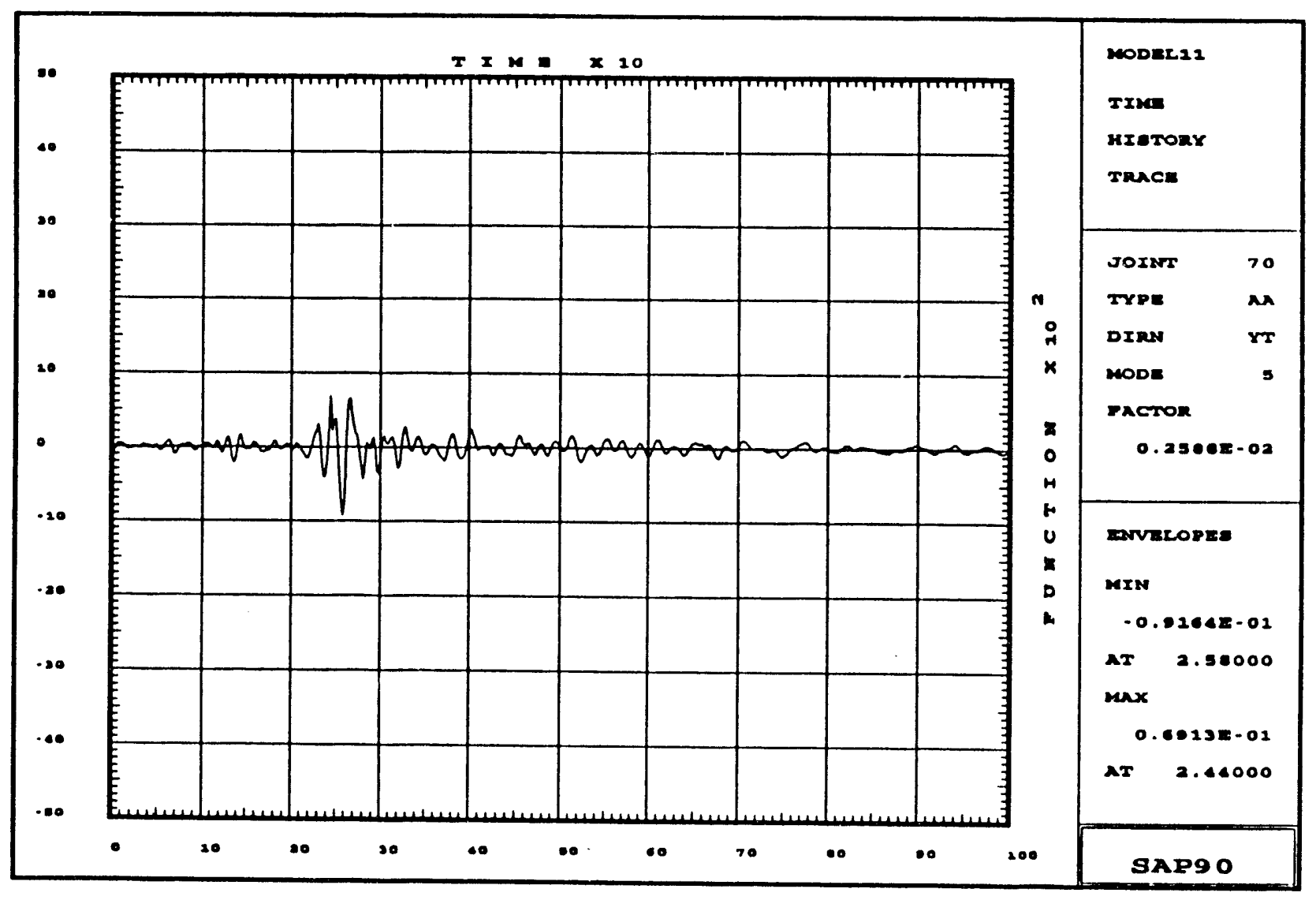

station 6 (Long span, Vertical) Theoretical Absolute Acceleration 


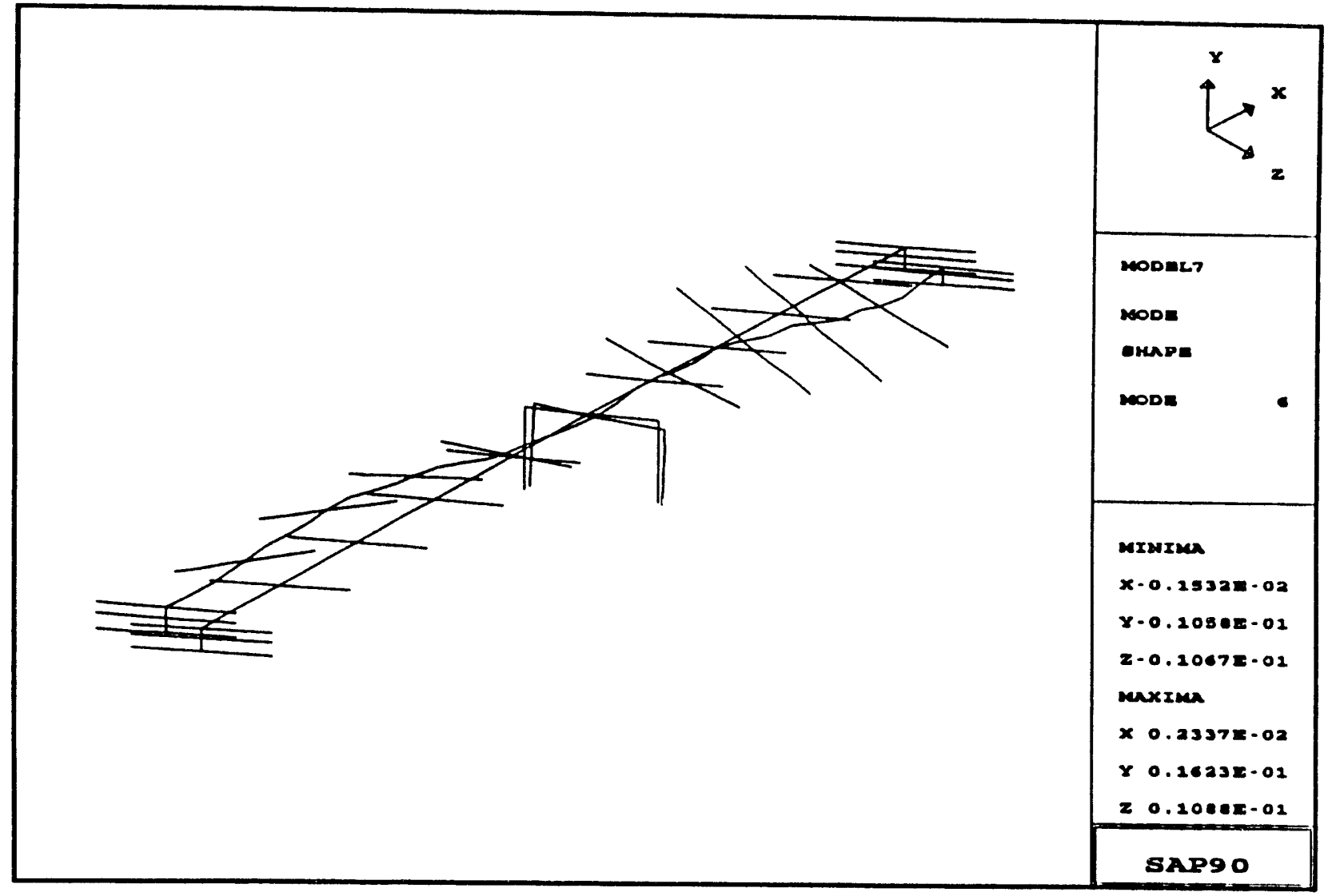

Model 11: Mode Bhape 6

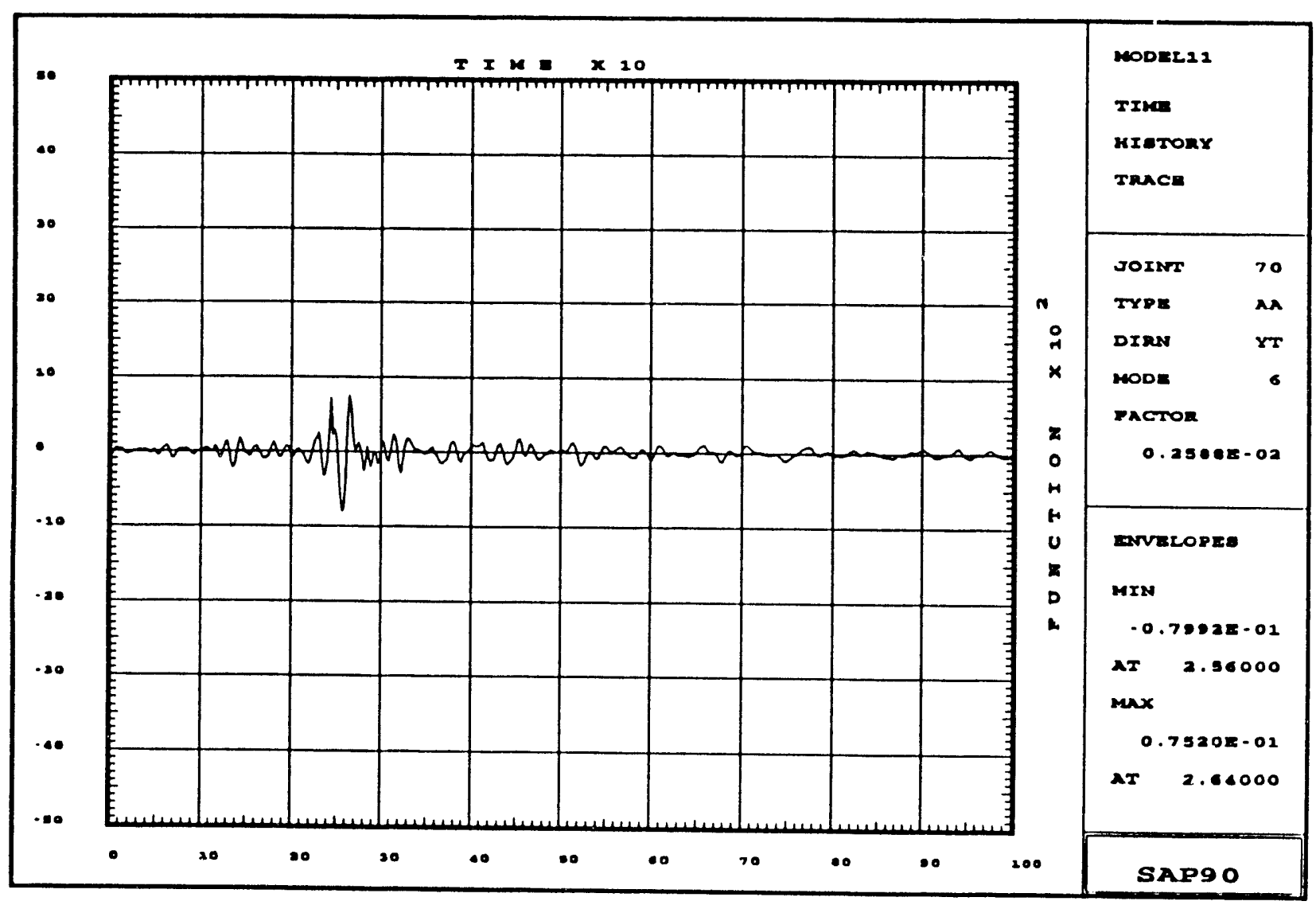

station 6 (Long 8pan, Vertical) Theoretical Absolute Acceleration 


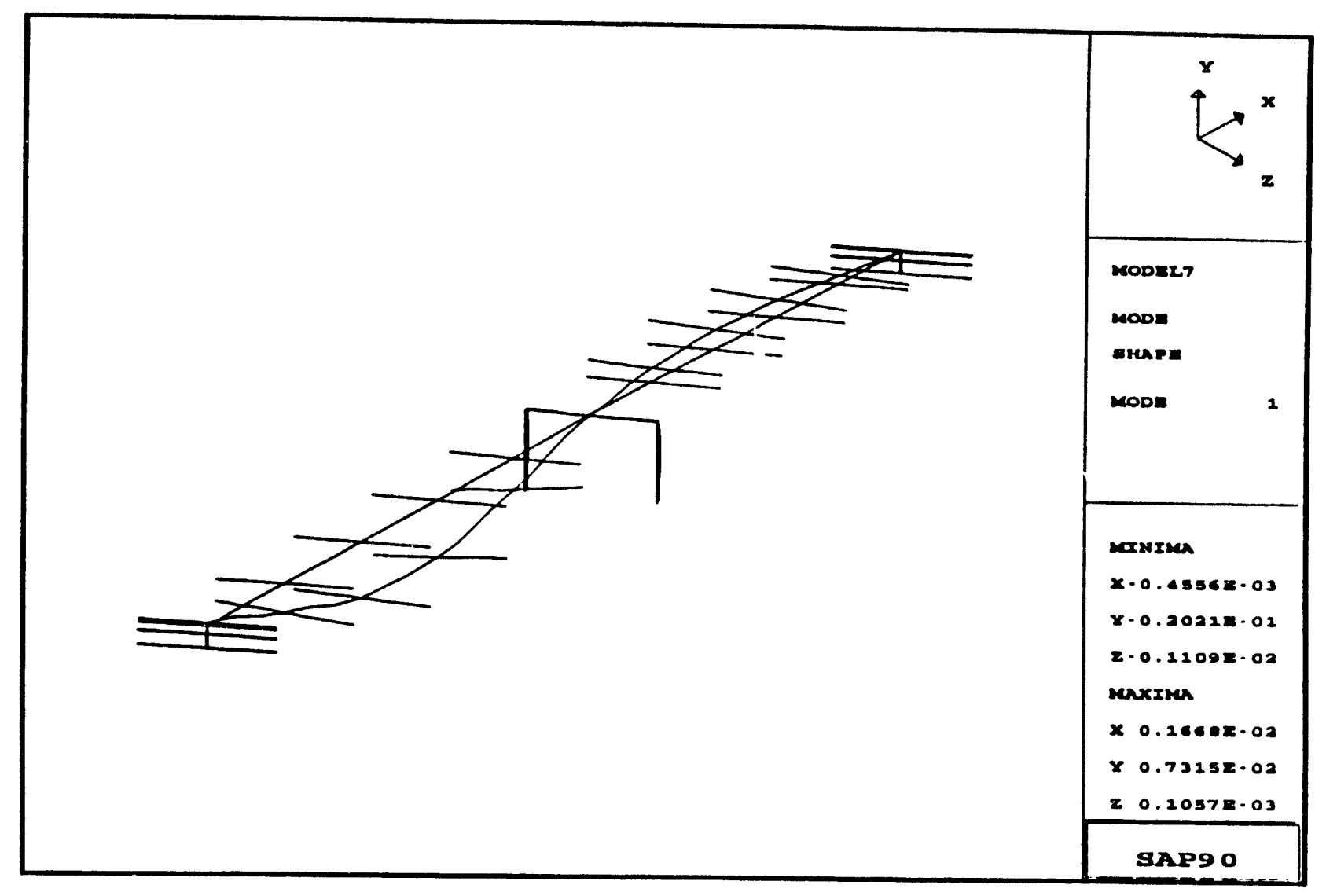

Model 11: Mode Bhape 1

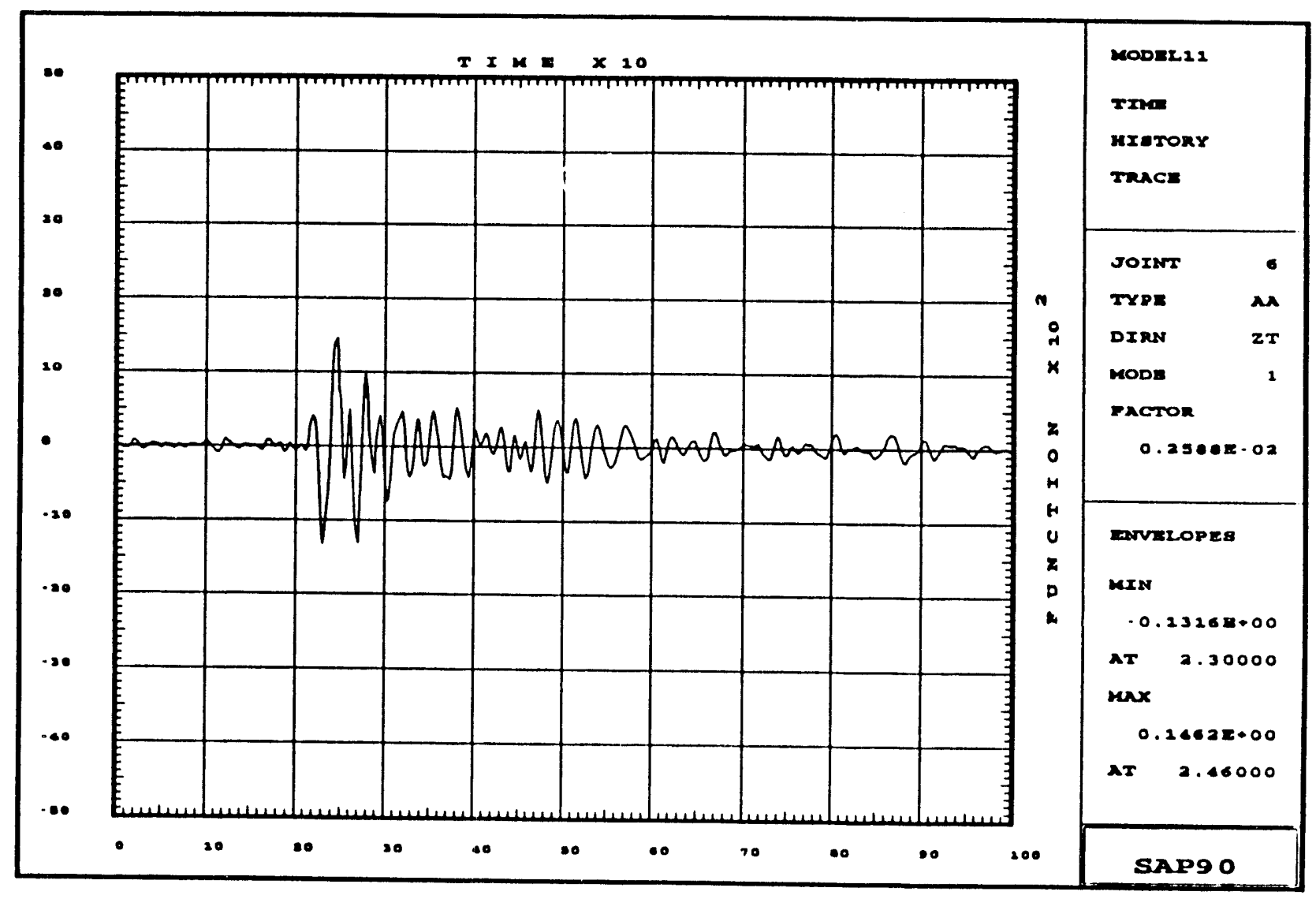

station 7 (Bent, Transverse) Theoretical Absolute Acceleration 


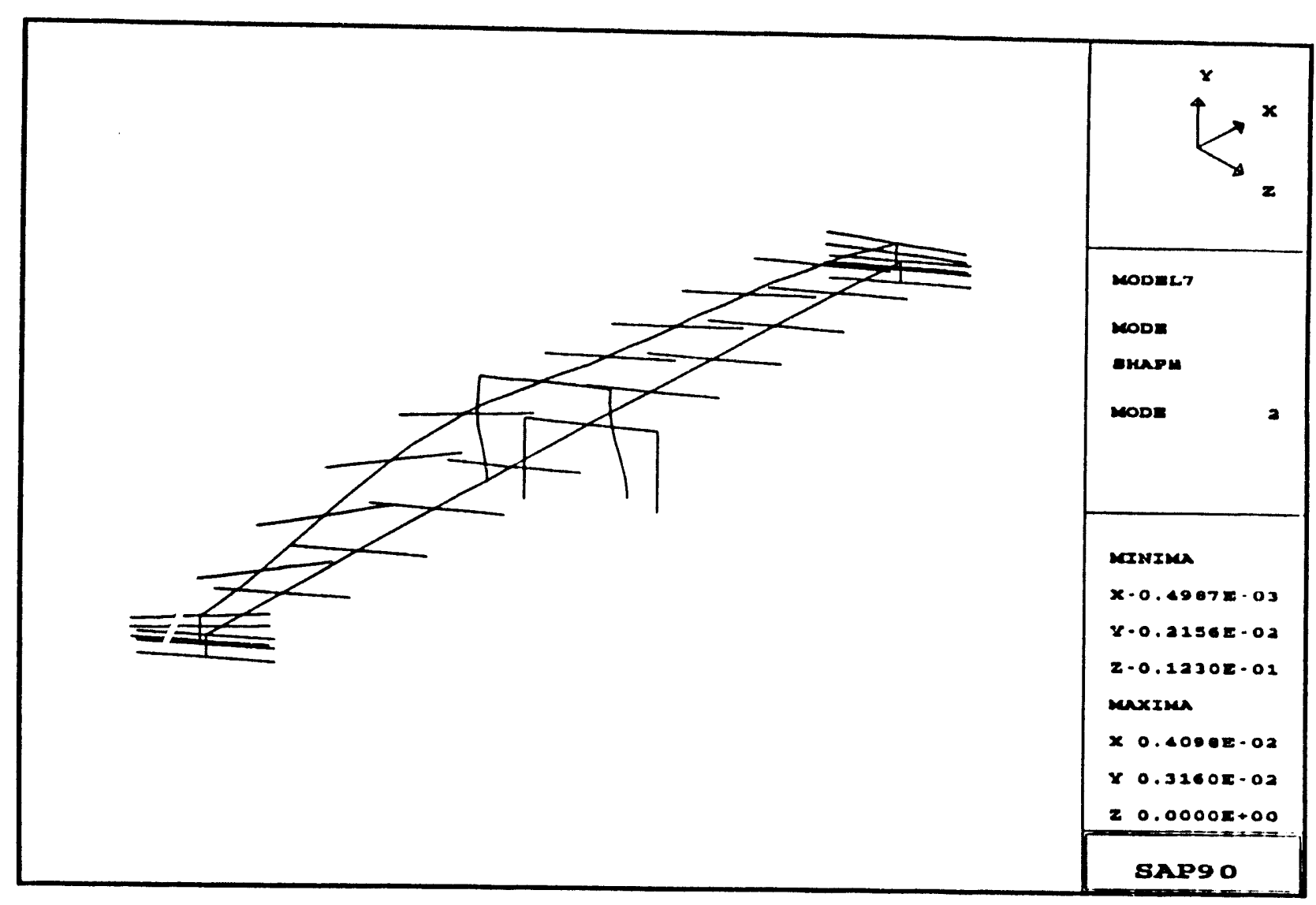

\section{Model 11: Mode Shape 2}

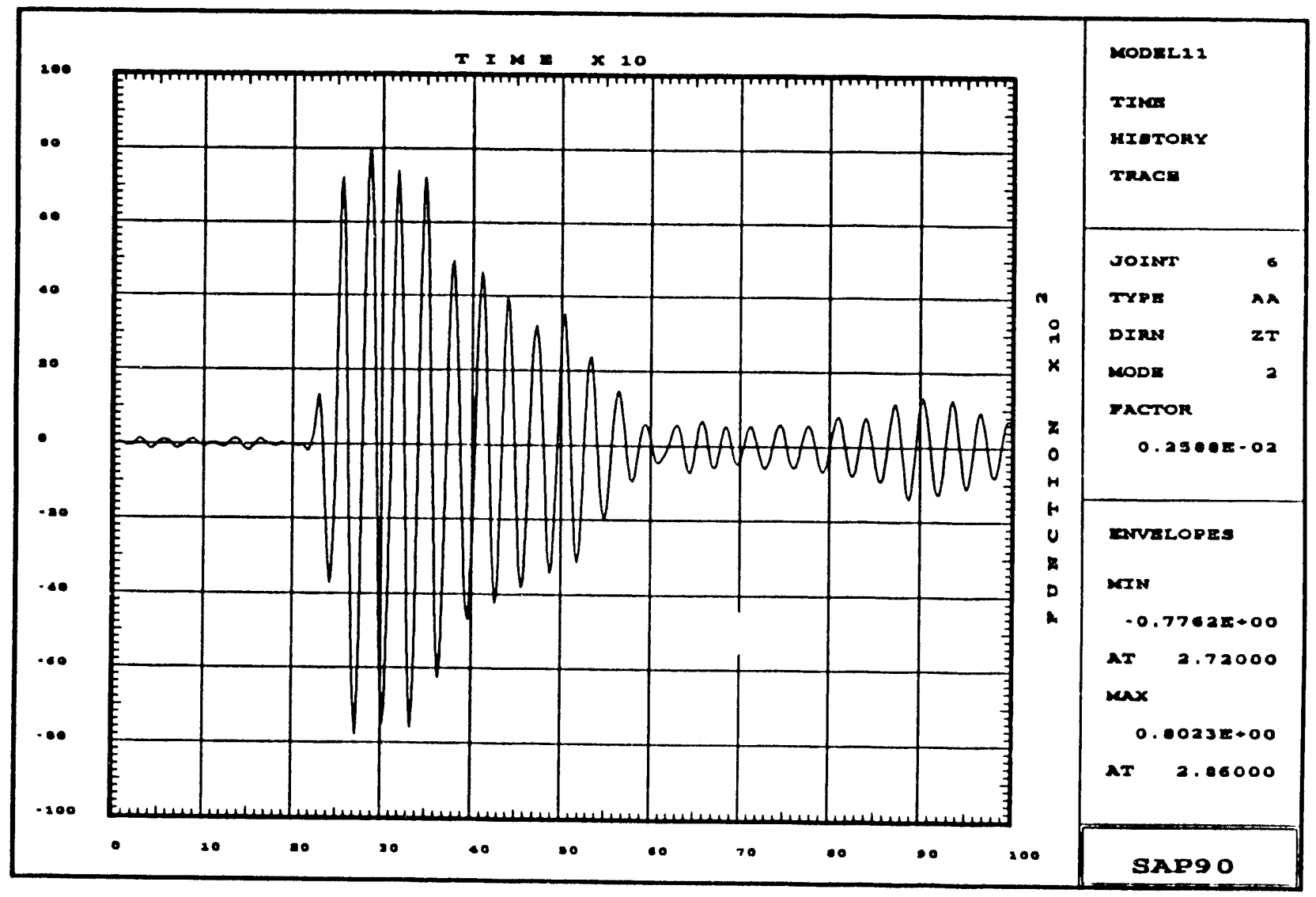

station 7 (Bent, Transverse) Theoretical Absoiute Acceleration 


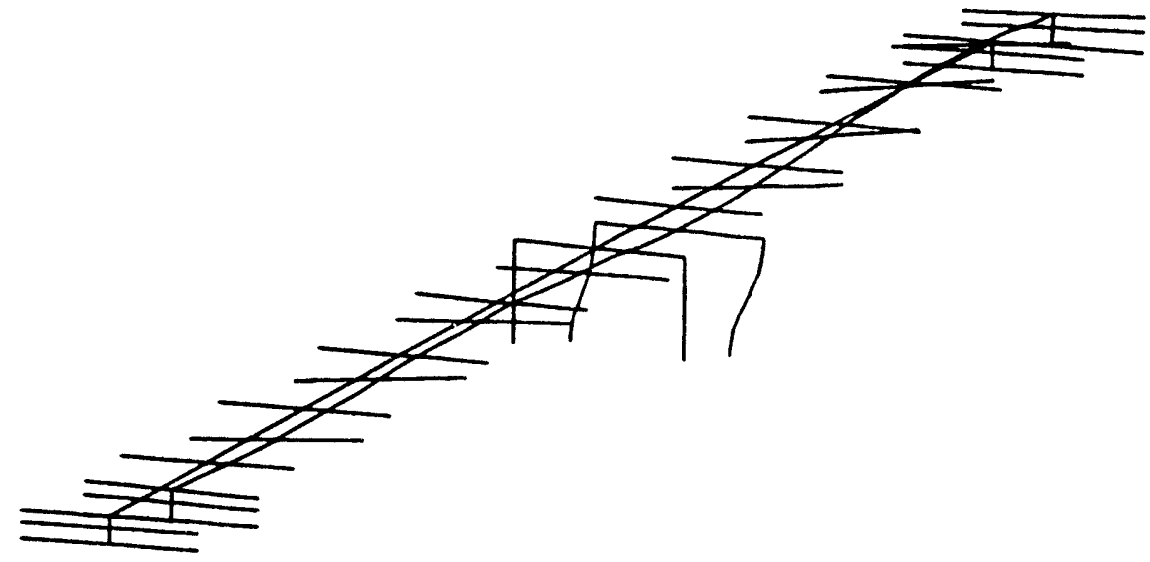

moDer.

MODE

areapm

MODE

3

crosim

$x 0.0000=+00$

$Y-0,1332 E-02$

$20.0000 z+00$

wxima

$\times 0.00302 .02$

Y $0.402=2=02$

$20.4726 \pi-02$

BAP9 0

\section{Model 11: Mode Shape 3}

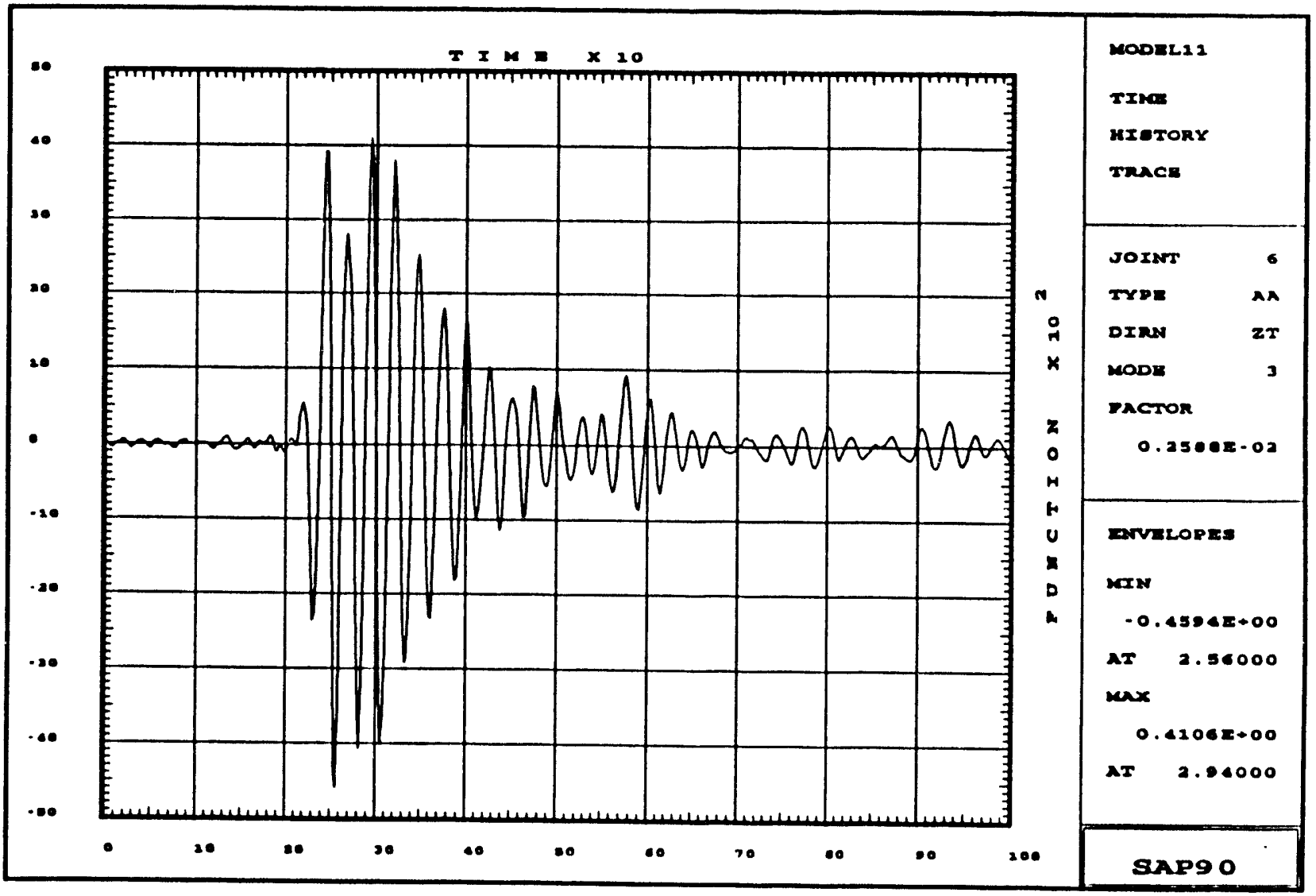

station 7 (Bent, Transverse) Theoretical Absolute Acceleration 


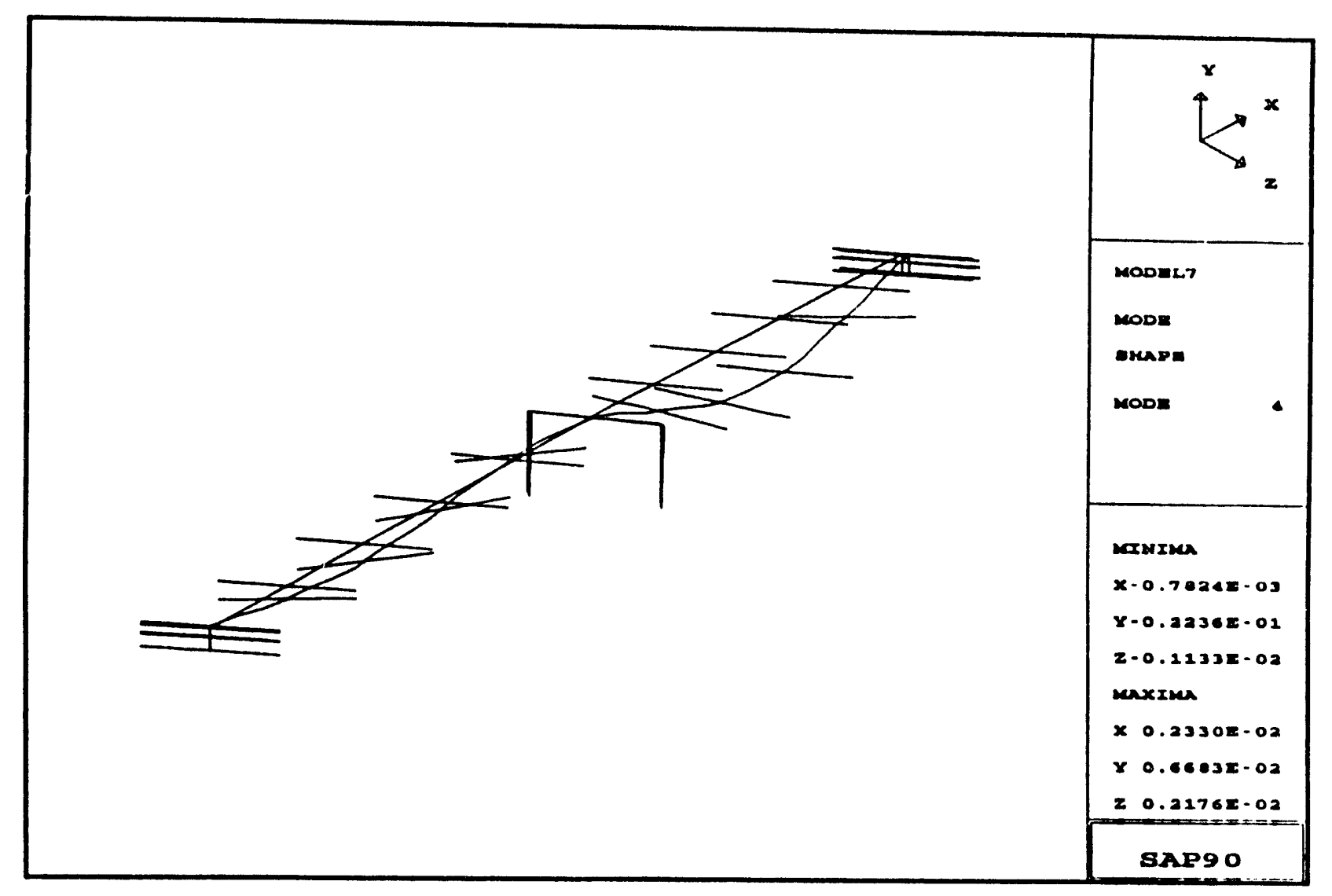

Model 11: Mode Shape 4

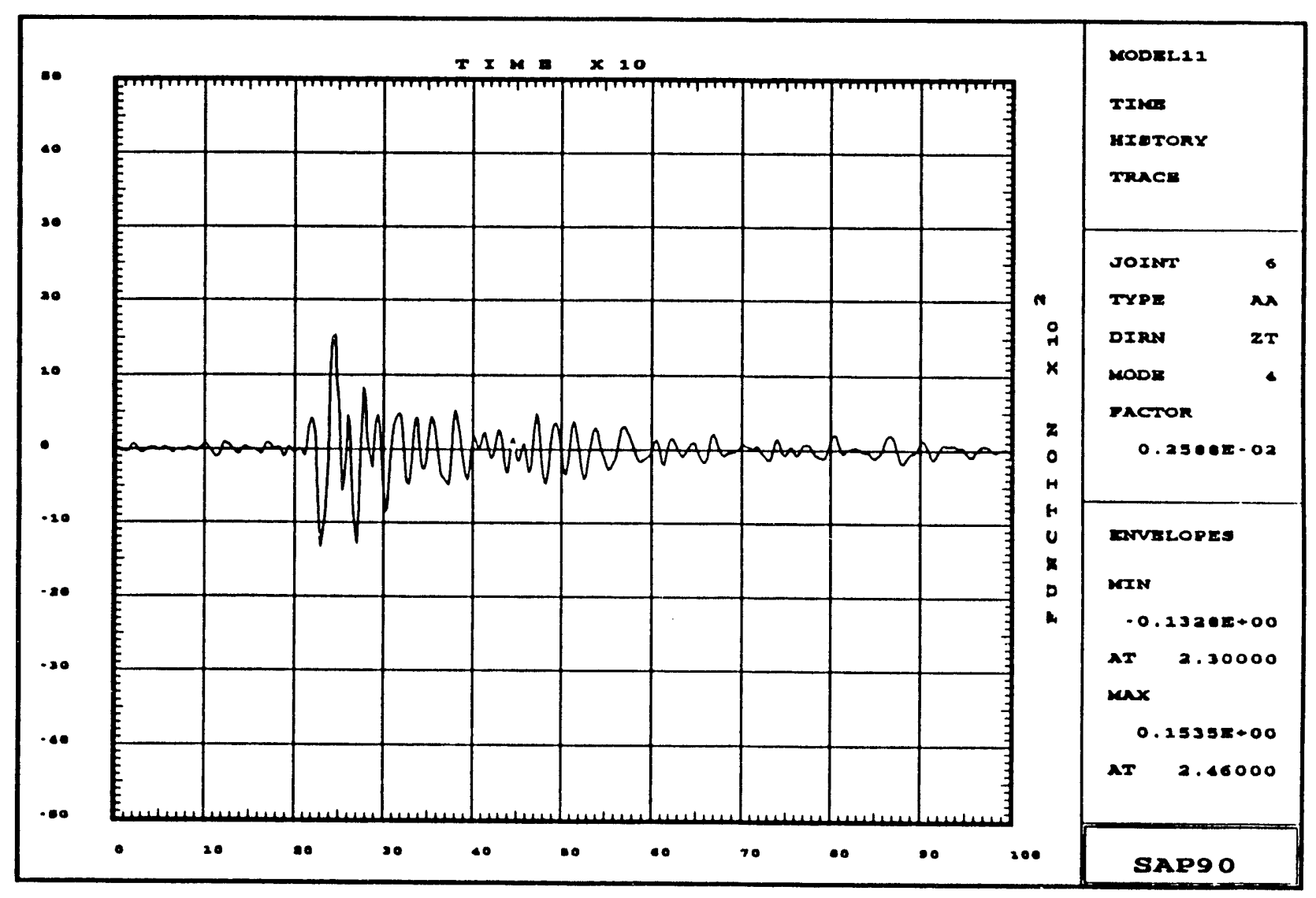

station 7 (Bent, Transverse) Theoretical Absolute Acceleration

Figure 3.11-11

Mode 4 Contribution to Acceleration at station 7 Model 11: Damping=02\%, all modes 


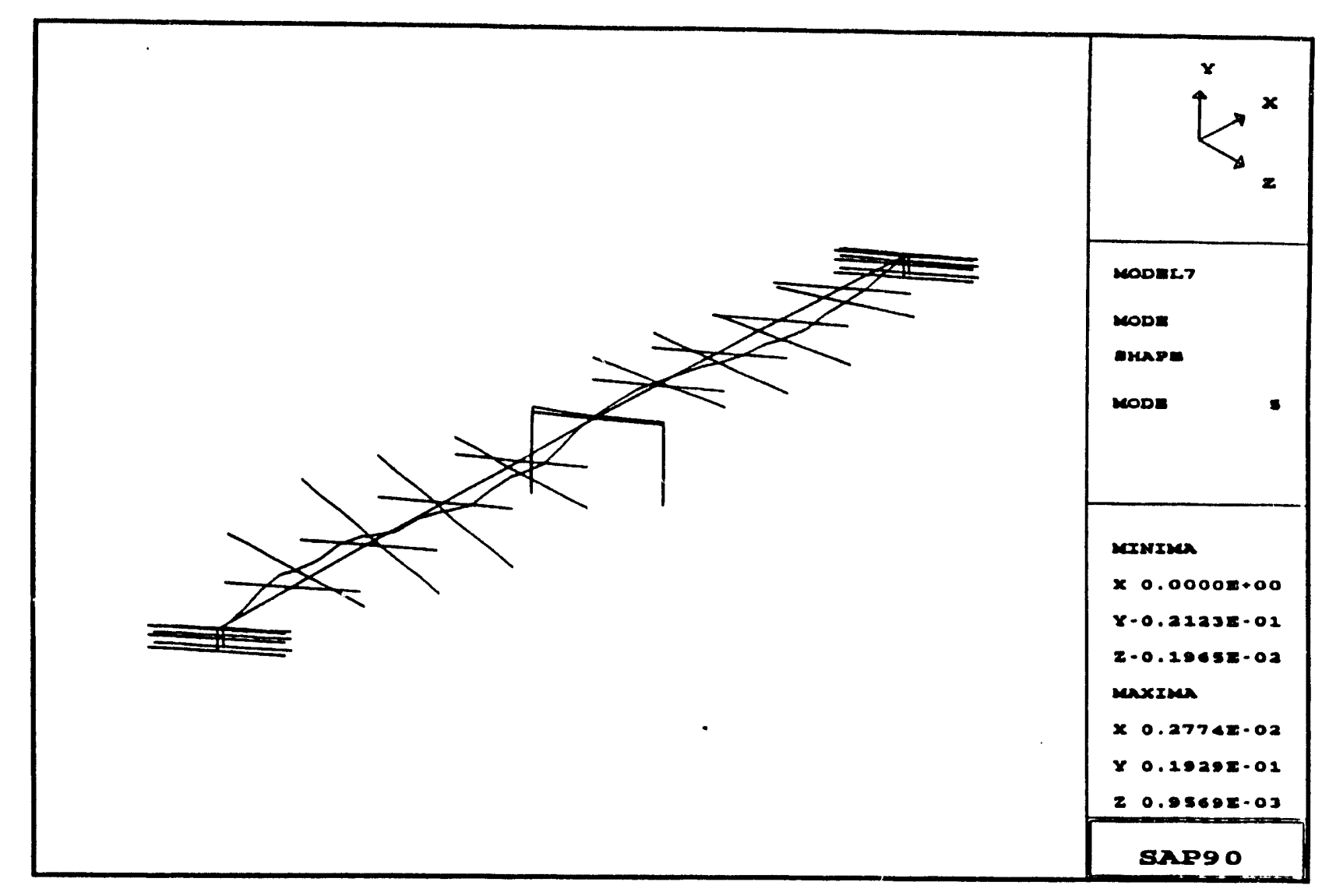

Model 11: Mode Shape 5

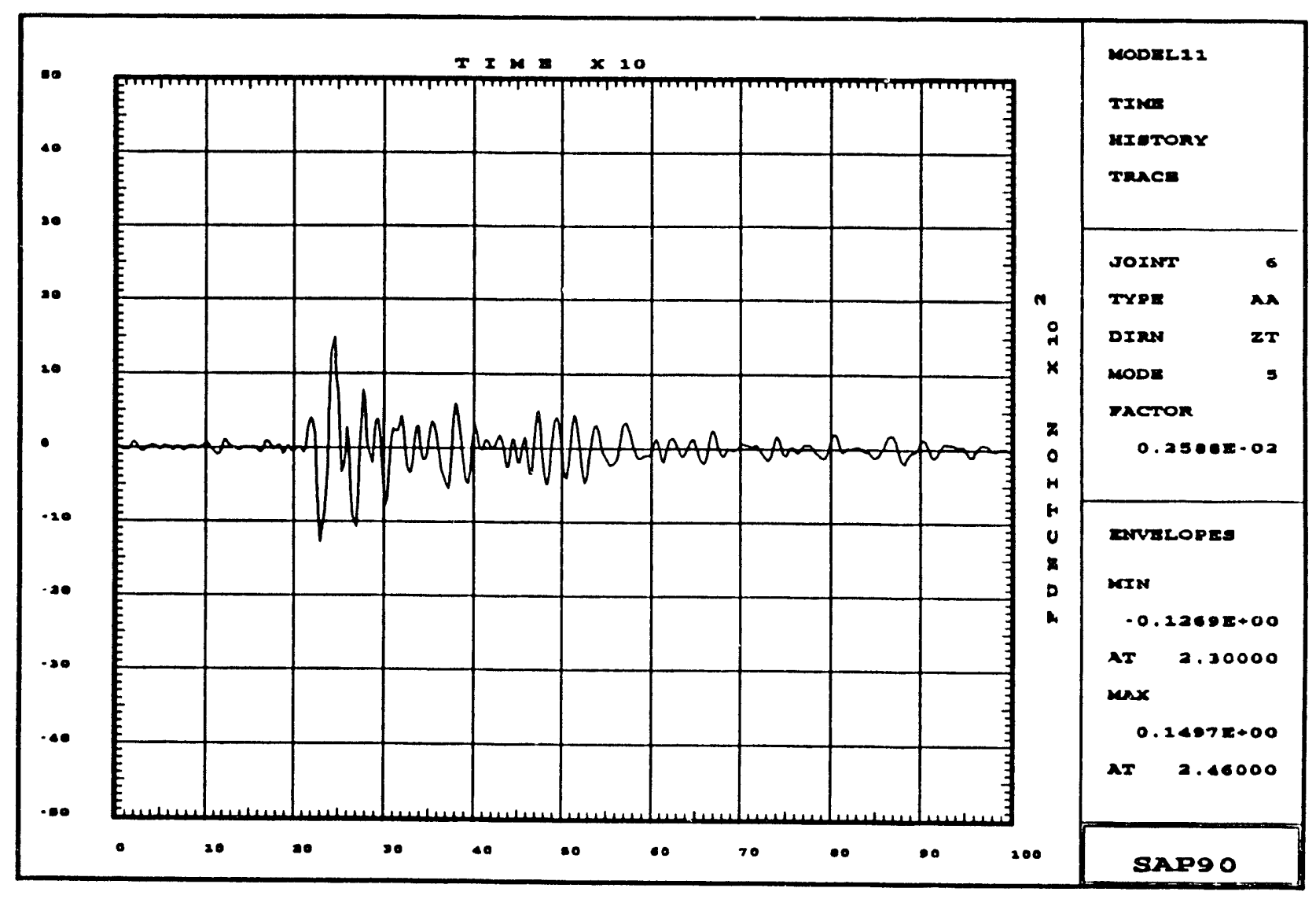

8tation 7 (Bent, Transverse) Theoretical Absolute Acceleration

Figure 3.11-12

Mode 5 Contribution to Acceleration at station 7 iodel 11: Damping=02\%, all modes 


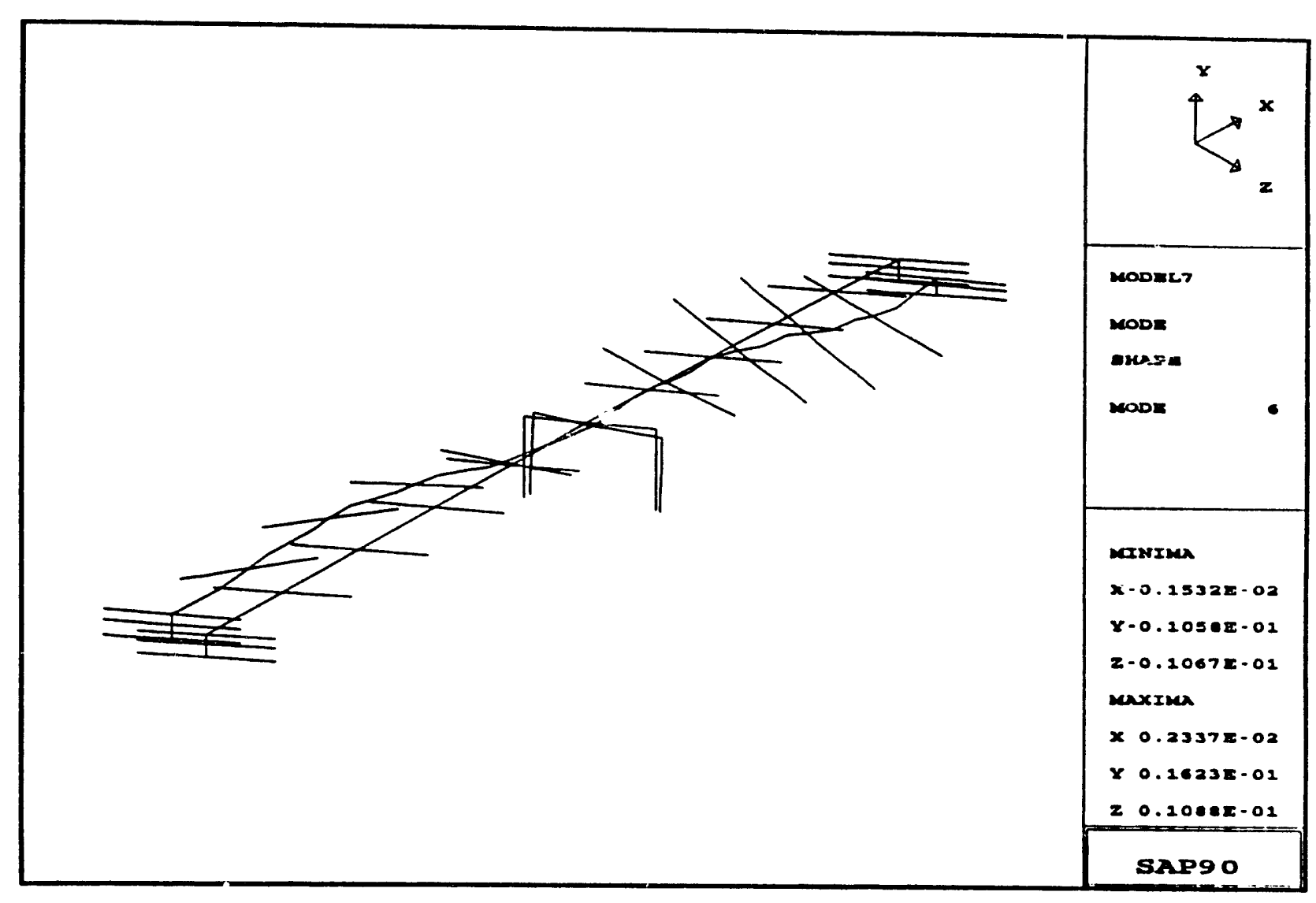

Model 11: Mode Shape 6

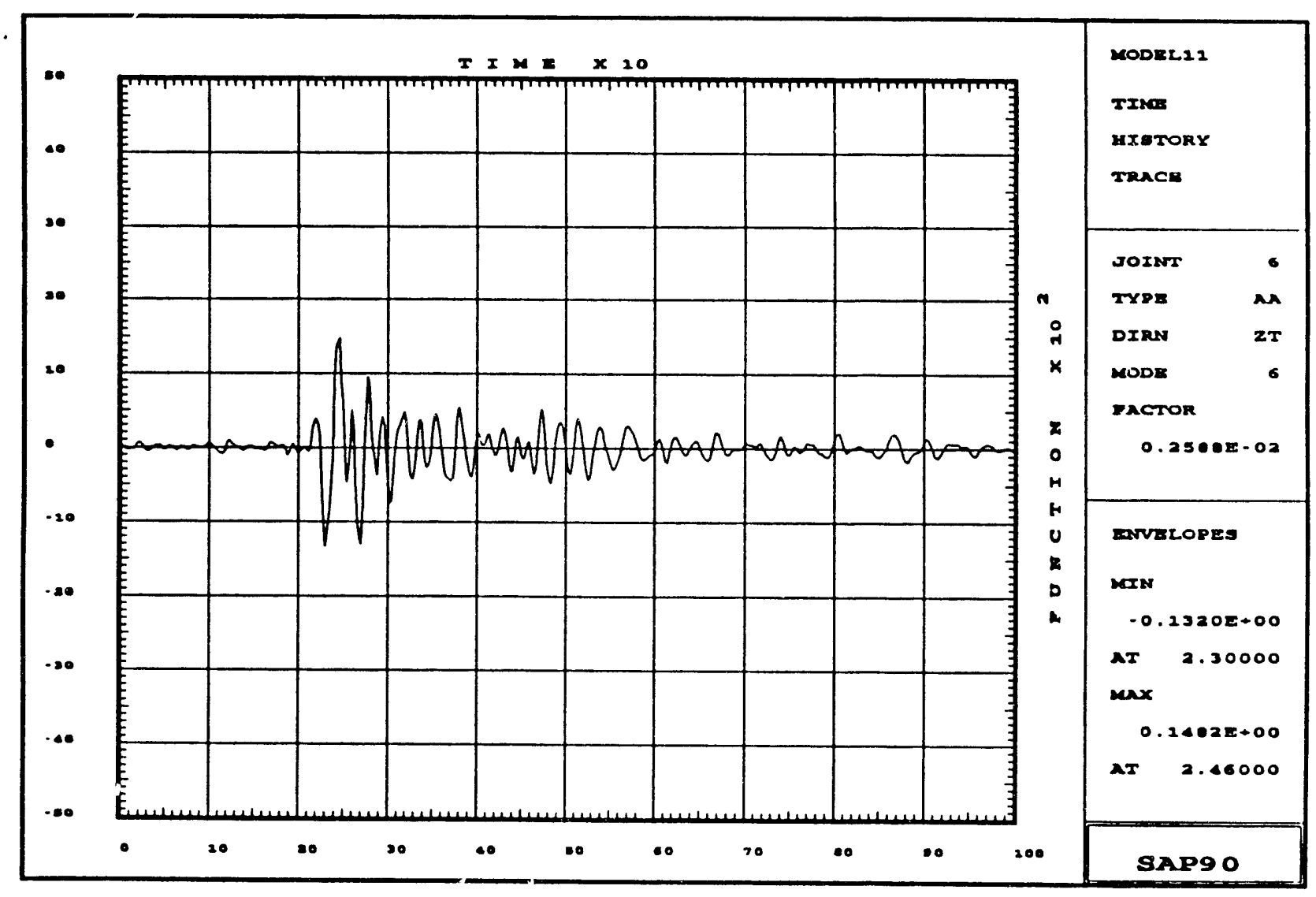

station 7 (Bent, Transverse) Theoretical Absolute Acceleration 


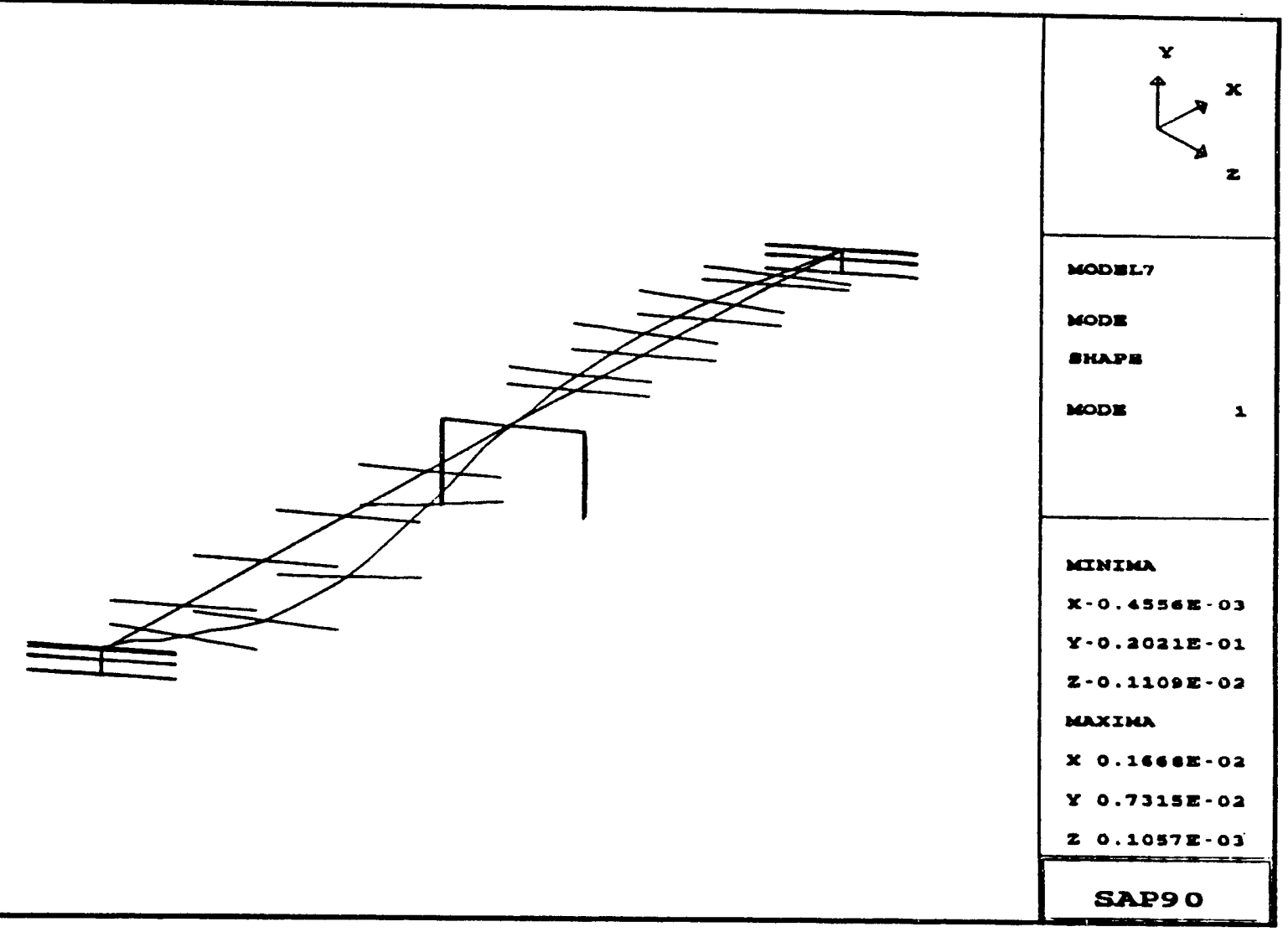

Model 11: Hode Shape 1

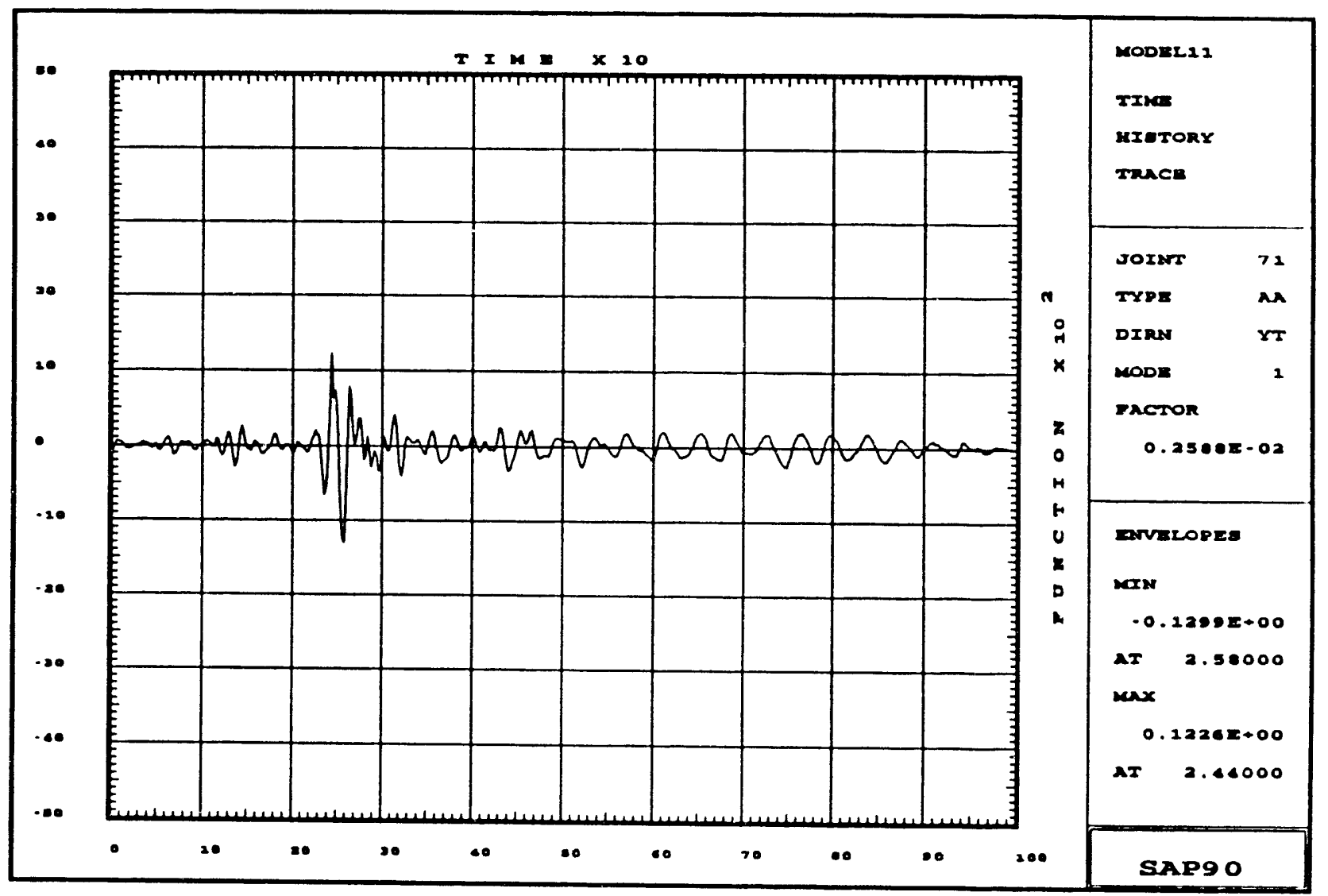

station 8 (Bhort span, Vertical) Theoretical Absolute Acceleration 

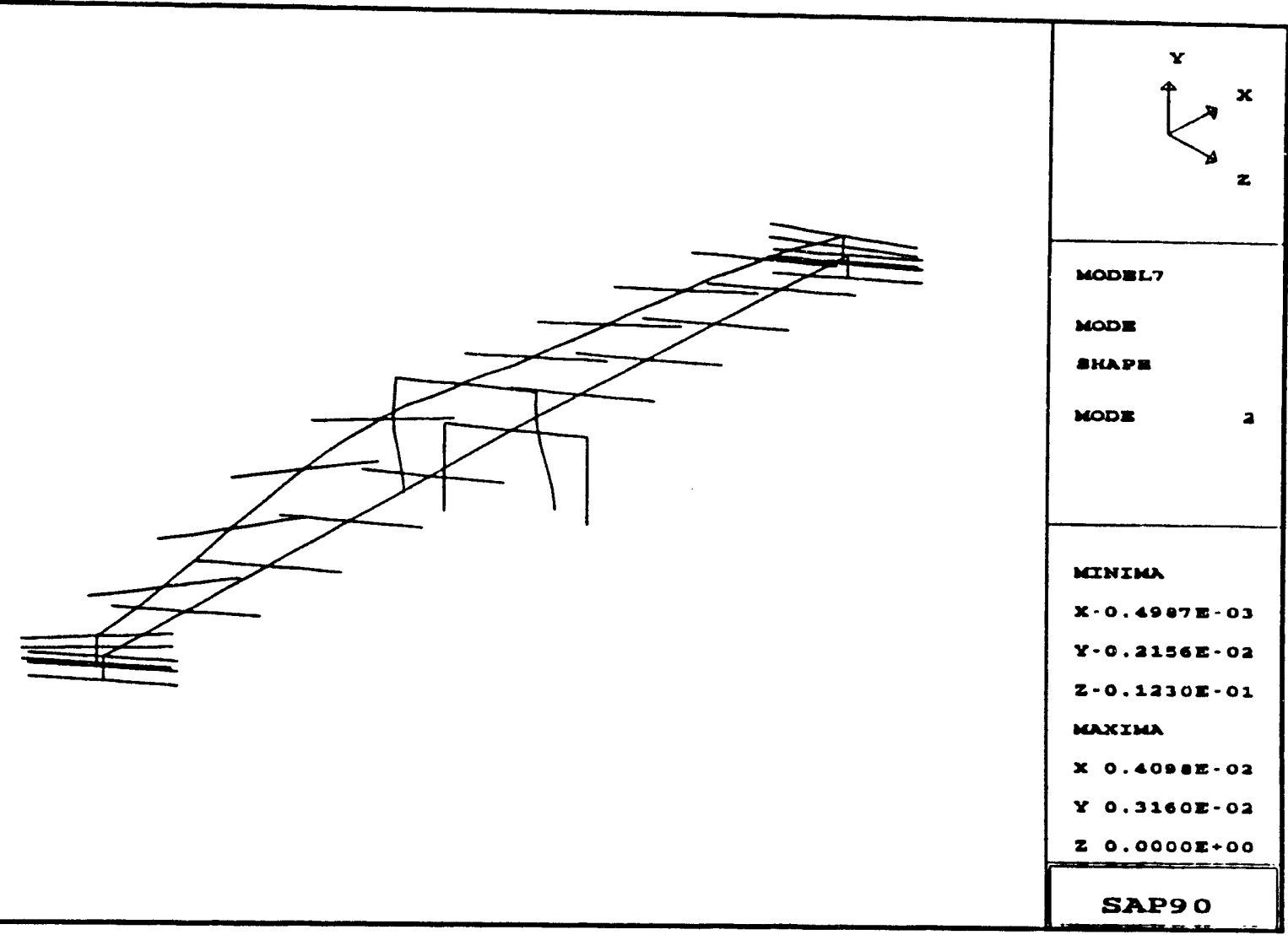

Model 11: Mode shape 2

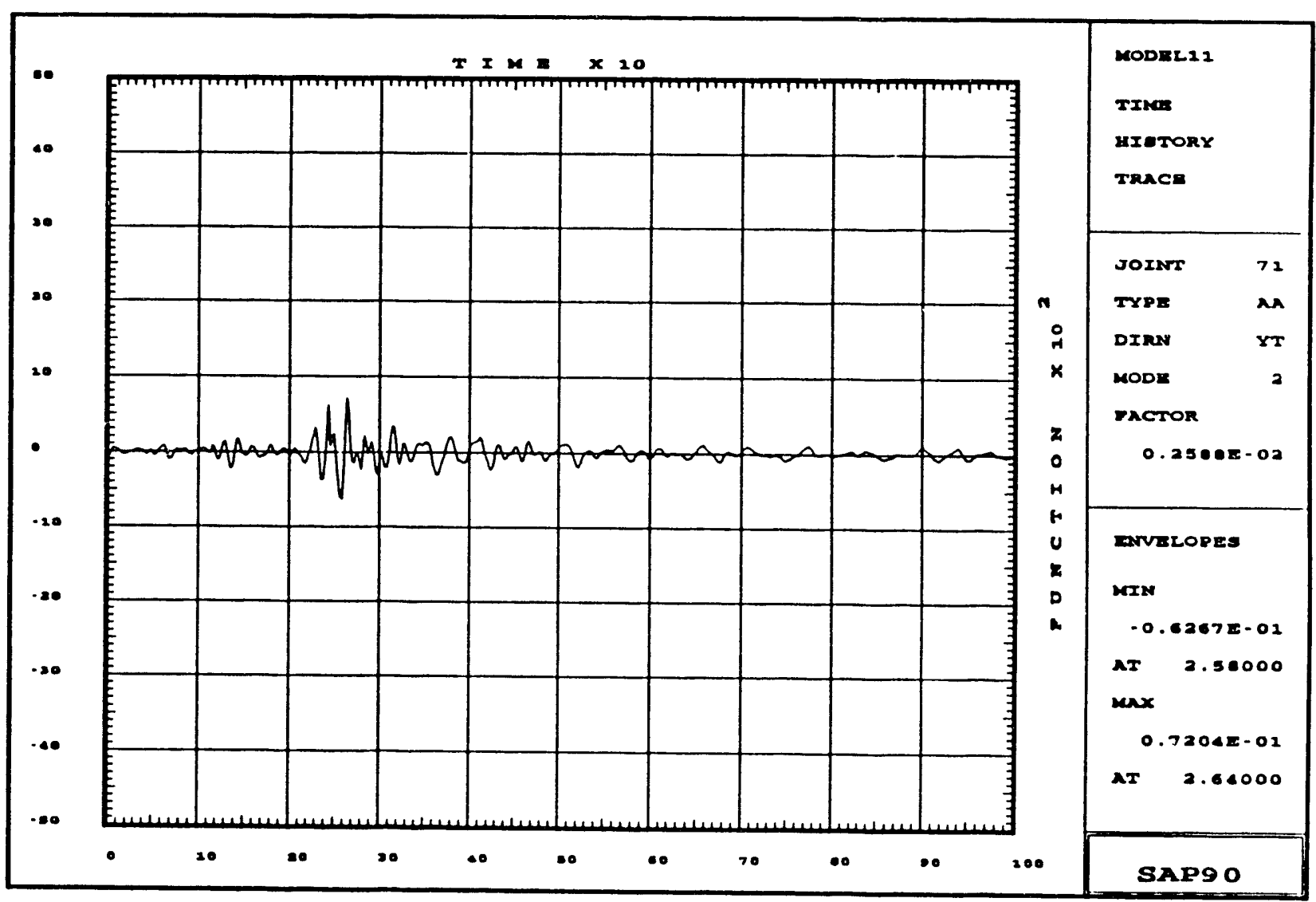

station 8 (short span, Vertical) Theoretical Absolute Acceleration 


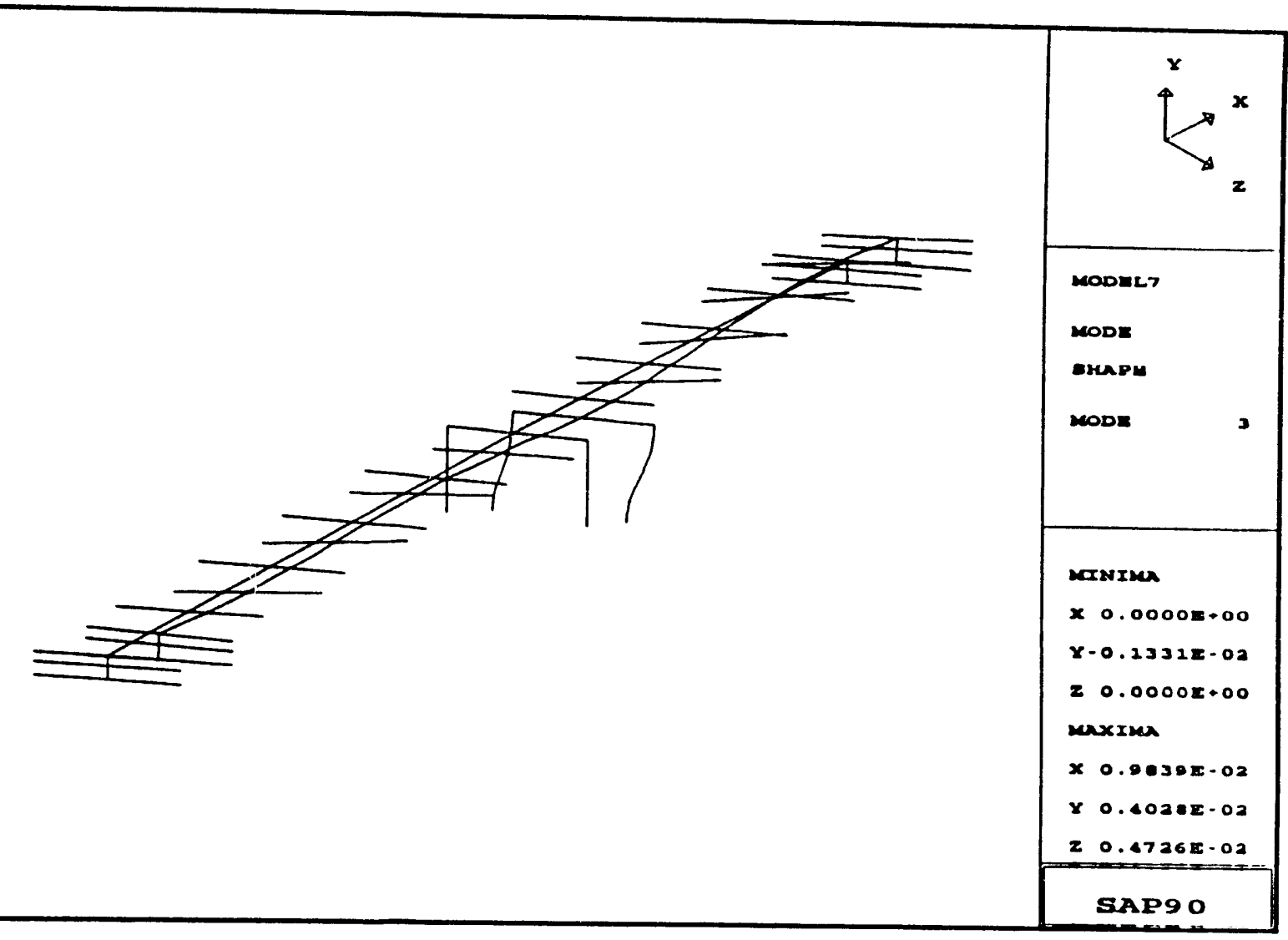

Model 11: Mode Shape 3

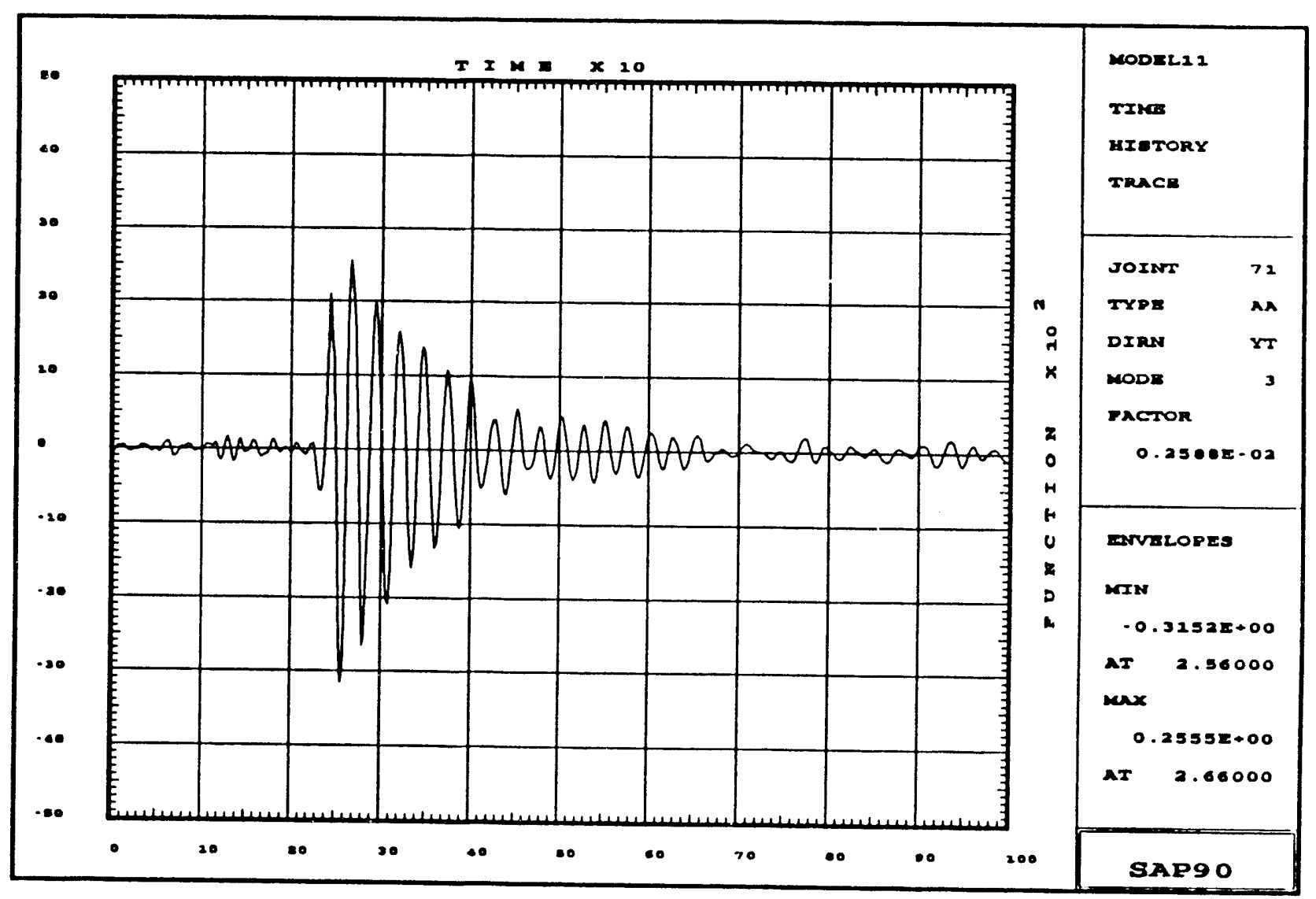

station 8 (8hort span, Vertical) Theoretical Absolute Acceleration 


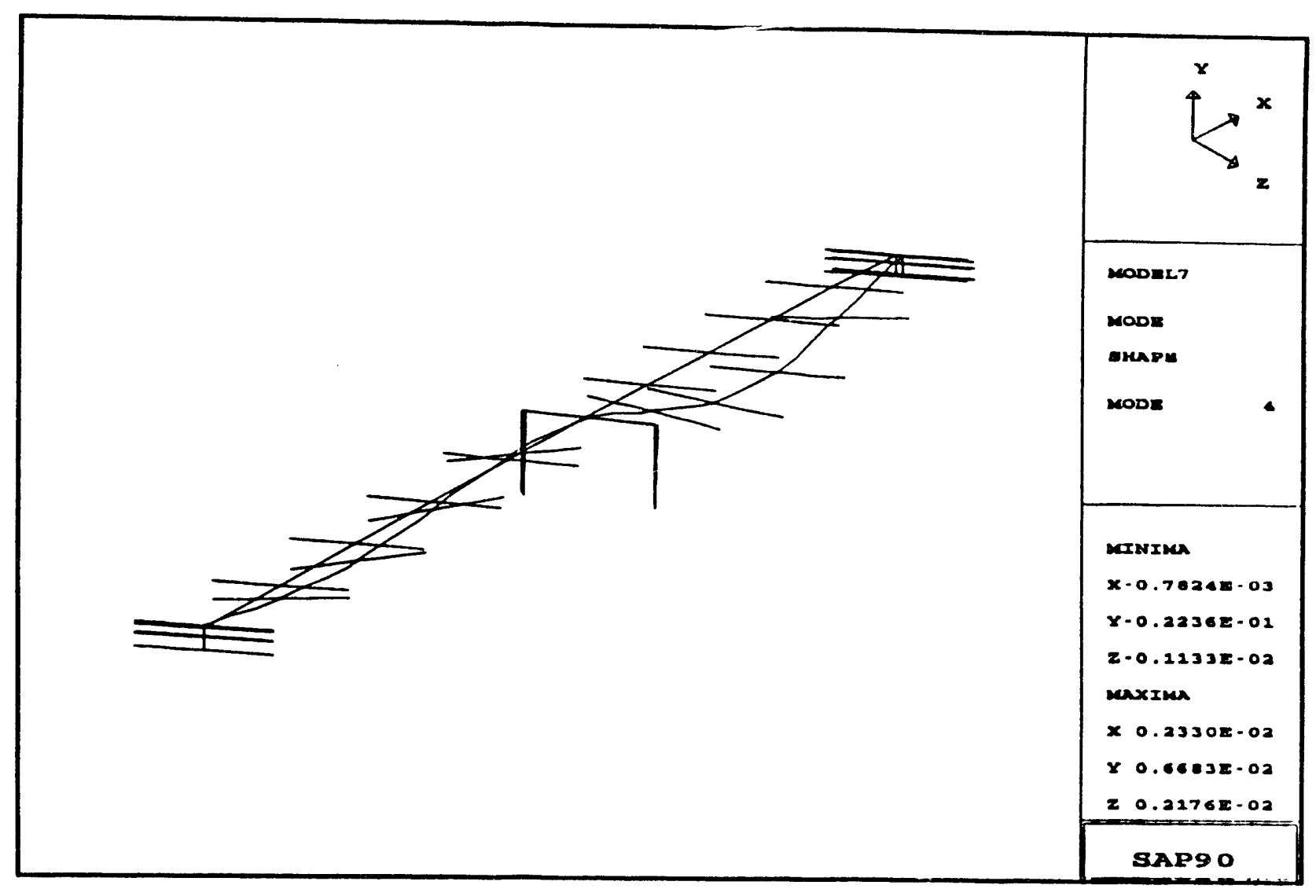

Model 11: Mode Shape 4

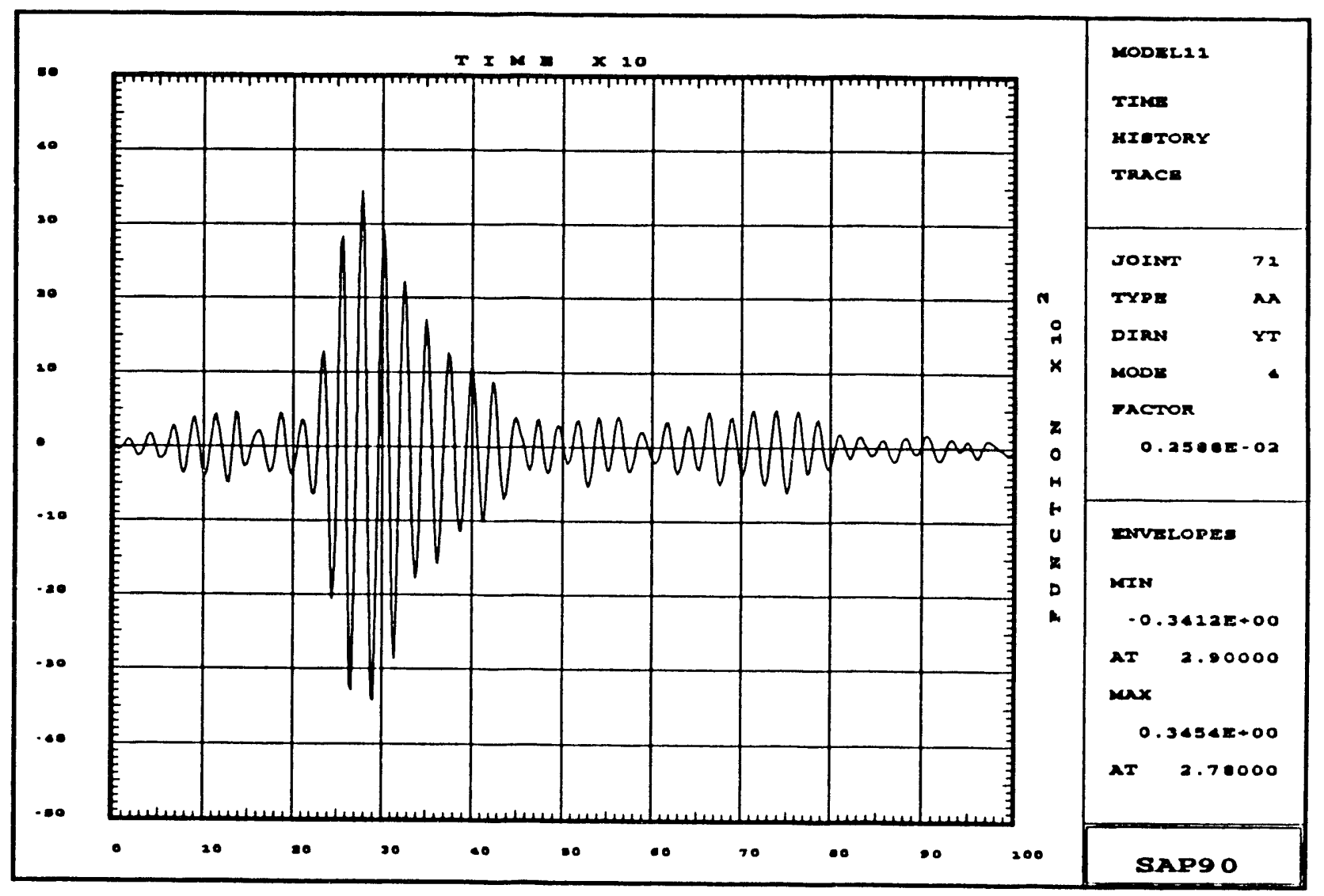

station 8 (short span, Vertical) Theoretical Absolute Acceleration 


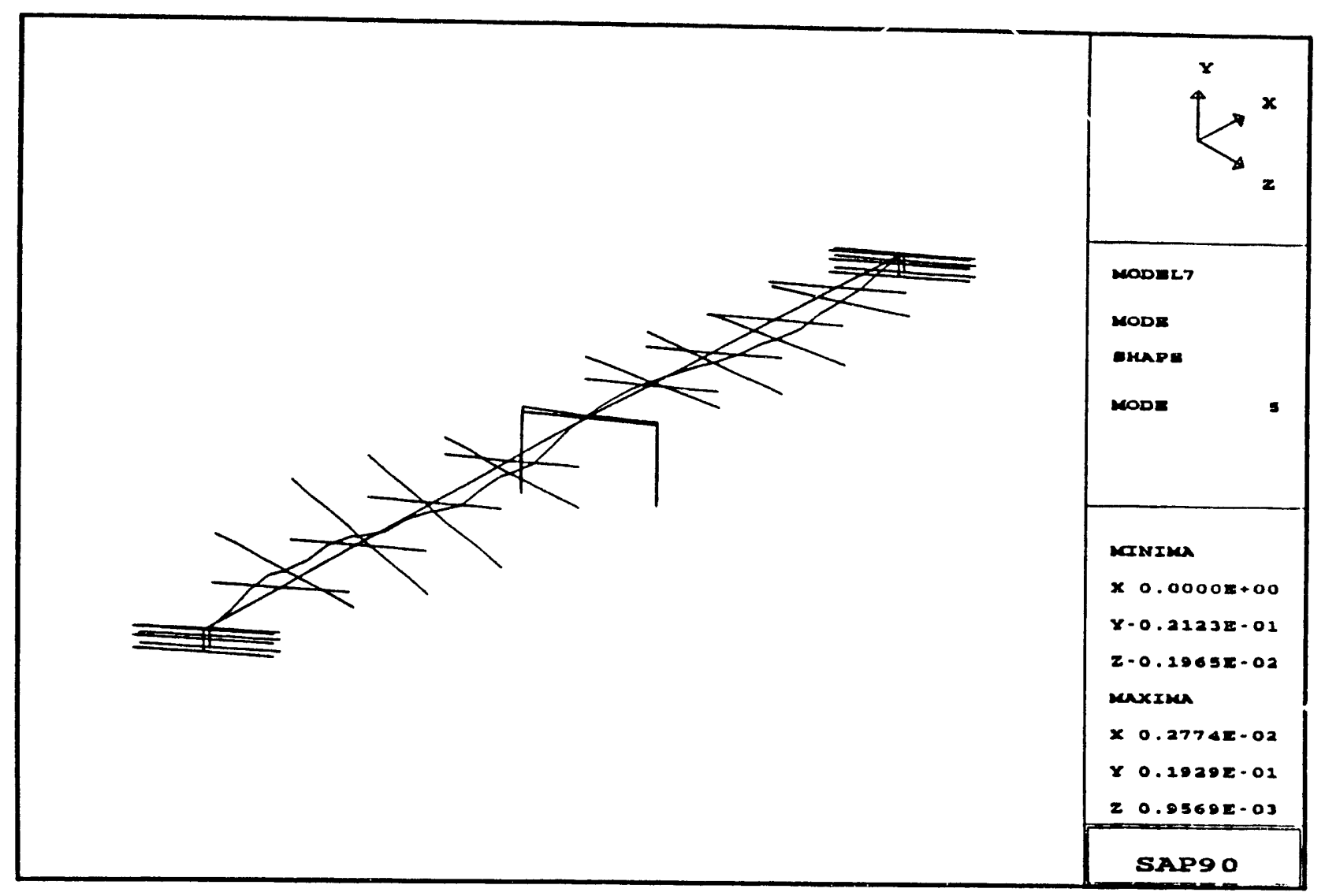

Model 11: Mode Shape 5

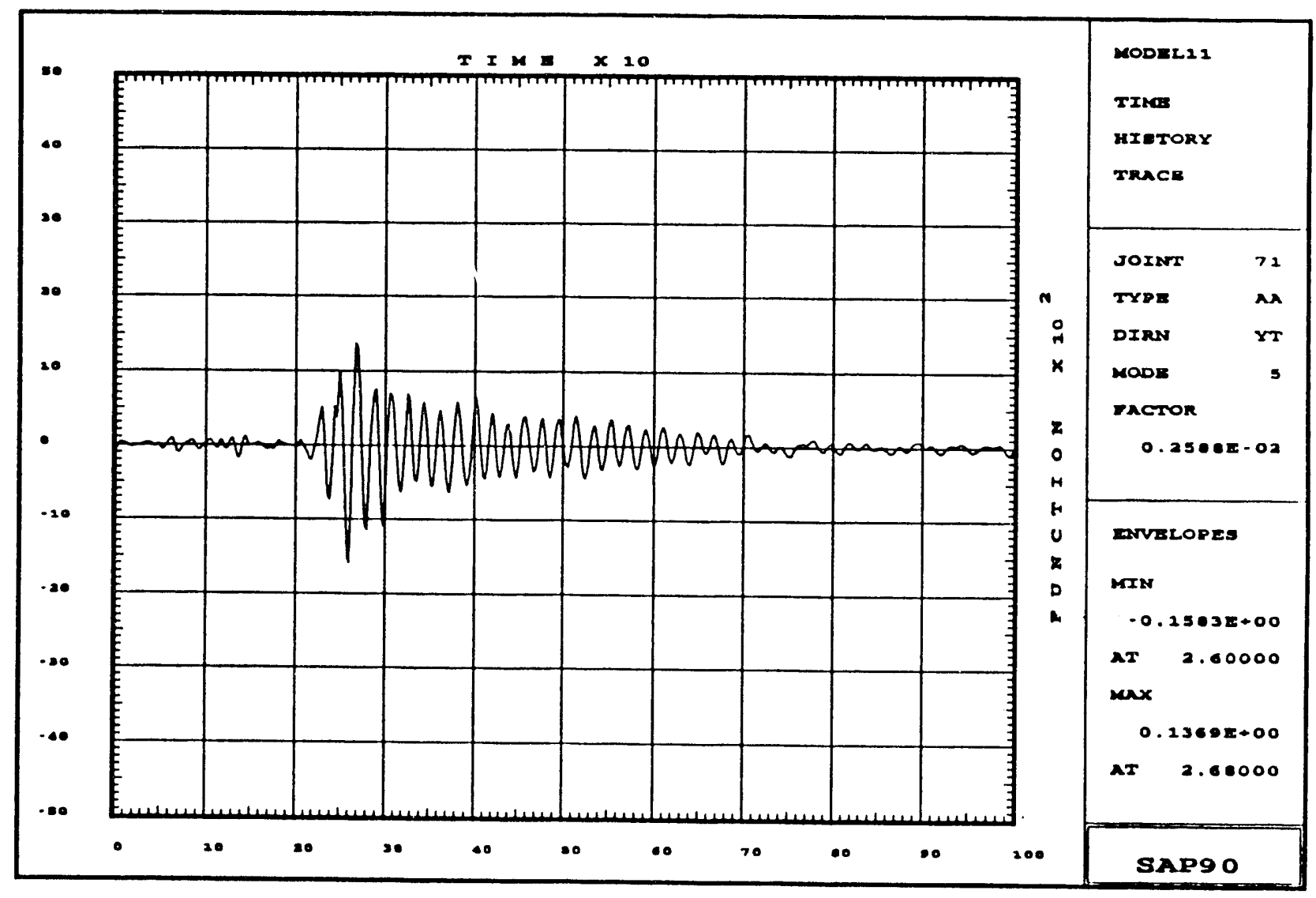

station 8 (8hort 8pan, Vertical) Theoretical Absolute Acceleration 


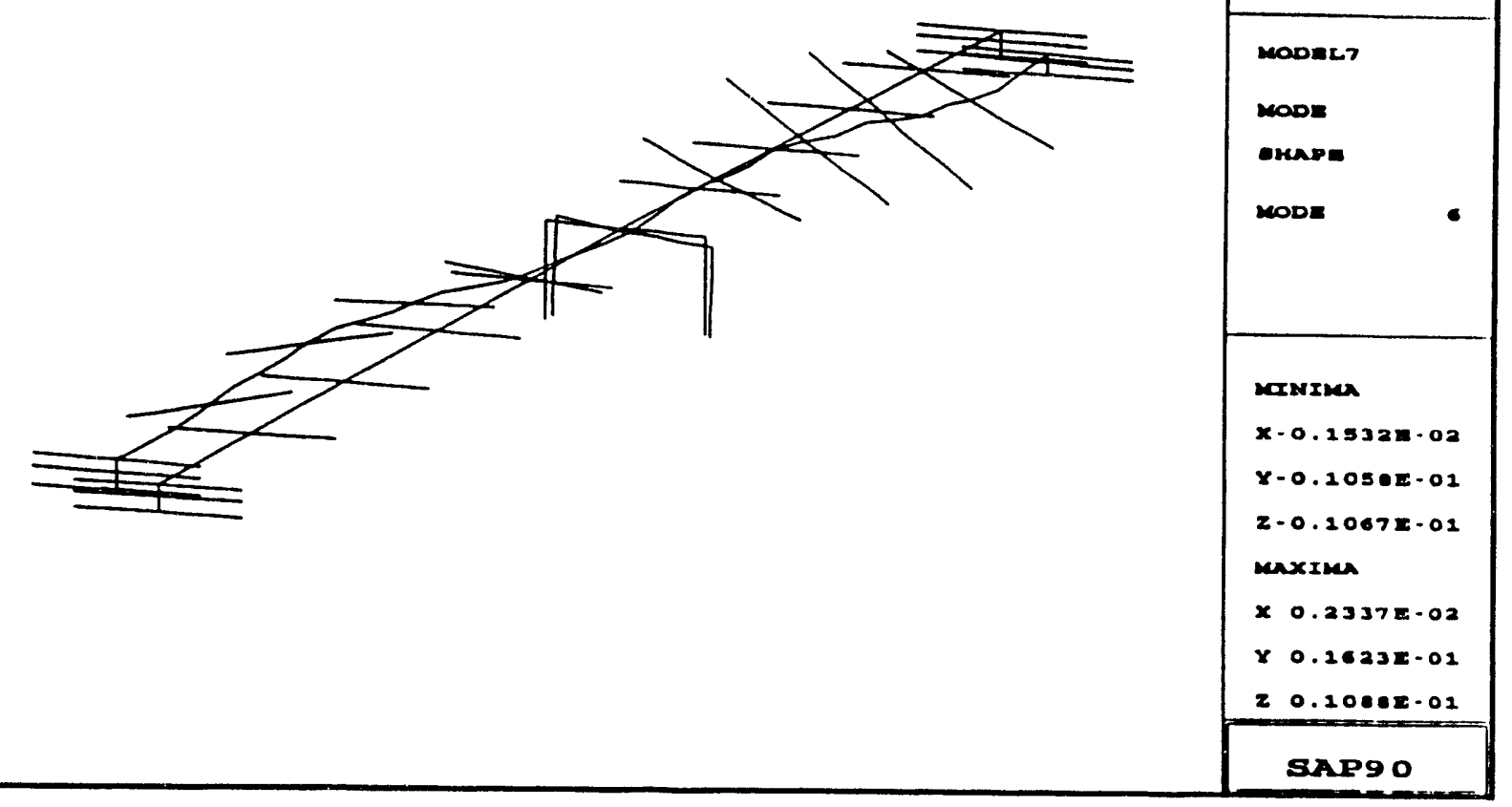

Model 11: Mode Bhape 6

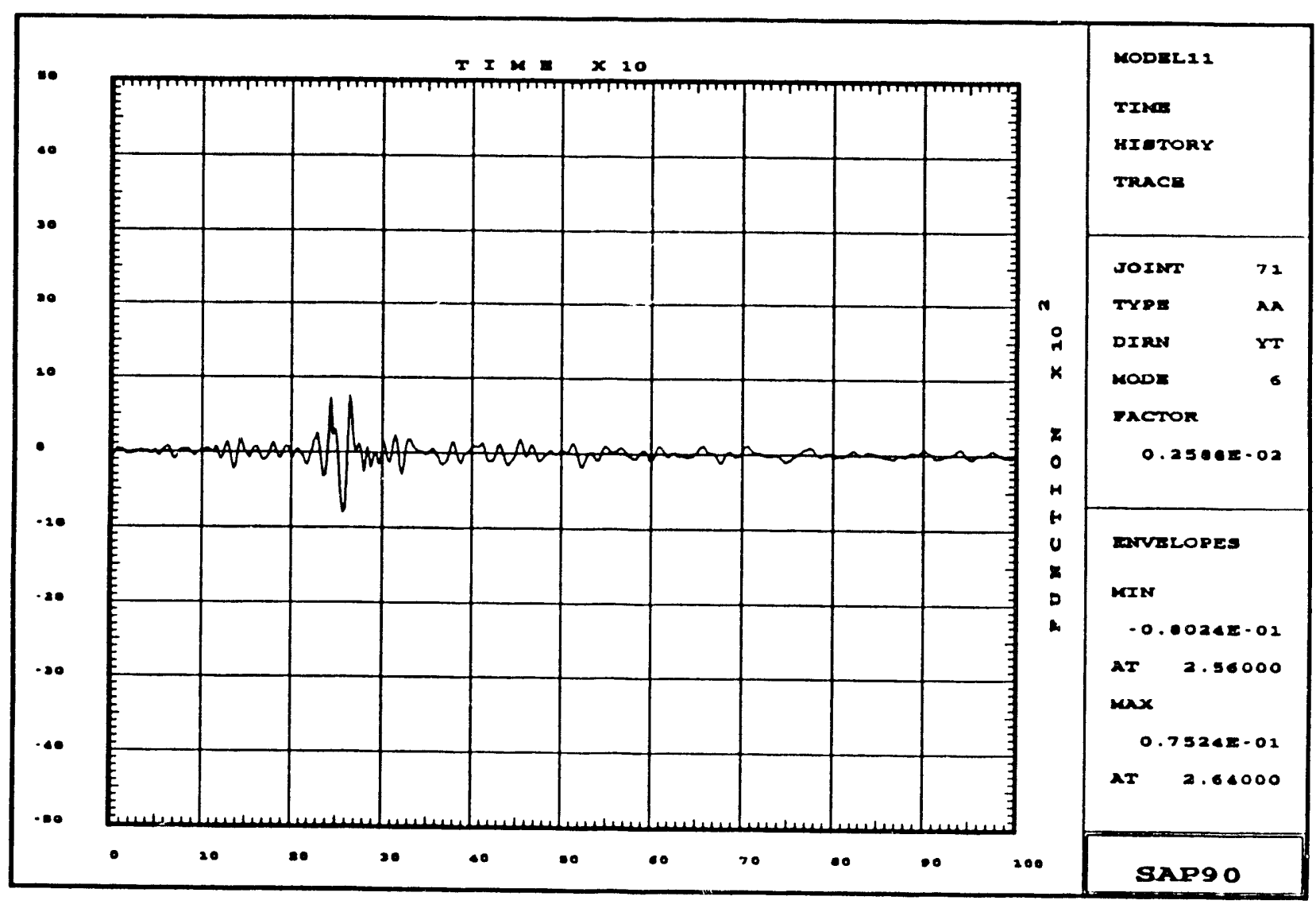

station 8 (8hort span, Vertical) Theoretical Absolute Acceleration

Figure 3.11-19

Mode 6 Contribution to Acceleration at station 8 Model 11: Damping $=02 \%$, all modes 


\subsection{Geometry}

The skewed geometry of the structure introduces complex elements into the fundamental mode shapes. For example, the transverse mode shapes contain torsional qualities. The first five mode shapes associated with the non-skewed geometry are truly fundamental.

The skewed geometry also produces a significantly different moment distribution for a static lateral load. Therefore, it is very important to consider the skewed geometry of the structure in any engineering analysis.

\subsection{Soil stiffness}

The placement of the equivalent soil springs in the model has a dramatic affect upon the analysis. Model 8 places the soil springs at the base of the abutment. Model 10 distributes the springs over the height of the abutment wall. There is a significant difference between the two time histories generated. There is also a difference between the shapes of the modes. However, the character of each of the modes (i.e. longitudinal, transverse, etc.) correspond directly between the models. The modal frequencies are also very similar.

Distributing the springs along the height of the abutment seems to yield a better representation of the structure's behavior after the strong motion of the earthquake. However, this type of model seems to overdamp the structure during the strong motion. These affects are due mostly to the way the longitudinal mode shape behaves, as it is the mode shape most affected by the soil springs at the abutment. Placing the springs at the base of the abutment produces a more conservative model, as it will tend to maximize accelerations and displacements in the structure.

\subsection{Rotational Inertia}

The structure's rotational inertia significantly affects the theoretical time histories. Model 11 shows the effect that the torsional mode shapes have on the theoretical accelerations at stations seven and eight. Model 9 ignores the rotational inertia. Not surprisingly, the theoretical time histories at stations seven and eight change significantly. The accelerations at station eight increase, and the accelerations at station seven actually decrease. This suggests that ignoring the affects of rotational inertia is not always conservative.

A stick model only marginally represents the torsional properties of a structure. The torsional interaction between the bridge deck and the bent cap, for example, is accomplished in the stick model by arbitrarily increasing the bending stiffnesses of the bent cap. Rotational inertia should be considered in a complete dynamic analysis, but it may be beyond the scope of a simple stick model.

$$
4-1
$$




\section{Conclusion}

Viscous demping is en inherently insccurate representation of atructuial demping for this bridge system. Viscous demping dempe all elements in a structure uniformly. For a nonhomogeneous structural system, it becomes impossible to correctly model the demping behavior. In order to adequately model the structure during the strongest ground motion, the structure must be overdamped after the strong motion.

It is very difficult to properly assion modal demping coefficients. The modal coefficients were held constent between models 8, 9, and 10. Even this was marginal, however. While the character of the modes did not change, the shapes of the modes did vary considerably. For example, al though models 8 and 10 both contain a longitudinal mode shape, the mode shape in model 10 has less of a vertical component and should probably be more heavily damped.

Unfortunately, in desion the demping coefficients cannot be tuned to fit the actual data, as such date will rarely exist. Therefore, the coefficients must be chosen conservatively low, resulting in overdesign and added inaccuracy in the analysis. An inelastic soll model would certainly yielda better representation of the damping behavior. 


\section{REFEREMCES}

1. Bridoe struLl Merual, November 1973, Appendix C.

2. Coltrans Bridge Desion Alds, October 1989, Pp. 14-2 - 14-3.

6-1 

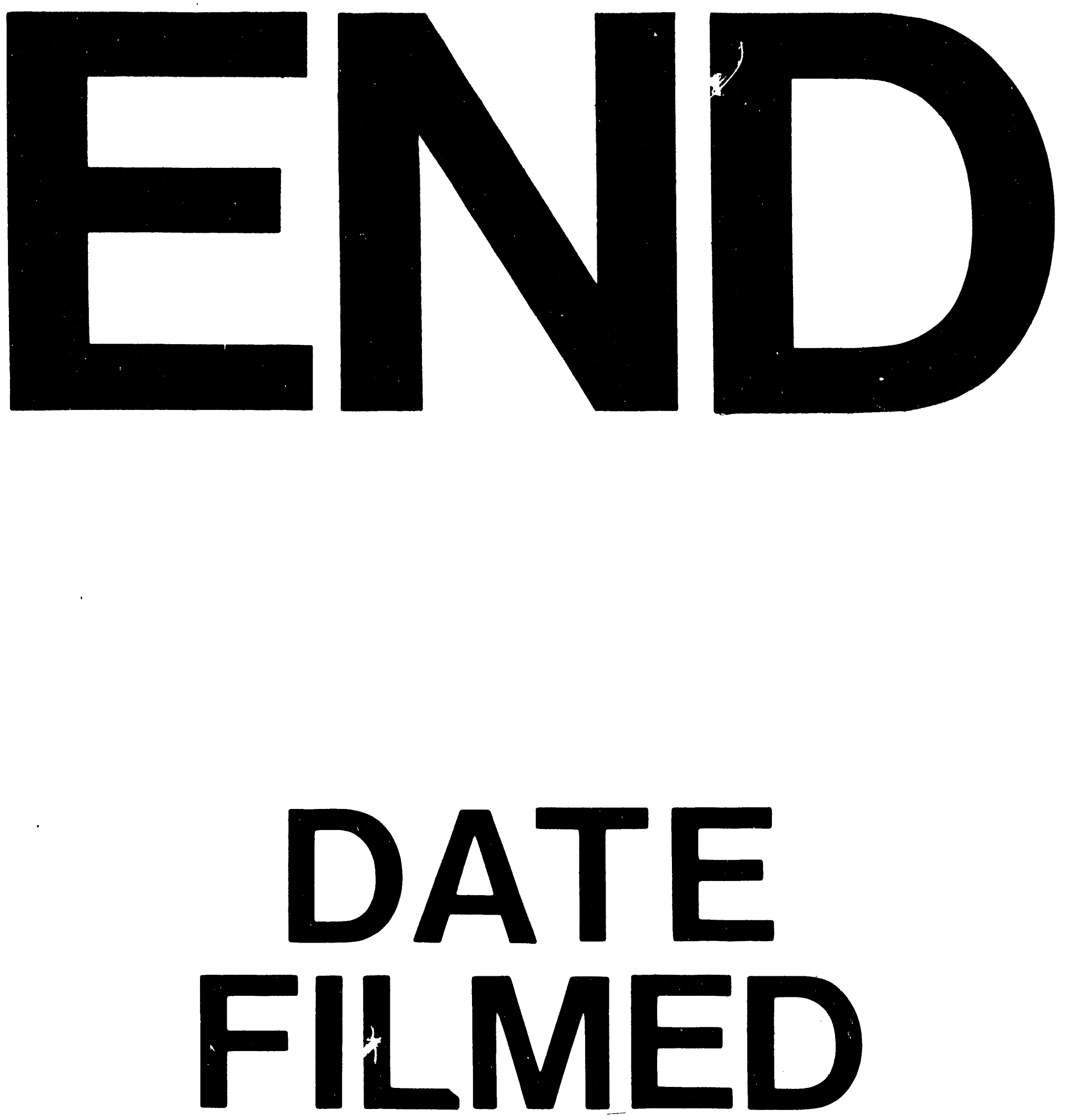

I

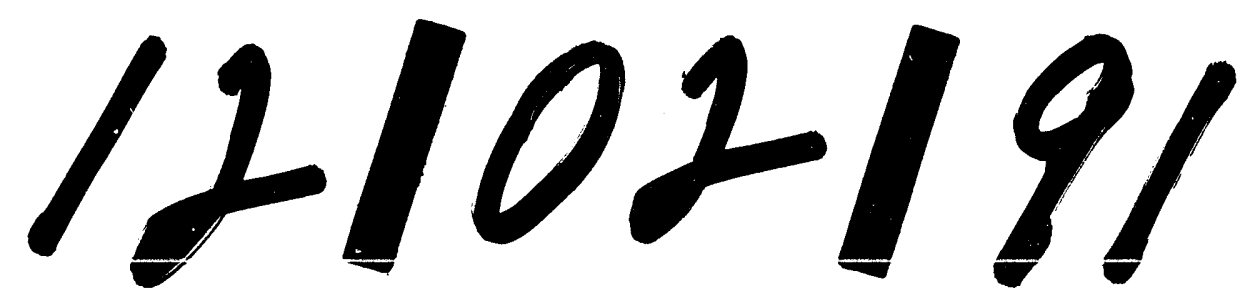

" 
